THOMAS REZEK MATSUMOTO

ESTUDO E CARACTERIZAÇÃO DAS PERDAS EM ACOPLAMENTOS MAGNÉTICOS DEVIDO À PRESENÇA DE BARREIRAS COM ALTA CONDUTIVIDADE ELÉTRICA 


\title{
ESTUDO E CARACTERIZAÇÃO DAS PERDAS EM ACOPLAMENTOS MAGNÉTICOS DEVIDO À PRESENÇA DE BARREIRAS COM ALTA CONDUTIVIDADE ELÉTRICA
}

\author{
Dissertação apresentada à Escola \\ Politécnica da Universidade de São \\ Paulo para obtenção do título de Mestre \\ em Ciências
}




\section{ESTUDO E CARACTERIZAÇÃO DAS PERDAS EM ACOPLAMENTOS MAGNÉTICOS DEVIDO À PRESENÇA DE BARREIRAS COM ALTA CONDUTIVIDADE ELÉTRICA}

Dissertação apresentada à Escola Politécnica da Universidade de São Paulo para obtenção do título de Mestre em Ciências

Área de Concentração:

Sistemas de Potência

Orientador: Prof. Dr. Ivan Eduardo Chabu 
Este exemplar foi revisado e corrigido em relação à versão original, sob responsabilidade única do autor e com a anuência de seu orientador.

São Paulo, de fevereiro de 2015.

Assinatura do autor

Assinatura do orientador

Matsumoto, Thomas Rezek

Estudo e caracterização das perdas em acoplamentos magnéticos devido à presença de barreiras com alta condutividade elétrica / T.R. Matsumoto. -- versão corr. -- São Paulo, 2015.

$77 p$.

Dissertação (Mestrado) - Escola Politécnica da Universidade de São Paulo. Departamento de Engenharia de Energia e Automação Elétricas.

1.Máquinas elétricas 2.Dispositivos magnéticos 3.Materiais magnéticos I.Universidade de São Paulo. Escola Politécnica. Departamento de Engenharia de Energia e Automação Elétricas II.t. 
Aos meus pais, Gilberto e Norma, ao meu irmão, Thiago e a minha noiva, Simoni. 


\section{AGRADECIMENTOS}

Ao meu orientador, professor Dr. Ivan Eduardo Chabu, pela diligência, presteza e paciência durante todas as etapas da realização deste trabalho.

Aos meus professores, Dr. Luiz Lebensztajn e Dr. Silvio Ikuyo Nabeta, pelos valiosos comentários e sugestões para o aperfeiçoamento desta dissertação.

À Equacional Elétrica \& Mecânica Ltda. por prover todos os recursos necessários à construção e à realização dos testes no protótipo.

Ao Departamento de Engenharia de Energia e Automação Elétricas da Universidade de São Paulo pelo financiamento concedido para a apresentação do artigo relacionado a este trabalho [37] no ICEM' 2014.

À Asea Brown Boveri, ABB, e aos meus colegas de trabalho, pelas inúmeras colaborações e incentivos.

À minha noiva, Simoni, pelas colaborações e incentivos ao longo deste trabalho. 
Para contribuir utilmente ao avanço da ciência, não se deve desprezar, por vezes, a realização de simples verificações. 


\section{RESUMO}

Os principais objetivos deste trabalho são estudar e caracterizar as perdas em acoplamentos magnéticos a ímãs permanentes, quando da existência de uma barreira de material condutor entre seus rotores. Tais perdas são originadas da circulação de correntes parasitas de Foucault na barreira e implicam um torque resistivo ao torque transmitido pelo acoplamento, diminuindo, dessa maneira, a eficácia de sua transmissão.

Com este estudo pretendeu-se investigar também a influência desse efeito resistivo na curva característica do acoplamento, ou seja, na curva torque em função do deslocamento angular entre os rotores. A determinação dessa influência da placa condutora no comportamento do acoplamento magnético é de suma importância, uma vez que permite seu correto dimensionamento em aplicações como bombas seladas e agitadores.

Para a determinação da influência da barreira, recorreu-se a uma abordagem analítica para o cálculo das perdas geradas pelas correntes parasitas, que são induzidas na placa condutora. Desta forma, foi possível obter o torque resistivo em função dos parâmetros construtivos do acoplamento e da velocidade de rotação. A validação da metodologia empregada será feita pela comparação dos resultados teóricos com os experimentais, através de ensaios num protótipo já construído.

Palavras-chave: Acoplamento magnético. Ímã permanente. Barreira condutora. Curva característica. 


\begin{abstract}
The main objectives of this work are to study and to determine losses in permanent magnet couplings in the presence of a conductive barrier between its rotors. These losses are originated from eddy currents that circulate in the barrier and entail a resistive torque to the torque that is transmitted by the coupling and therefore, reduces the efficiency of its transmission.

With this study, it was also intended to investigate such resistive effect influence in the coupling characteristic curve, i.e. in the torque versus angular shift between rotors curve. The determination of the conductive barrier influence on the magnetic coupling behavior is of major importance, since it allows the correct designing in applications as sealed pumps and magnetic stirrers.

In order to determine the barrier influence, an analytical approach was used in order to calculate the losses generated by the eddy current circulation, which are induced in the conductive wall. As a result, it was possible to obtain the resistive torque as a function of the magnet coupling geometrical parameters and angular speed. The validation of the employed methodology will be made comparing the theoretical results with the experimental ones, obtained from tests in the existing prototype.
\end{abstract}

Keywords: Magnetic coupling. Permanent magnet. Conductive barrier. Performance curve. 


\section{LISTA DE ILUSTRAÇÕES}

Figura 1.1 - Exemplo de aplicação do acoplamento magnético: compressor [32] ....16

Figura 1.2 - Exemplo de aplicação do acoplamento magnético: bombas para

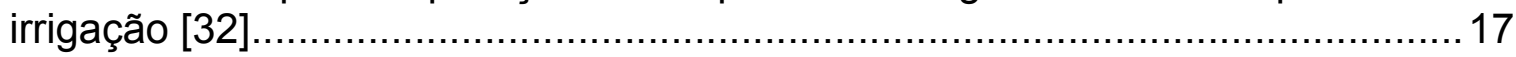

Figura 1.3 - Exemplo de aplicação do acoplamento magnético: bomba hidráulica

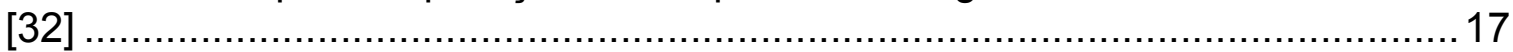

Figura 1.4 - Exemplo de aplicação do acoplamento magnético: ventiladores [32] ... 17

Figura 1.5 - Exemplo de aplicação do acoplamento magnético: esteira

transportadora [32] ........................................................................ 18

Figura 1.6 - Exemplo de aplicação do acoplamento magnético: agitadores [33]......19

Figura 1.7 - Exemplo de aplicação do acoplamento magnético: bombas seladas [34]19

Figura 1.8 - Exemplo de aplicação do acoplamento magnético: bomba artificial para

o coração humano................................................................................... 19

Figura 2.1 - Esquema tridimensional da configuração radial [35] .......................... 22

Figura 2.2 - Esquema bidimensional da configuração radial [36] ...........................22

Figura 2.3 - Esquema tridimensional da configuração axial [35] ...........................23

Figura 2.4 - Esquema bidimensional da configuração axial [36] ............................23

Figura 2.5 - Vista frontal do rotor do protótipo ............................................... 24

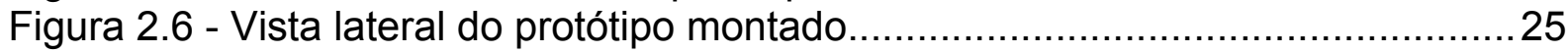

Figura 2.7 - Parametrização na configuração axial [5] ..................................... 25

Figura 2.8 - Gráfico da força tangencial entre um par de ímãs em função do ângulo

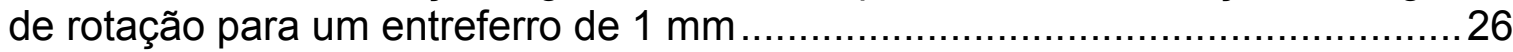

Figura 2.9 - Gráfico do torque teórico em função do ângulo de rotação para o protótipo do acoplamento magnético com $1 \mathrm{~mm}$ de entreferro ..........................27

Figura 2.10 - Comparação entre o torque medido e calculado em função do deslocamento angular para vários entreferros ................................................29

Figura 3.1 - Parâmetros do rotor do acoplamento magnético.................................38

Figura 3.2 - Configuração do acoplamento magnético ..................................... 39

Figura 3.3 - Modelo equivalente da configuração do acoplamento magnético ..........39

Figura 3.4 - Sistema de coordenadas adotado .............................................. 40

Figura 3.5 - Fluxograma da metodologia analítca adotada ................................ 53

Figura 3.6 - Novo ponto de operação do ímã considerando a reação de armadura.54

Figura 4.1 - Arranjo experimental esquemático para medição do torque resistivo ...55

Figura 4.2 - Arranjo experimental na sala de ensaios .........................................56

Figura 4.3 - Arranjo para medição do deslocamento angular em movimento ...........57

Figura 4.4 - Arranjo experimental esquemático para medição do torque transmitido

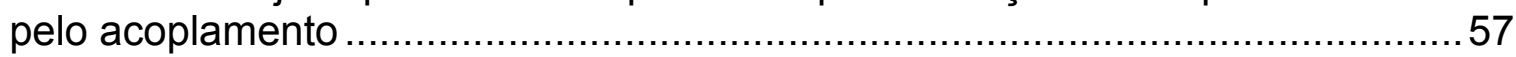

Figura 5.1 - Resultados analíticos e experimentais para a barreira de alumínio ......58

Figura 5.2 - Resultados analíticos e experimentais para a barreira de cobre.......... 59

Figura 5.3 - Resultados analíticos e experimentais para a barreira de aço inox ......59

Figura 5.4 - Comparativo entre o torque resistivo para as barreiras de diferentes materiais

Figura 5.5 - Deslocamento angular com e sem a barreira para diversos carregamentos...

Figura C.0.1 - Ponto de operação do ímã 


\section{LISTA DE SÍMBOLOS}

\begin{tabular}{|c|c|}
\hline$\alpha$ & ângulo de rotação entre rotores \\
\hline$\alpha^{-1}$ & profundidade de penetração das correntes induzidas \\
\hline$\vec{B}$ & vetor campo magnético \\
\hline$B_{a c}$ & indução magnética no entreferro \\
\hline$B_{\text {estat }}$ & indução magnética no entreferro na condição estática \\
\hline$B_{r}$ & indução magnética devido à reação de armadura \\
\hline$B_{\text {rem }}$ & remanência do ímã \\
\hline$d$ & espessura da barreira condutora \\
\hline$\vec{E}$ & vetor campo elétrico \\
\hline $\overrightarrow{e_{x}}$ & versor na direção tangencial do acoplamento \\
\hline $\overrightarrow{e_{y}}$ & versor na direção axial do acoplamento \\
\hline $\overrightarrow{e_{z}}$ & versor na direção radial do acoplamento \\
\hline$f$ & freqüência \\
\hline$F_{y}$ & força tangencial entre dois ímãs \\
\hline$F_{r}$ & força magneto-motriz da reação de armadura \\
\hline$g$ & distância do ímã até a barreira condutora \\
\hline$\vec{H}$ & vetor intensidade de campo magnético \\
\hline$H_{c}$ & força coercitiva do ímã \\
\hline$\vec{J}$ & vetor densidade de corrente induzida \\
\hline$L$ & raio externo do rotor \\
\hline$L_{m}$ & espessura do ímã \\
\hline$\lambda$ & arco entre um par de polos \\
\hline$n$ & velocidade angular, rotações por segundo \\
\hline$p$ & número de pares de polos \\
\hline$\mu_{r}$ & permeabilidade magnética relativa \\
\hline$\mu_{0}$ & permeabilidade magnética no vácuo \\
\hline$\rho$ & resistividade da barreira condutora \\
\hline
\end{tabular}


$r_{1}$

$\mathfrak{R}$

$S_{\text {polo }}$

$S_{m}$

$\phi_{a c}$

$T$

$\omega$

W raio do centro dos ímãs

relutância magnética

área do polo

área do ímã

fluxo magnético por polo no entreferro

torque resistivo

frequência angular das correntes induzidas na barreira, radianos por segundo

potência dissipada na barreira por unidade de área 


\section{SUMÁRIO}

RESUMO ............................................................................... VIII

1 INTRODUÇÃO ........................................................................14

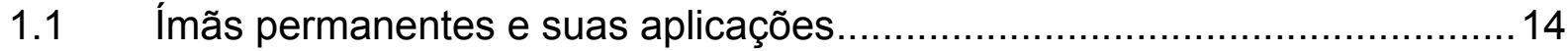

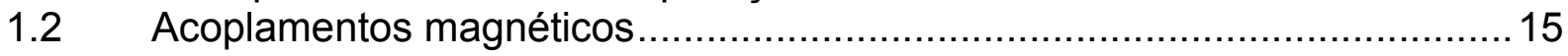

2 ESTADO DA ARTE...............................................................21

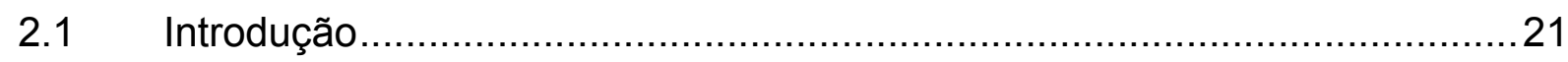

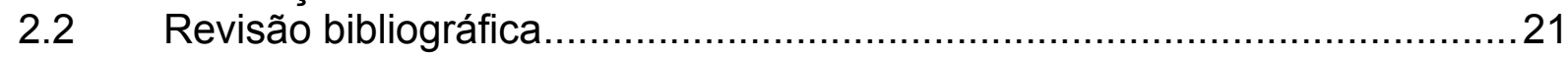

2.2.1 Topologias dos acoplamentos magnéticos ..........................................21

2.2.2 Cálculo da curva característica para a configuração adotada ....................24

2.2.3 Cálculo do torque resistivo devido à barreira condutora ...............................30

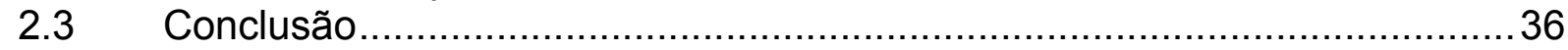

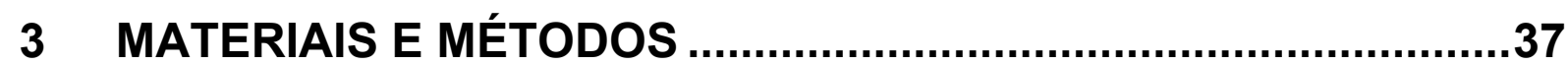

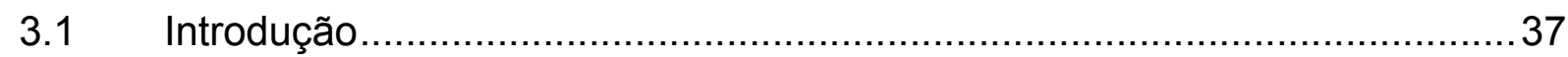

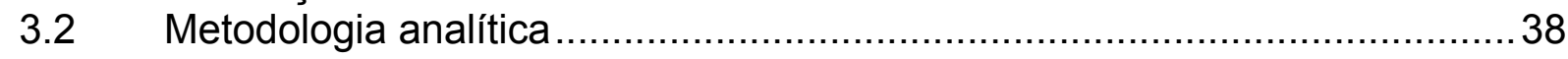

4 VERIFICAÇÃO EXPERIMENTAL..........................................55

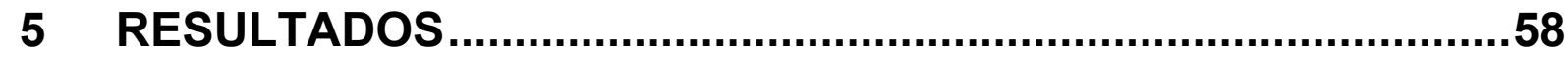

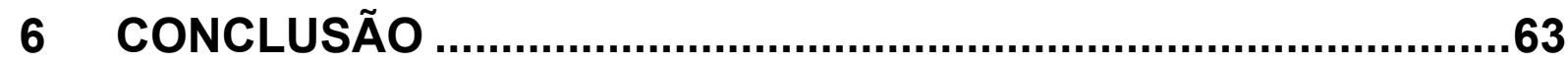

7 PROPOSTAS PARA A CONTINUAÇÃO DOS ESTUDOS .............65

REFERÊNCIAS ......................................................................66

ANEXO A - FORMULAÇÃO DA FORÇA TANGENCIAL NA CONFIGURAÇÃO AXIAL .........................................................70

ANEXO B - PROGRAMAÇÃO EM MATLAB ${ }^{\circledR}$ DA FORMULAÇÃO DA FORÇA TANGENCIAL NA CONFIGURAÇÃO AXIAL .........................72 ANEXO C - OBTENÇÃO DA INDUÇÃO NO ENTREFERRO NA CONDIÇÃO ESTÁTICA

ANEXO D - PROGRAMAÇÃO EM MATLAB ${ }^{\circledR}$ DO CÁLCULO DO TORQUE RESISTIVO 
INTRODUÇÃO

\section{1 Ímãs permanentes e suas aplicações}

$\mathrm{Na}$ atualidade, os ímãs permanentes possuem uma grande importância na vida cotidiana devido à sua vasta difusão em diversas aplicações. Alguns exemplos dessas utilizações estão em setores como os da eletrônica, o de telecomunicações, o industrial, o automobilístico, o aeroespacial, o militar e inclusive o da medicina. Esta enorme gama de áreas nas quais os ímãs são empregados se vale de sua característica principal, que é a capacidade de manter um campo magnético de intensidade relativamente elevada por tempo indeterminado e sem consumo de energia, diferentemente de um eletroímã, por exemplo. Além dessa característica principal, a versatilidade e o baixo custo dos ímãs permanentes também permitiram sua utilização não somente nas diversas áreas citadas, mas como em diversos equipamentos dentro de cada área. Em aplicações comerciais, por exemplo, eles são empregados não só em ímãs de geladeira e brinquedos, mas também em altofalantes, discos rígidos e ventoinhas de computadores, além de inúmeros outros produtos.

As atuais possibilidades de aplicações de ímãs permanentes foram resultado de diversas melhorias em suas propriedades que ocorreram ao longo de sua história. Como descrito por Parker [1], os primeiros registros de ímãs permanentes datam por volta de 600 a.C. e foram feitos por Tales de Mileto. Tratava-se da magnetita $\left(\mathrm{Fe}_{3} \mathrm{O}_{4}\right)$, que no seu estado natural é magnética e por conta disso era usada por marinheiros para guiar o caminho. Ainda segundo Parker [1], os primeiros ímãs permanentes artificiais foram agulhas de ferro imantadas com a magnetita, para serem utilizadas em bússolas. Existem registros dessa prática desde 1200 d.C. em poemas franceses, mas também há referências indicando sua manufatura na China, por volta de 500 d.C. Desde então, várias ligas surgiram através de combinações 
que melhoravam as características magnéticas do material, como a que surgiu na Alemanha em 1901 com manganês e alumínio, além de ligas de cobalto, originadas no Japão em 1917. Na década de 1940, houve outra melhora substancial nas propriedades dos ímãs permanentes e esses passaram então a competir economicamente e funcionalmente com os eletroímãs. Desde então, os ímãs passaram a se difundir principalmente em alto-falantes e em pequenos motores de corrente contínua. No começo da década de 1970, surgiram os ímãs de terras raras, com liga de samário-cobalto ( $\mathrm{SmCo}$ ), permitindo novas soluções à medida que possuíam características muito superiores aos ímãs então disponíveis, como os de ferrite e os de alnico (liga de alumínio, níquel e cobalto). Tais características são basicamente uma maior força coercitiva e maior densidade de fluxo remanente, o que implica maior produto de energia máximo. Após o advento dos ímãs de samáriocobalto, surgiu em 1983 uma nova geração de ímãs de terras raras com os ímãs de neodímio-ferro-boro $(\mathrm{NdFeB})$. Embora tal ímã de neodímio tenha sido o substituto natural do ímã de samário-cobalto, este último ainda possui vantagens em aplicações a altas temperaturas.

\subsection{Acoplamentos magnéticos}

Um dos dispositivos que mais se beneficia das características superiores dos ímãs permanentes de terras raras, principalmente o de neodímio, é sem dúvida o acoplamento magnético. Este tipo de acoplamento se caracteriza por permitir a transmissão de torque sem qualquer tipo de contato físico entre o eixo condutor e o eixo conduzido. Além dessa característica, outra peculiaridade é o escorregamento que ocorre entre os eixos quando o torque transmitido passa de um determinado limite, o que acaba por desconectá-los. Dessa forma, os acoplamentos magnéticos permitem o acionamento de uma carga completamente isolada em ambientes estanques, como é o caso de agitadores e bombas seladas. O emprego dessa tecnologia traz uma série de benefícios em relação ao uso de selos mecânicos, já que não só elimina o risco de vazamentos e de contaminação com o ambiente 
externo, mas também reduz drasticamente os custos de manutenção. Essa redução na manutenção possui uma série de implicações positivas, uma vez que reduz também o tempo de parada para uma troca preventiva ou por falha do selo mecânico. Além dessas vantagens, os acoplamentos magnéticos minimizam ou até eliminam a vibração mecânica que é transmitida ao eixo motor, diminuindo, portanto, os esforços nos mancais e no próprio motor, o que implica aumento na vida útil desses componentes. Outra vantagem que permite uma maior vida útil do motor é a sua proteção contra sobrecargas e eventuais bloqueios de eixo, já que ocorre um escorregamento intrínseco ao dispositivo quando o torque transmitido excede um determinado limite. Ademais, esse tipo de acoplamento possui uma alta tolerância ao desalinhamento não apenas axial e radial, mas como angular entre os eixos, de maneira que isso também auxilia na redução de esforços nos mancais. Além de todas essas características, ainda é possível citar sua alta eficiência energética, já que ao transmitir torque sem contato físico, não gera perdas por atrito.

A maioria das aplicações dos acoplamentos magnéticos está concentrada na área industrial. Exemplos dessas aplicações estão em eixos de motores que acionam bombas, sopradores, ventiladores e outros processos que estão sujeitos a sobrecargas que podem bloquear o eixo. Tais aplicações podem ser visualizadas nas Figuras 1.1, 1.2, 1.3, 1.4 e 1.5 que mostram, respectivamente, acoplamentos magnéticos utilizados em compressores, bombas para irrigação, bombas hidráulicas, ventiladores e esteiras transportadoras.

Figura 1.1 - Exemplo de aplicação do acoplamento magnético: compressor [32]

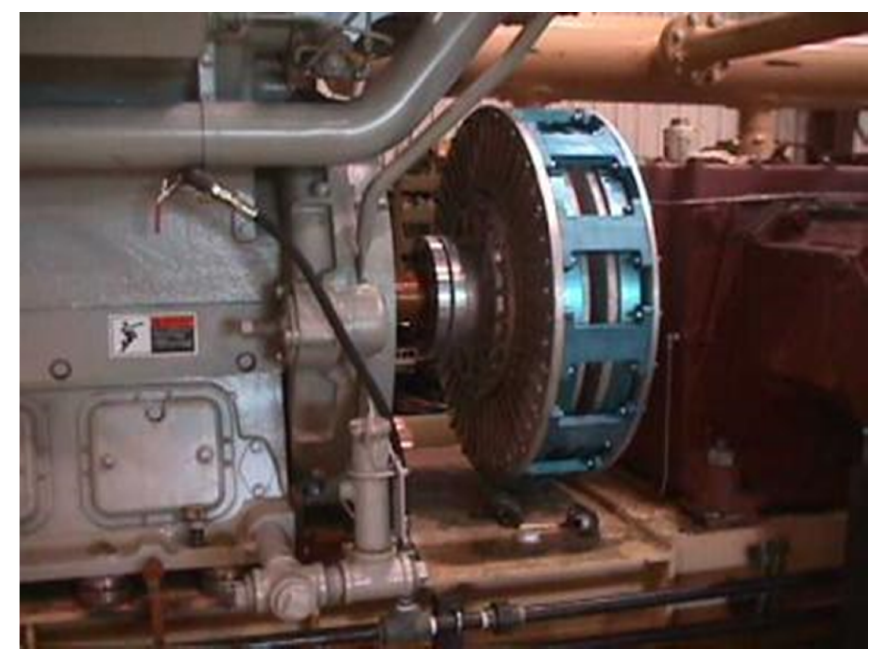


Figura 1.2 - Exemplo de aplicação do acoplamento magnético: bombas para irrigação [32]

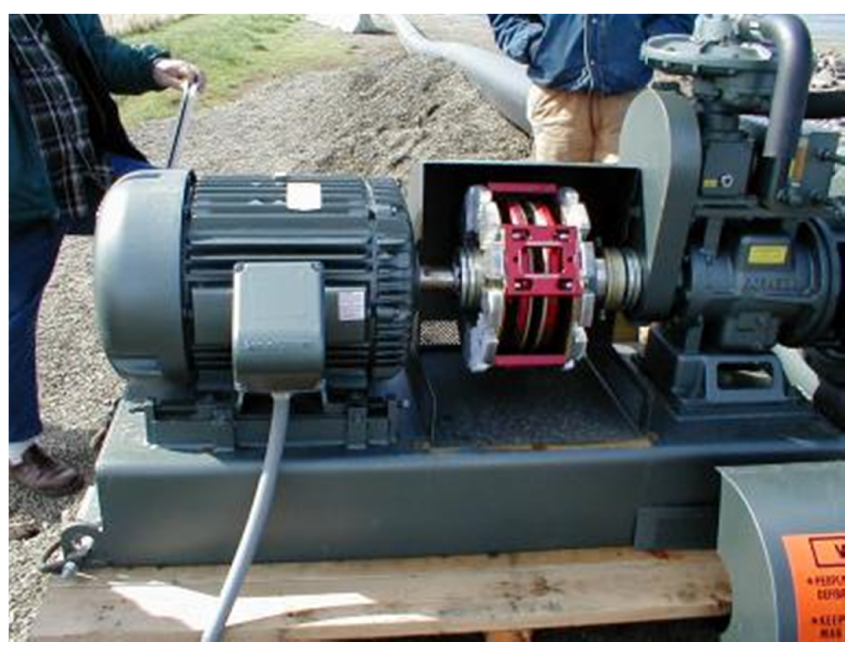

Figura 1.3 - Exemplo de aplicação do acoplamento magnético: bomba hidráulica [32]

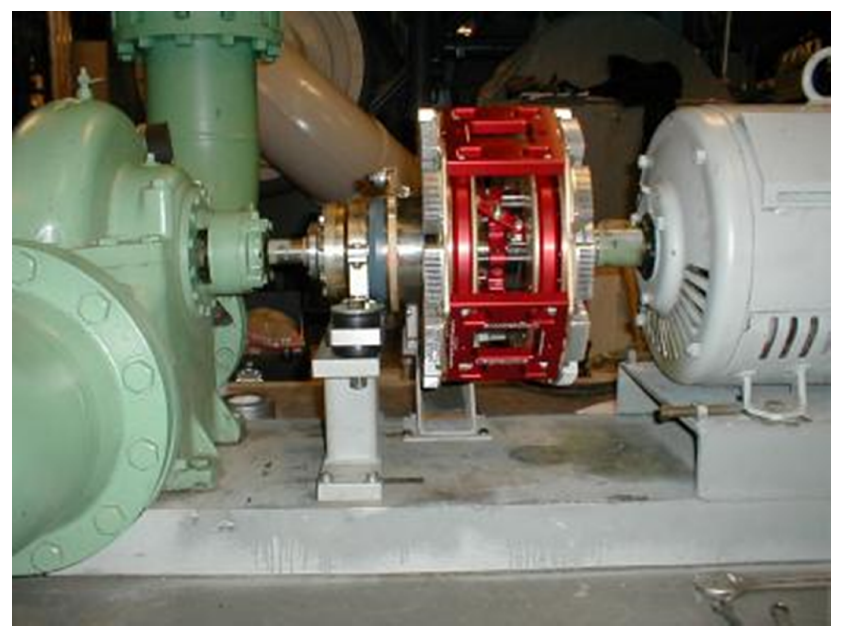

Figura 1.4 - Exemplo de aplicação do acoplamento magnético: ventiladores [32]

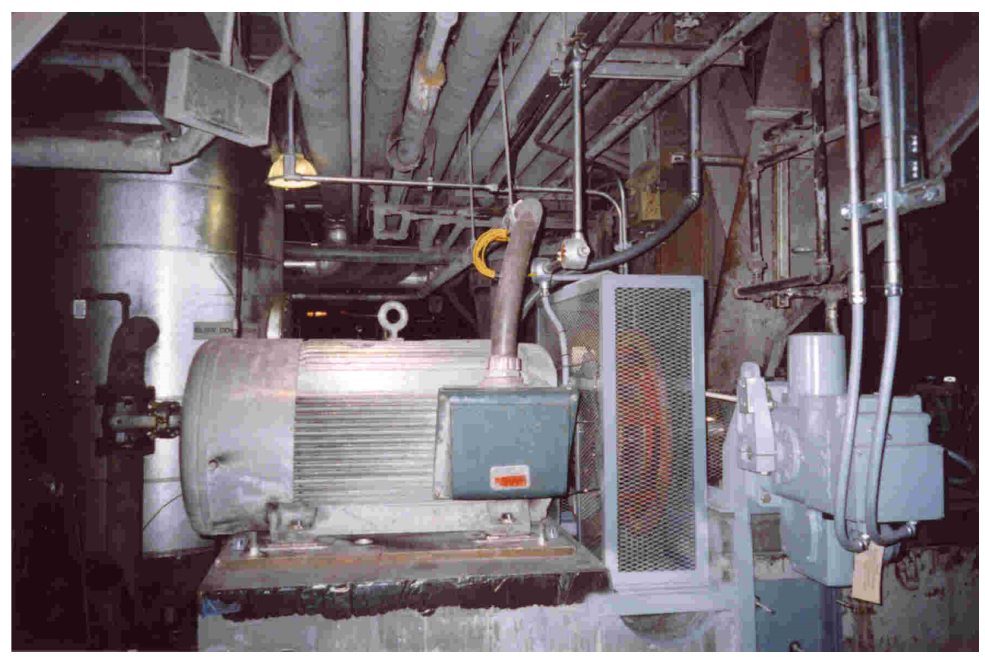


Figura 1.5 - Exemplo de aplicação do acoplamento magnético: esteira transportadora [32]

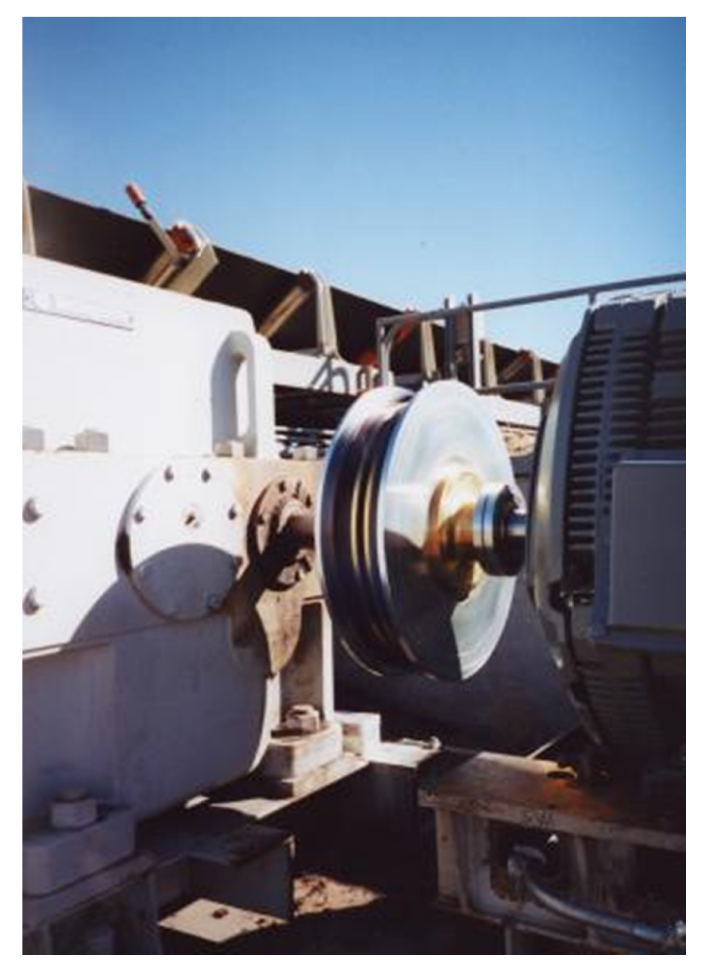

Outro tipo de aplicação importante, que advém do fato do acoplamento magnético ser capaz de transmitir torque sem contato físico entre os rotores, é no acionamento de cargas que estão completamente isoladas em tanques com alta pressão e/ou material corrosivo, tóxico ou contaminante. Nessas aplicações, como é o caso de agitadores e bombas seladas, o emprego de um selo mecânico acaba sendo proibitivo em alguns casos, além de incorrer no risco de vazamentos e ter um custo associado à sua manutenção. Exemplos dessas aplicações estão ilustrados nas Figuras 1.6, 1.7 e 1.8, que mostram, respectivamente, acoplamentos magnéticos empregados em agitadores, em bombas seladas e num protótipo de bomba artificial para o coração humano. 
Figura 1.6 - Exemplo de aplicação do acoplamento magnético: agitadores [33]

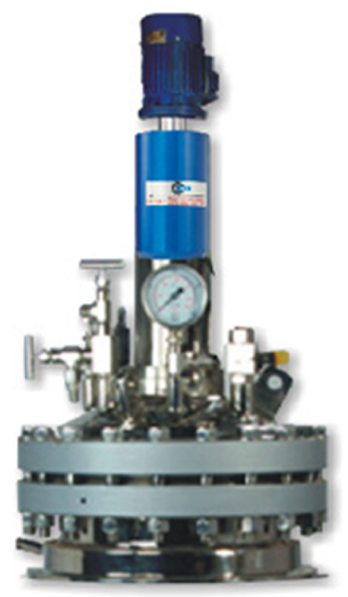

Figura 1.7 - Exemplo de aplicação do acoplamento magnético: bombas seladas [34]

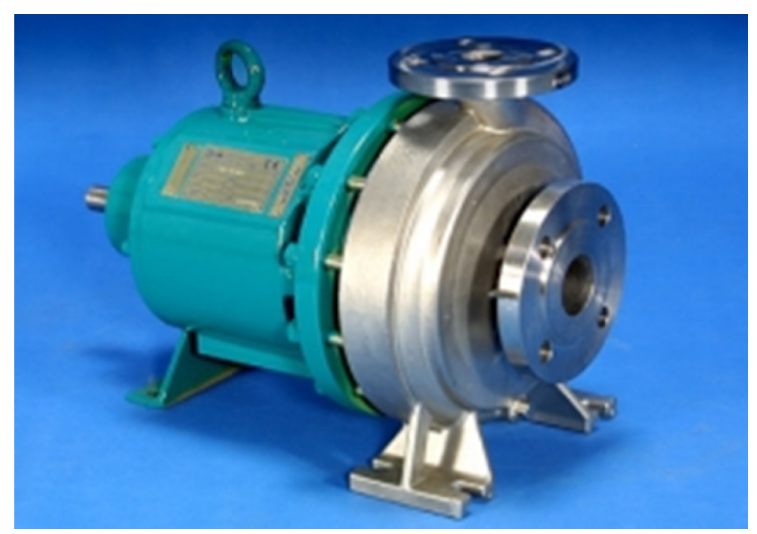

Figura 1.8 - Exemplo de aplicação do acoplamento magnético: bomba artificial para o coração humano

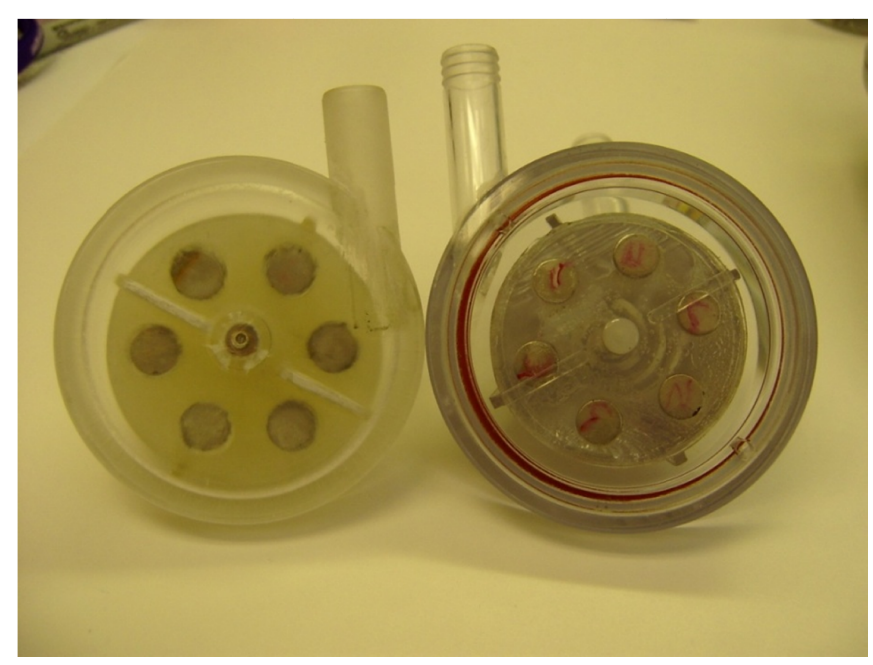


Em suma, as vantagens dos acoplamentos magnéticos podem ser caracterizadas principalmente pelo seu baixo custo de aquisição e de manutenção; alta eficiência energética; robustez e maior confiabilidade no processo; além da proteção contra sobrecargas e eventuais bloqueios no eixo. Embora possuam um baixo custo de aquisição, é necessário realizar um estudo para cada aplicação específica, com o intuito de determinar quais são os materiais mais adequados e em que configuração. Tendo em vista esses diversos aspectos dos acoplamentos magnéticos, se torna de suma importância a correta caracterização de seu comportamento em suas diversas aplicações, uma vez que permite seu dimensionamento de forma precisa. Para tanto, foi objeto de estudo deste trabalho o funcionamento do acoplamento em meio a uma barreira entre os seus rotores, configuração típica de aplicações como em agitadores e em bombas seladas. Com este estudo pretende-se elaborar e testar uma metodologia analítica de cálculo das perdas nessas barreiras para então se determinar o efeito sobre a sua curva característica, ou seja, a curva de torque em função do ângulo de rotação. 


\subsection{Introdução}

Neste capítulo, será exposto um breve resumo das topologias dos acoplamentos magnéticos, além da metodologia adotada para o cálculo de sua curva característica na ausência de barreira condutora entre os rotores. Em seguida, serão apresentadas algumas das metodologias existentes na literatura para o cálculo do torque resistivo em freios do tipo Foucault (correntes parasitas), cuja metodologia será adaptada ao acoplamento magnético com barreira condutora entre os rotores.

\subsection{Revisão bibliográfica}

2.2.1 Topologias dos acoplamentos magnéticos

A literatura descreve várias topologias para os acoplamentos magnéticos a ímãs permanentes. Entretanto, qualquer acoplamento magnético consiste basicamente de dois rotores, sendo um deles ligado à força motriz, que conduz o movimento, e o outro ligado à carga, sendo conduzido pelo primeiro. Em ambos os rotores estão alojados ímãs permanentes, de forma que existe uma posição estável e qualquer deslocamento angular de um dos rotores implica um torque no sentido de restabelecer a posição inicial estável. Esse torque é resultante das forças de atração 
e de repulsão exercidas pelos ímãs, que por sua vez é devido ao deslocamento angular de sua posição estável.

Segundo Furlani [2], as topologias mais comuns para os acoplamentos magnéticos são duas: a configuração radial e a configuração axial. A primeira configuração pode ser visualizada nas Figuras 2.1 e 2.2, nas quais os ímãs adjacentes de um mesmo rotor possuem sentidos de magnetização contrários e os ímãs do outro rotor estão dispostos na mesma configuração, a certa distância na direção radial da magnetização.

Figura 2.1 - Esquema tridimensional da configuração radial [35]

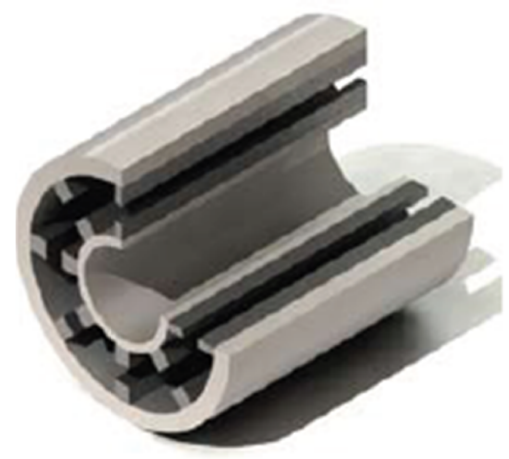

Figura 2.2 - Esquema bidimensional da configuração radial [36]

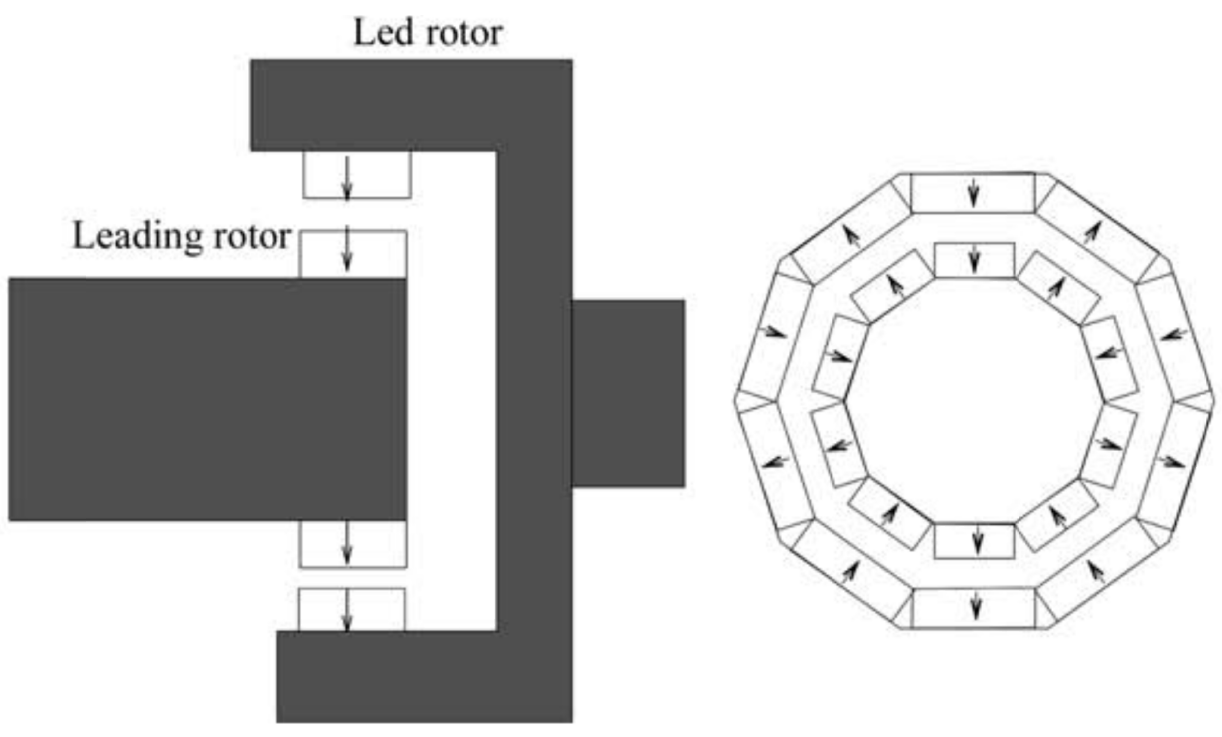

Nessa configuração radial, a força axial nos eixos é nula, uma vez que a força de atração entre os ímãs atua radialmente ao longo de todo o eixo. Entretanto, é fácil 
notar que essa topologia possui uma alta instabilidade na direção radial, pois qualquer desvio lateral nos eixos implica um desequilíbrio nas forças de atração entre os ímãs. Isso ocorre, pois alguns ímãs se aproximariam, aumentando a força de atração entre os rotores, no sentido do deslocamento, e outros se afastariam, diminuindo a força de atração na parte oposta, que é contrária ao deslocamento.

A outra topologia muito utilizada é a configuração axial, ilustrada nas Figuras 2.3 e 2.4, cujos ímãs adjacentes de um mesmo rotor também possuem sentidos de magnetização contrários e os ímãs do outro rotor estão dispostos na mesma configuração a certa distância na direção axial da magnetização.

Figura 2.3 - Esquema tridimensional da configuração axial [35]

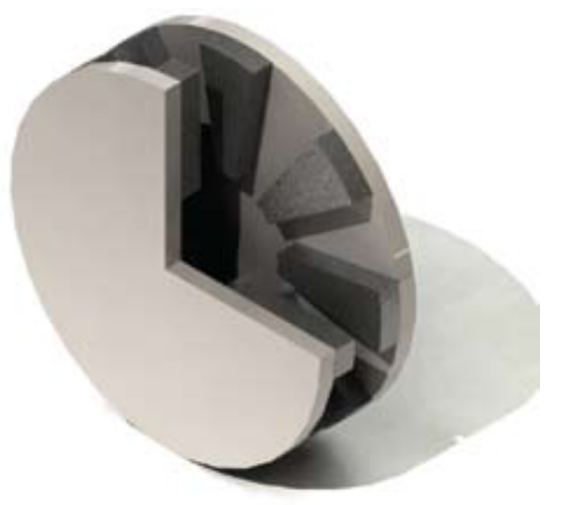

Figura 2.4 - Esquema bidimensional da configuração axial [36]

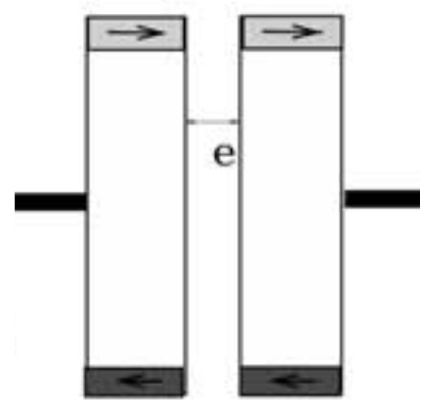

Nessa configuração, existe uma alta força axial que é exercida nos eixos devido à atração entre os ímãs dos dois rotores, entretanto, essa configuração contribui para manter os rotores alinhados na posição central. 


\subsubsection{Cálculo da curva característica para a configuração adotada}

O protótipo de acoplamento magnético, cujo estudo e desenvolvimento estão detalhados em [3] e [4], se pautou na facilidade de execução para a escolha da topologia adotada. Embora a topologia axial apresente a desvantagem de possuir uma força axial de atração a ser compensada, ela possui maior facilidade para se fixar os ímãs do que a configuração radial. Ademais, essa força axial pode ser sustentada pelos mancais e o ajuste para se levantar as curvas para vários entreferros pode ser feito de forma simples, enquanto que na outra configuração seriam necessários diversos rotores para tanto. Por esses motivos, foi adotada a topologia axial no protótipo do acoplamento magnético.

A Figura 2.5 mostra a vista frontal de um dos rotores do protótipo do acoplamento, enquanto a Figura 2.6, a vista lateral desse acoplamento completamente montado.

Figura 2.5 - Vista frontal do rotor do protótipo

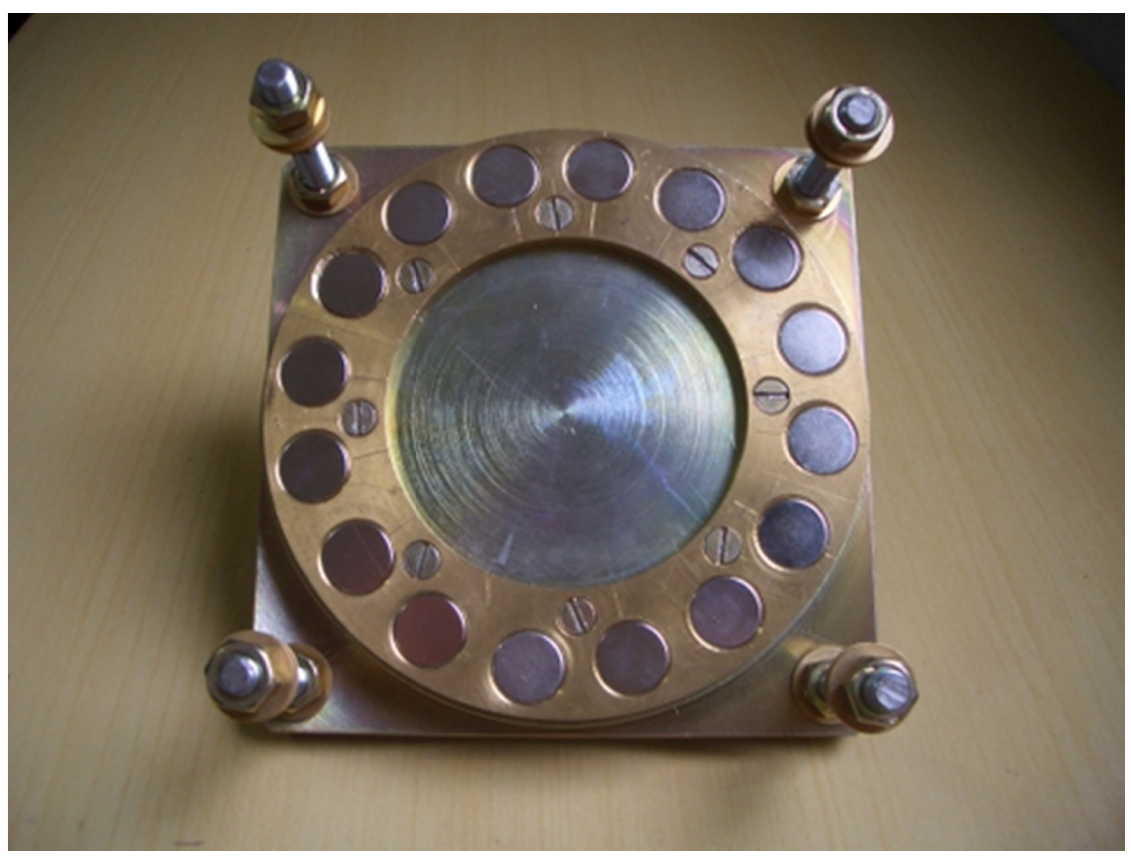


Figura 2.6 - Vista lateral do protótipo montado

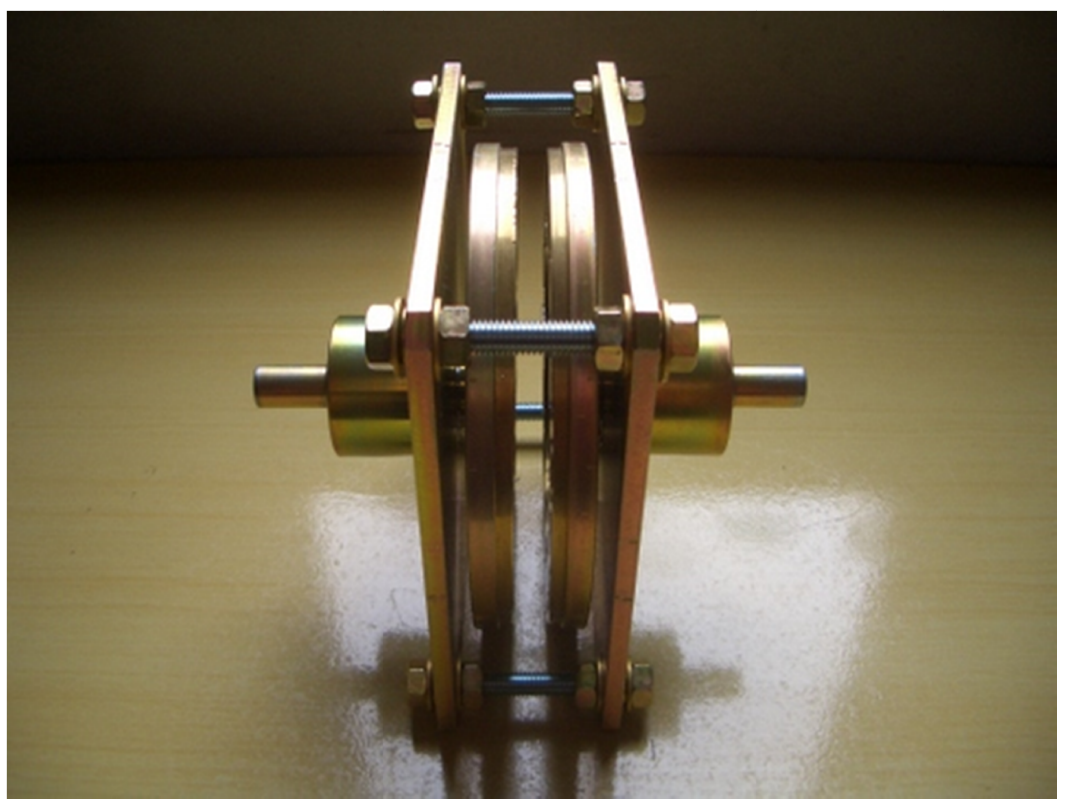

A partir dos estudos apresentados por Eliès e Lemarquand [5] sobre os acoplamentos magnéticos com construção axial, foi formulada a componente tangencial da força $\left(F_{y}\right)$ entre os ímãs nessa configuração, com base na teoria das cargas magnéticas [6].

Figura 2.7 - Parametrização na configuração axial [5]

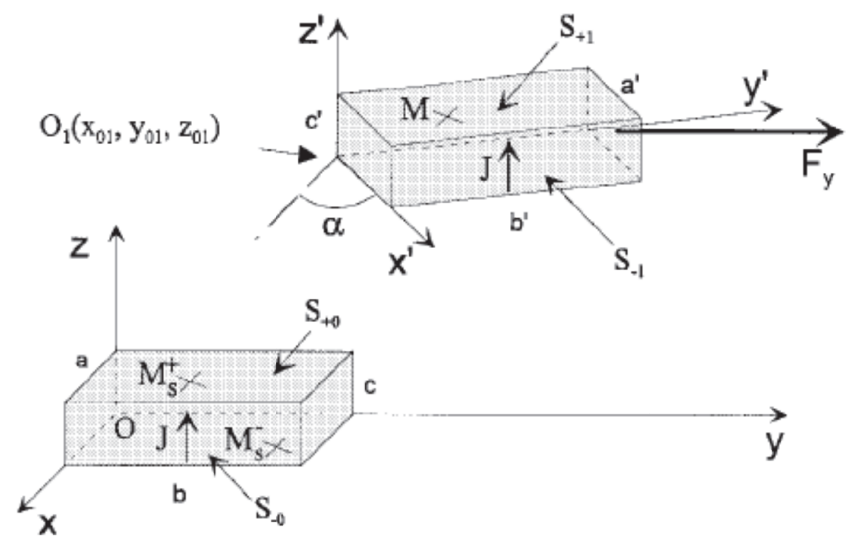

Os parâmetros utilizados para o cálculo da força tangencial estão mostrados na Figura 2.7, na qual o ímã 0 de dimensões a, b e c está fixo com um de seus vértices na origem 0 . Já o ímã 1 , de dimensões a', b' e c', possui o vértice correspondente no ponto $\mathrm{O}_{1}$, cujas coordenadas são $\left(\mathrm{x}_{01}, \mathrm{y}_{01}, \mathrm{z}_{01}\right)$. Ademais, o ímã 1 está deslocado de um ângulo $\alpha$ em relação aos planos $X O Z$ e $X^{\prime} O_{1} Z^{\prime}$ e ambos os ímãs possuem 
magnetização J em tesla. Essa parametrização é particularmente conveniente para a configuração axial, pois pode representar a posição de cada um dos ímãs dos rotores, variando-se a e o ponto $\mathrm{O}_{1}$.

Como a parametrização considera ímãs com seção retangular e o protótipo utiliza ímãs circulares, calculou-se o ímã de seção quadrada cuja área equivale à do ímã empregado no protótipo. Pode-se assumir que tal aproximação não acarreta em grandes desvios, pois a teoria está baseada na interação entre as superfícies dos ímãs. Assim sendo, o lado do ímã quadrado equivalente para o cálculo teórico é de $14,2 \mathrm{~mm}$, pois o diâmetro do ímã do protótipo é de $16 \mathrm{~mm}$. Ademais, é importante ressaltar que tais ímãs do protótipo possuem magnetização de 1,2 T, espessura de 5 $\mathrm{mm}$ e o centro deles está disposto a um raio de $58,4 \mathrm{~mm}$ no rotor.

Segundo Eliès e Lemarquand [5], a expressão de $F_{y}$ não pode ser avaliada analiticamente, então foi necessária a utilização de técnicas de integração numérica disponíveis no Matlab ${ }^{\circledR}$. A formulação da expressão da força tangencial está detalhada no Anexo $A$, enquanto os scripts utilizados nessa ferramenta de cálculo estão mostrados no Anexo B.

Figura 2.8 - Gráfico da força tangencial entre um par de ímãs em função do ângulo de rotação para um entreferro de $1 \mathrm{~mm}$

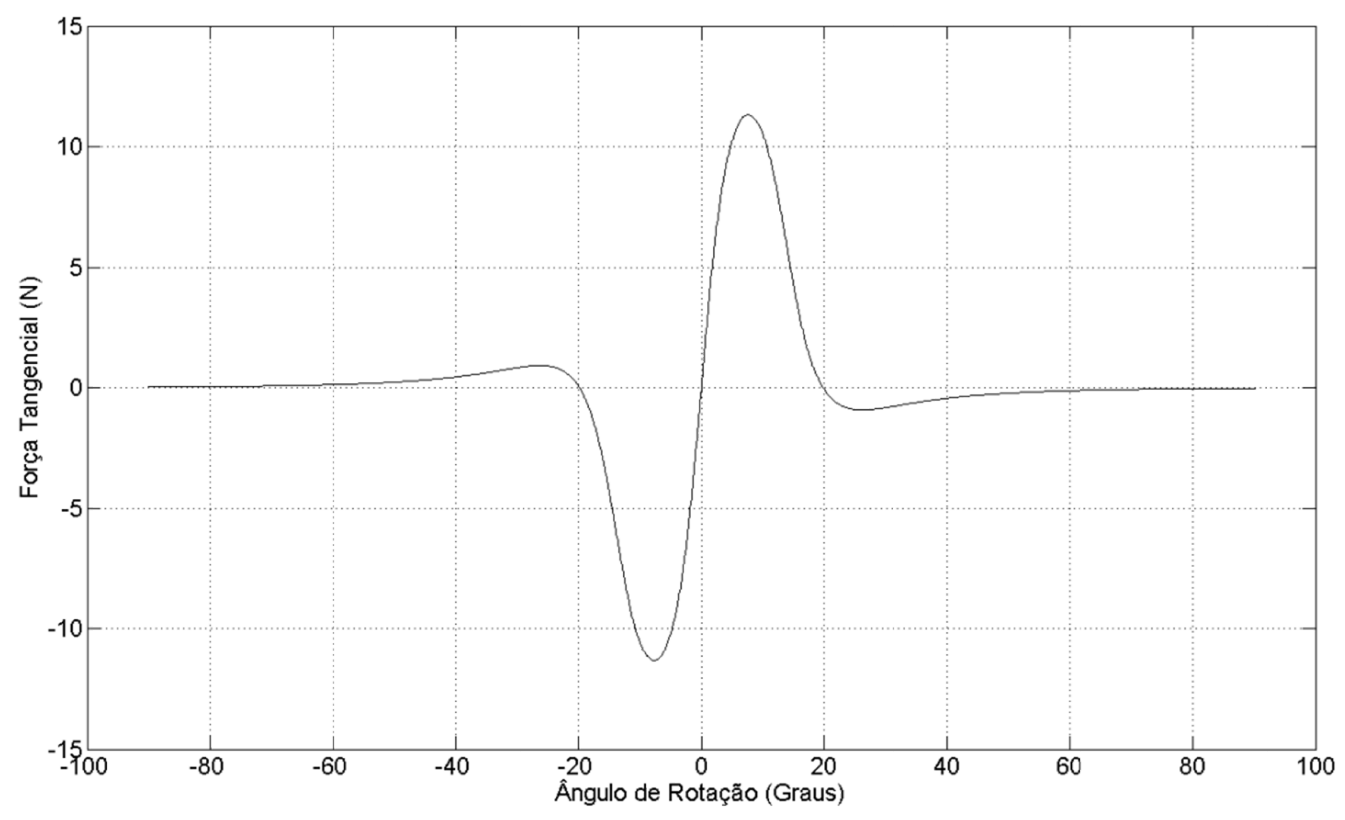


O resultado desse tratamento analítico para os parâmetros do protótipo construído em [3] está mostrado na Figura 2.8. Nessa figura, tem-se a força tangencial em função do ângulo de rotação para um par de ímãs com $1 \mathrm{~mm}$ de entreferro.

A determinação da curva característica do acoplamento magnético, isto é, a curva do torque transmitido em função do ângulo de rotação entre os rotores, é realizada a partir do cálculo da força tangencial entre os ímãs. Inicialmente, calcula-se a força tangencial que é exercida em um determinado ímã em um rotor devido à presença de todos os ímãs do rotor adjacente, para um determinado ângulo de rotação. Tais forças são então somadas e multiplicadas pelo raio dos ímãs, para a obtenção do torque por ímã. Esse último resultado é então multiplicado pelo número de ímãs no rotor para obter o torque final transmitido, já que todos os ímãs estão sujeitos à mesma força tangencial resultante, por conta de seu espaçamento uniforme. Este procedimento é então repetido para cada ângulo de rotação de interesse para a obtenção de sua curva característica.

O resultado desta metodologia para o protótipo desenvolvido em [3] está ilustrado na Figura 2.9, que mostra sua curva característica teórica para um entreferro de $1 \mathrm{~mm}$.

Figura 2.9 - Gráfico do torque teórico em função do ângulo de rotação para o protótipo do acoplamento magnético com $1 \mathrm{~mm}$ de entreferro

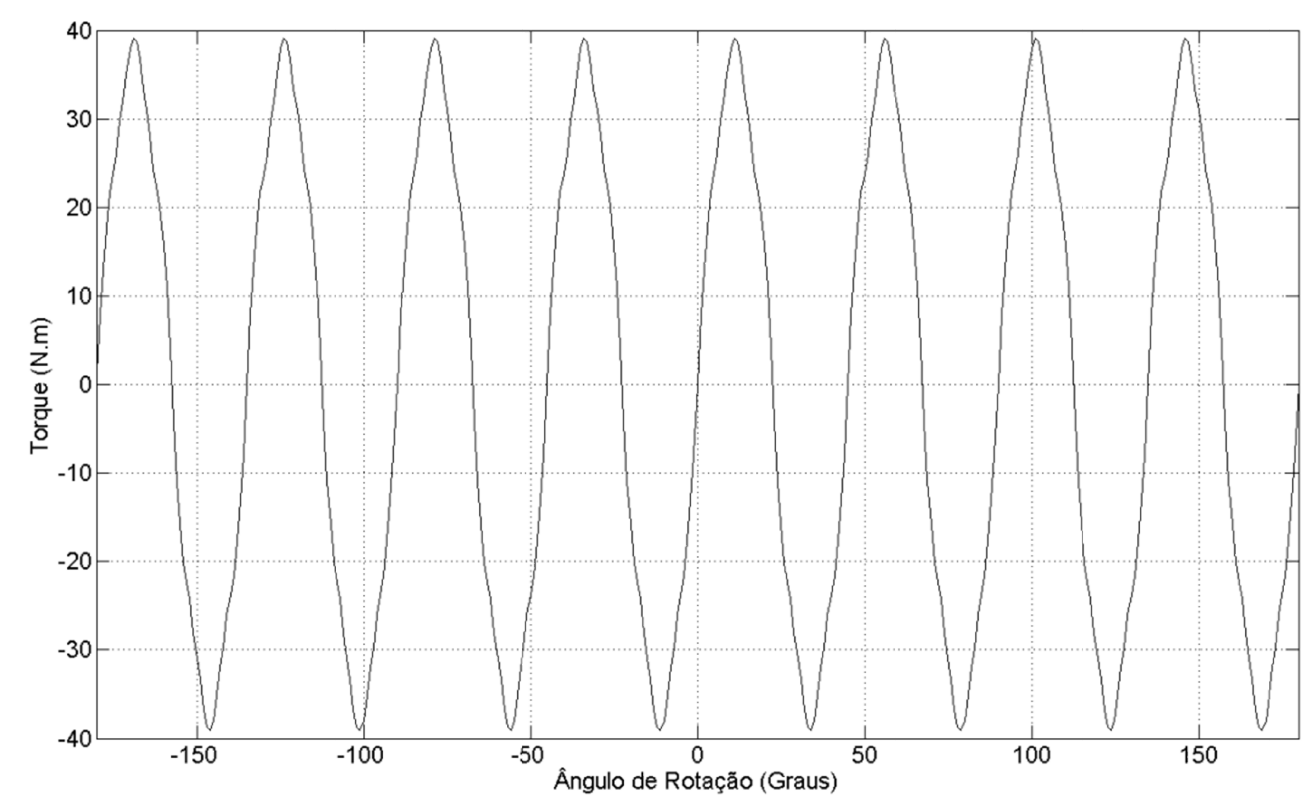


comportamento do gráfico da Figura 2.9 pode ser explicado com base na posição relativa entre os ímãs e no número de polos. Analisando-se o intervalo do ângulo de rotação que vai desde $0^{\circ} \mathrm{a}+45^{\circ}$ (correspondente a dois passos polares), nota-se que o torque parte de um valor nulo (posição de equilíbrio estável); passa por um máximo (torque positivo), atinge novamente um valor nulo (posição de equilíbrio instável, entretanto), passa por um mínimo (torque negativo) e finalmente atinge outra posição de equilíbrio estável.

Essa posição de equilíbrio estável pode ser explicada pelo fato de que, nessa situação, os ímãs dos diferentes rotores estão se atraindo, de forma que um deslocamento em qualquer um dos sentidos faz com que os ímãs se alinhem novamente.

A posição na qual temos um torque máximo pode ser explicada pelo fato de que nessa posição, os ímãs de um determinado rotor são atraídos pelos ímãs do outro rotor que antes estavam pareados com eles e repelidos pelos vizinhos desses com igual intensidade. Ambos os torques exercidos são no sentido de restabelecer a posição inicial.

Já na posição de equilíbrio instável, os ímãs de um rotor repelem os ímãs do outro rotor (e vice-versa) exercendo uma força axial apenas. Nessa situação, as faces dos ímãs voltadas para fora possuem o mesmo polo magnético das faces correspondentes dos ímãs do outro rotor.

A posição de torque mínimo é equivalente à posição de torque máximo, com a diferença que o sentido do torque é contrário. Dessa forma, a tendência do movimento é de estabelecer uma nova posição de equilíbrio estável.

Outro ponto importante mostrado no gráfico da Figura 2.9 é que o comportamento descrito repete-se oito vezes, como era de se esperar, pois é igual número de pares de polos e, logo, o número de interações entre eles.

As curvas experimentais em [3] que foram levantadas e confrontadas com os resultados teóricos estão mostradas nos gráficos da Figura 2.10. Nesses gráficos, as curvas características do acoplamento foram levantadas experimentalmente e teoricamente para entreferros de 19, 16, 13, 10 e $8 \mathrm{~mm}$.

Como é possível observar nos gráficos da Figura 2.10, a ferramenta de cálculo desenvolvida apresentou resultados muito próximos das curvas levantadas 
experimentalmente, validando, portanto, a metodologia de cálculo empregada pela ferramenta. A média aritmética dos valores absolutos dos erros foi menor que $10 \%$ para os dados apresentados.

Cabe ressaltar que para deslocamentos angulares negativos, isto é, deslocamentos no sentido oposto em relação ao adotado, os resultados foram os mesmos, assim optou-se por não repetir os dados na Figura 2.10 para uma melhor visualização.

Figura 2.10 - Comparação entre o torque medido e calculado em função do deslocamento angular para vários entreferros
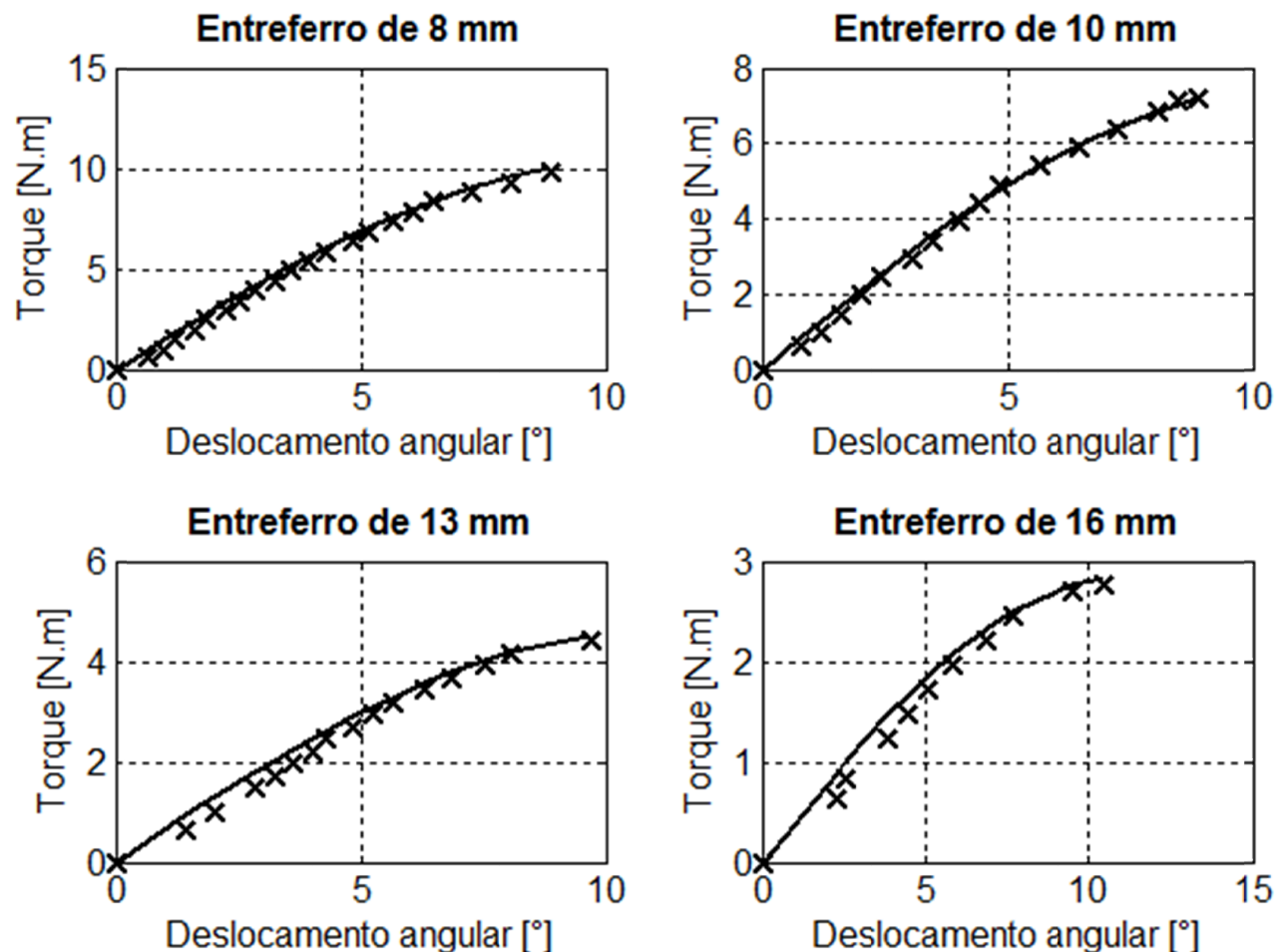

Entreferro de $19 \mathrm{~mm}$

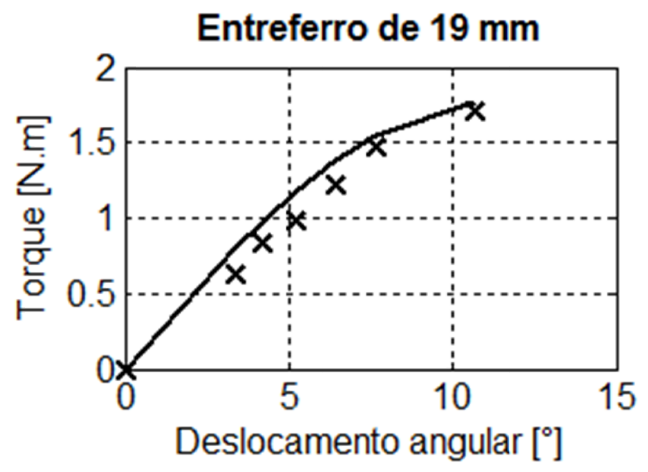

Deslocamento angular [ $\left.{ }^{\circ}\right]$ $\times$ Valores experimentais
- Valores calculados

Além desse ponto, também é importante ressaltar que para deslocamentos maiores que meio passo polar $\left(11,25^{\circ}\right)$, ou seja, além do torque máximo, a medição se torna 
impraticável, pois qualquer vibração acaba deslocando o rotor ligado à carga de sua posição estável.

Para se ilustrar a capacidade de transmitir potência do protótipo do acoplamento magnético, temos que para uma rotação de 3600 RPM e um entreferro de $8 \mathrm{~mm}$, o torque máximo é de $10 \mathrm{~N} . \mathrm{m}$, resultando em uma potência transmitida de $3,7 \mathrm{~kW}$ ou 5 cv. Agora, se supormos a mesma rotação, mas um entreferro de $1 \mathrm{~mm}$, o torque máximo teórico é de $40 \mathrm{~N} . \mathrm{m}$, o que implica uma potência transmitida de $15 \mathrm{~kW}$, ou ainda $20 \mathrm{cv}$, o que é relativamente alto para um dispositivo dessas dimensões.

\subsubsection{Cálculo do torque resistivo devido à barreira condutora}

A curva característica de um acoplamento magnético é fortemente influenciada pela presença de uma barreira condutora entre os rotores, como é o caso de aplicações em bombas seladas e agitadores. Nessas aplicações, a movimentação dos ímãs do acoplamento magnético acaba por induzir correntes parasitas de Foucault na barreira, que é estacionária. Tais correntes induzidas produzem um campo magnético contrário à variação do campo magnético dos ímãs, tendendo a enfraquecer seu campo e diminuir seu ponto de operação. Dessa maneira, a interação dessas correntes induzidas com o campo resultante gera um torque contrário à movimentação, de forma que isso diminui o torque máximo que pode ser transmitido pelo acoplamento magnético. Esse efeito traz como consequência o aumento do deslocamento angular para uma determinada carga. As metodologias existentes na literatura para o cálculo desse torque resistivo têm como base o estudo desse fenômeno em freios e em acoplamentos por correntes parasitas. Nesse tipo de freio, o disco condutor acaba sendo a parte móvel, enquanto a estrutura com os ímãs é fixa. Já no acoplamento por correntes parasitas ambas as partes são móveis, de maneira que as correntes são induzidas pelo escorregamento entre os rotores. Entretanto, tais diferenças acabam sendo irrelevantes, pois o efeito final é o mesmo, 
tanto no acoplamento magnético, como nos freios e nos acoplamentos por correntes parasitas.

Segundo Davies [7], as primeiras tentativas de se analisar os acoplamentos por correntes parasitas foram realizadas por Rudenberg em 1906. Esse primeiro estudo foi baseado na determinação de uma solução para a equação da difusão, mas ao assumir uma permeabilidade constante para o ferro, não se conseguiu descrever o comportamento do acoplamento de forma satisfatória. Em 1923, Rosenberg obteve melhores resultados ao assumir certas simplificações nas correntes e densidades de fluxo no meio condutor. Já em 1946, Gibbs apresentou o primeiro tratamento válido do assunto ao conseguir manipular algebricamente a curva da permeabilidade. Em 1963, Davies [7] partiu dessa tratativa feita por Gibbs, mas a refinou em vários aspectos questionáveis, como o cálculo da reação de armadura feito inicialmente. Como resultado, Davies [7] obteve curvas teóricas muito próximas das curvas experimentais, validando, portanto, sua metodologia.

Nesse mesmo ano de 1963, Hansen e Timmler [8] apresentaram expressões simplificadas envolvendo a corrente de excitação da bobina, velocidade e torque, além de correções para ajuste dos resultados obtidos. Entretanto, nenhuma comparação com resultados práticos foi realizada. Ainda em 1963, Malti e Ramakumar [9] foram pioneiros em desenvolver uma teoria tridimensional para o acoplamento por correntes parasitas com um anteparo de ferro. Diversas curvas experimentais foram levantadas variando-se a excitação, a geometria e o número de polos, de maneira que os resultados obtidos foram muito concordantes com os cálculos teóricos.

Em 1942, Smythe [10] estudou as correntes parasitas em disco de material condutor, como é o caso do cobre. A formulação obtida foi diferente das formulações presentes nas referencias anteriores, já que o material não é magnético e, portanto, não satura. Um aspecto importante em sua formulação é a inclusão do efeito de enfraquecimento no campo causado pelas correntes parasitas, entretanto, não houve comparação com resultados experimentais.

Em 1965, Gonen e Stricker [11] analisaram o freio por correntes parasitas com eletroímãs e disco de ferro. Nessa análise, foi utilizado o vetor de Poynting para o cálculo do fluxo de potência e obtenção do torque resistivo, de maneira que os resultados teóricos ficaram muito próximos dos experimentais. 
No ano seguinte, Davies [12] estendeu sua formulação ao estudar uma configuração dentada, ligeiramente diferente da primeira, obtendo novamente resultados em linha com os experimentais.

Em 1972, Schieber [13] desenvolveu um estudo sobre o efeito de freio da indução de correntes parasitas por um único polo em uma fina camada de metal condutivo não magnético. Nesse estudo foi desprezada a espessura do material condutor e do enfraquecimento causado pelas correntes induzidas, de maneira que em 1974, quando Schieber [14] realizou os testes experimentais, não foram obtidos resultados muito precisos.

No ano de 1975, Davies [15] fez novamente uma extensão de seus estudos ao considerar a adição de anéis de cobre nas extremidades do cilindro de ferro, na qual circulam as correntes parasitas. Tal adição é feita para se minimizar as perdas nessas bordas, que não contribuem para a transmissão de torque já que apenas as correntes axiais são efetivas. Com esse estudo, uma maior precisão foi obtida, já que os efeitos de borda não estavam contemplados na formulação.

Em 1977, Davies, Wright e McKibbin [16] elaboraram um modelo tridimensional para acoplamentos por correntes parasitas considerando uma camada de cobre entre o entreferro e o cilindro de ferro. Nessa configuração, a maior parte do torque produzido se deve à superfície de cobre, mas também há uma contribuição devido à circulação de correntes parasitas ao longo do cilindro de ferro. Os resultados obtidos mostram uma boa correlação entre teoria e prática, mas para excitações muito altas o erro aumenta drasticamente por conta da saturação do ferro.

Em 1984, Nagaya et al. [17] desenvolveram uma formulação para o cálculo das forças de frenagem e coeficientes de amortecimento para freios com ímãs cilíndricos e placas condutoras de forma arbitrária. Embora esse estudo apresente uma forma genérica de se abordar placas de formas arbitrárias, ele só é aplicável a pequenas velocidades relativas entre o ímã e a placa condutora. Isso se deve ao fato de que tal abordagem não leva em consideração o enfraquecimento do campo principal causado pelas correntes parasitas nem a influência da espessura da placa. Tal estudo foi generalizado para ímãs seccionados em diversos setores em 1987, por Nagaya e Karube [18]. 
No ano de 1991, Wouterse [19] apresentou um modelo teórico para freios por correntes parasitas unipolares, mas com polos relativamente afastados entre si. Nesse estudo, o autor reúne diversos valores experimentais de outros autores. Embora os resultados obtidos não sejam tão precisos, podem servir de base para uma primeira aproximação, por conta de sua simples formulação.

Ainda no mesmo ano de 1991, Liu, Vourdas e Binns [20] desenvolveram uma solução analítica por meio do vetor potencial magnético para o cálculo do campo gerado pelos ímãs permanentes. Com essa abordagem foi possível avaliar as perdas devido às correntes parasitas induzidas no estator de ferro, de maneira que os resultados condizem com os dados experimentais.

Em 1994, Nehl et al. [21] desenvolveram um modelo bidimensional de elementos finitos para o cálculo da curva característica de um acoplamento por correntes parasitas constituído por ímãs permanentes. Nessa abordagem puderam ser levantadas curvas para discos de alumínio e ferro, além de configurações com e sem material ferromagnético atrás dos ímãs permanentes. Ademais, também foi estudada a influência do número de polos. Os resultados foram validados experimentalmente para uma determinada configuração de acoplamento com disco de ferro. Nesse estudo constatou-se que o material ferromagnético atrás dos ímãs aumenta o torque desenvolvido no freio, já que diminui a relutância magnética. Além disso, constatou-se também que a configuração com disco de alumínio apresenta um torque máximo a rotações menores, mas mesmo assim em menor amplitude que nas configurações com disco de ferro. Isso se deve ao fato de que a relutância com disco de alumínio é maior do que na configuração com disco de ferro, diminuindo, portanto, a força magneto-motriz disponível.

Em 1997, Lequesne, Liu e Nehl [22] continuaram os estudos em [21] para investigar a influência dos materiais, configurações, número de polos e a espessura do ímã no desempenho dos freios por correntes parasitas. Embora combinações de ferro com uma camada de alumínio ou cobre no disco foram estudadas com o método dos elementos finitos, não foi realizado nenhum outro experimento para validar os novos resultados obtidos.

No ano de 1999, Edwards et al. [23] desenvolveram um modelo analítico bidimensional para freios lineares por correntes parasitas com placa não magnética e ímãs permanentes. Esse estudo aborda uma configuração com ímãs nos dois 
lados da placa, de forma a se assemelhar em muito com o acoplamento magnético a ímãs permanentes e uma barreira entre os rotores. Além do cálculo da força resistiva, efeitos como o pelicular, efeitos nas bordas da placa condutora e efeitos nas extremidades dos polos também foram levados em consideração. Os resultados experimentais foram condizentes com o previsto pela teoria desenvolvida, com a ressalva de variações devido a aspectos mecânicos da montagem experimental.

No ano de 2000, Dietrich [24] se baseou nos trabalhos de Davies em [7] e [12] para desenvolver uma abordagem mista, envolvendo cálculos analíticos e simulações numéricas para a análise de freios por correntes parasitas em materiais ferromagnéticos. A partir da simulação numérica, são calculadas duas constantes para serem empregadas na formulação analítica, que é então utilizada para a obtenção da curva de torque em função da rotação. Os resultados obtidos experimentalmente foram bem próximos aos valores calculados para os dois protótipos utilizados.

Em 2001, Lesobre, Ahmed e Drecq [25] estudaram freios por correntes parasitas compostos por um disco condutor magnético e excitação por corrente contínua. A metodologia desenvolvida nesse estudo adota uma abordagem bidimensional por elementos finitos para o cálculo da densidade de fluxo magnético na superfície do disco. Em seguida, os autores adotam uma metodologia analítica para o cálculo da densidade de corrente com base no valor de fluxo obtido por elementos finitos. Com essa densidade de corrente é possível calcular as perdas totais no disco e consequentemente, o torque desenvolvido. Nessa abordagem também foram considerados efeitos de borda e de saturação, de maneira que os resultados foram condizentes com os obtidos exclusivamente por elementos finitos. A vantagem de se utilizar esse método combinado é sua maior simplicidade se comparado a uma análise tridimensional por elementos finitos, além de se obter de maneira mais precisa a densidade de fluxo no disco, se comparado com uma abordagem puramente analítica. Entretanto, tal estudo poderia ter sido complementado com experimentos práticos, visando validar ambas as metodologias utilizadas.

Em 2002, Lee e Park [26] desenvolveram um método analítico para um freio por correntes parasitas, cujos elementos eram um eletroímã e um disco condutor não magnético. A metodologia envolvia os conceitos da lei de Coulomb, do método das imagens, das condições de contorno aplicáveis, da lei de Ampère e da força de 
Lorentz, de maneira que se diferencia das demais abordagens, que envolvem o conceito de vetor potencial magnético. Embora a metodologia seja diferente, os resultados obtidos foram bem próximos aos resultados experimentais, de maneira que uma das fontes de erros apontada foi a elevação de temperatura no disco devido à circulação das correntes parasitas. Dependendo da excitação empregada, o aumento da temperatura poderia chegar a $20^{\circ} \mathrm{C}$, ocasionando uma grande diferença na resistividade do material.

No ano de 2003, Canova e Vusini [27] abordaram praticamente a mesma geometria que Edwards et al. utilizaram em [23], mas com a diferença de estudarem o freio circular ao invés do linear como havia sido feito. A abordagem analítica desenvolvida não foi descrita completamente, mas os resultados obtidos foram comparados com uma simulação por elementos finitos em duas dimensões para sua validação. Em seguida, Canova e Vusini propuseram uma metodologia híbrida entre o método analítico apresentado e o de elementos finitos em duas dimensões para considerar os efeitos nas bordas das placas. O resultado obtido foi então comparado com testes experimentais, verificando-se boa correlação entre ambos. Após esse estudo, ainda foi apresentado um método puramente analítico para a correção devido a tais efeitos de borda, de maneira a apresentar bons resultados se comparado com os experimentais.

Dois anos depois, os mesmos autores, Canova e Vusini [28], apresentaram um estudo para a configuração radial dos acoplamentos por correntes parasitas, com base na formulação anterior. Embora os resultados analíticos se aproximem dos obtidos por elementos finitos, não foram realizados testes experimentais para sua verificação.

Em 2007, Amati et al. [29] desenvolveram um estudo de sensibilidade dinâmica dos parâmetros dos acoplamentos por correntes parasitas. O modelo analítico utilizado foi baseado no trabalho de Canova e Vusini [27], de maneira que foram determinados os parâmetros equivalentes em termos de indutância, resistência e constante eletromecânica para modelar o acoplamento. De posse de tais variáveis, foi realizado um estudo de sensibilidade dos principais parâmetros do dispositivo, sendo validado com simulações por elementos finitos.

No ano de 2009, Baum e Eberhardt [30] estudaram o freio por correntes parasitas com dois pares de polos, ímãs permanentes e um disco de material condutivo e não 
magnético. Na abordagem analítica desenvolvida, foi estudado o comportamento a baixas rotações e a altas rotações, na qual o enfraquecimento do campo dos ímãs se torna relevante. Tais comportamentos são combinados em uma única formulação, cujos resultados mostram boa correlação se comparados com os experimentais. Embora a dedução da metodologia seja bem detalhada, o arranjo experimental não apresenta todos os parâmetros utilizados, de maneira que não é possível reproduzir os resultados computados com essa metodologia apresentada. Cabe ressaltar que os ímãs adotados nesse arranjo são de neodímio-ferro-boro e o disco de cobre foi resfriado a água na realização do experimento.

Ainda no mesmo ano de 2009, Srivastava e Kumar [31] apresentaram uma abordagem alternativa do problema ao utilizarem a transformada de Fourier para o cálculo da curva característica do freio por correntes parasitas. Os resultados obtidos com essa abordagem estão bem próximos dos resultados experimentais, embora a análise por elementos finitos acabasse apresentando melhores resultados.

\subsection{Conclusão}

Como descrito neste capítulo, existem diversos estudos sobre o efeito das correntes parasitas originadas da movimentação relativa entre um meio condutor e uma fonte de campo magnético. Embora existam variações nas configurações adotadas, como o tipo da fonte de campo magnético e o material na qual são induzidas as correntes, os efeitos envolvidos são os mesmos, assim como as dificuldades em se elaborar uma formulação analítica abrangente. Um ponto importante a se destacar foi a preocupação da maioria dos autores em validar a metodologia desenvolvida, seja por simulações através de elementos finitos, por experimentos ou por ambos.

Os fundamentos envolvidos nos acoplamentos com barreira condutora entre os rotores, assim como a metodologia analítica adotada para a determinação de seu comportamento, serão abordados no próximo capítulo. 


\section{$3.1 \quad$ Introdução}

Em aplicações como bombas seladas e agitadores, normalmente se encontra uma barreira de material condutor, que separa os meios nos quais se encontram o motor e a carga. Através dessa barreira, o acoplamento magnético transmite o movimento de um rotor a outro pela interação entre os campos magnéticos gerados pelos ímãs. Dessa forma, de acordo com a lei de Faraday-Lenz, como há movimento relativo entre o meio condutor e o campo magnético, então surgem correntes induzidas nesse meio cujo campo magnético se opõe à variação de fluxo causada pelo movimento, tendendo a enfraquecer os ímãs. Com esse enfraquecimento do campo no entreferro, o deslocamento angular para um determinado torque transmitido se torna maior, pois os ímãs se atraem e repelem com menos força. Ademais, a interação das correntes induzidas com o campo externo resultante provoca o surgimento de uma força contrária ao movimento, que é decorrente da força de Lorentz. Como consequência, a reação dessa força ocorre nos rotores do acoplamento magnético, de maneira a retardar seu movimento e a converter parte da energia cinética transmitida em calor dissipado no disco. Tais perdas no disco são provenientes da circulação das mesmas correntes induzidas nesse meio, que possui uma determinada resistividade. Dessa forma, para se determinar o efeito da barreira condutora na curva característica do acoplamento magnético, primeiramente é necessário descrever as correntes induzidas devido ao campo resultante, para então se calcular as perdas dissipadas no disco. Uma vez determinadas tais perdas, o torque resistivo nos rotores do acoplamento magnético é facilmente obtido, pois é decorrente dessa conversão de parte da energia cinética transmitida em calor dissipado no disco. 


\subsection{Metodologia analítica}

A metodologia analítica utilizada para o cálculo das perdas na barreira condutora se baseia no trabalho de Davies [7] e de Dietrich [24], com as modificações necessárias para se considerar a topologia do acoplamento. Os parâmetros que descrevem o rotor do acoplamento estão ilustrados na Figura 3.1, na qual "L" se refere ao raio externo do rotor; " $r_{1}$ ", ao raio até o centro dos ímãs; " $\lambda$ ", ao arco correspondente a um par de polos e "p", ao número de pares de polos.

Figura 3.1 - Parâmetros do rotor do acoplamento magnético

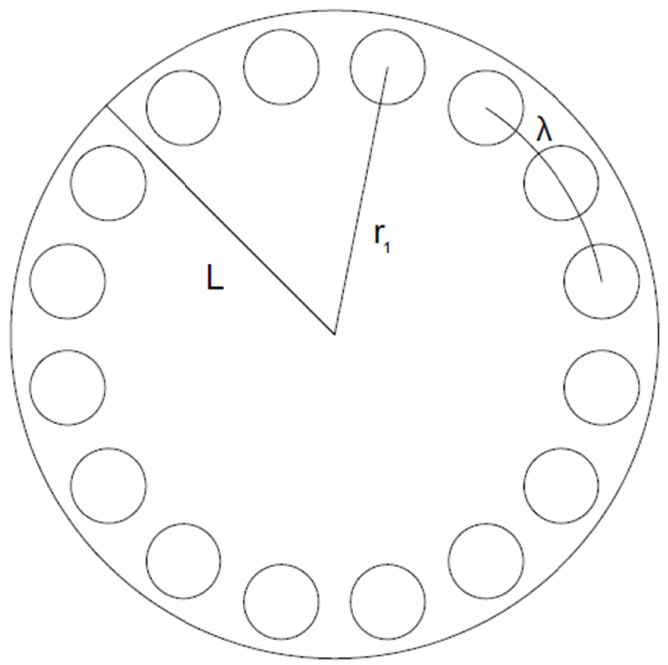

Segundo Edwards et al. [23], a configuração mostrada na Figura 3.2 pode ser analisada como um par de freios por correntes parasitas como mostra a Figura 3.3, se considerado o dobro do torque obtido, metade do entreferro e metade da espessura da barreira condutora. Essa equivalência permite manter a distribuição do campo magnético praticamente a mesma no entreferro, pois embora seja considerada a metade dos ímãs, o entreferro total também foi reduzido pela metade. Com isso, é possível calcular o torque resistivo para um dos lados do acoplamento, de maneira que ao se dobrar esse resultado, tem-se o efeito devido a ambos os rotores. 
Figura 3.2 - Configuração do acoplamento magnético

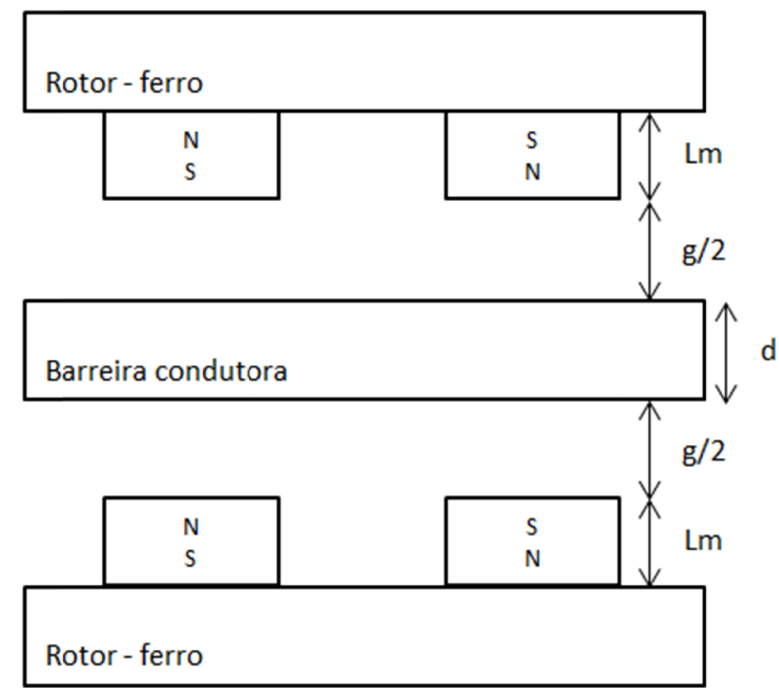

Figura 3.3 - Modelo equivalente da configuração do acoplamento magnético

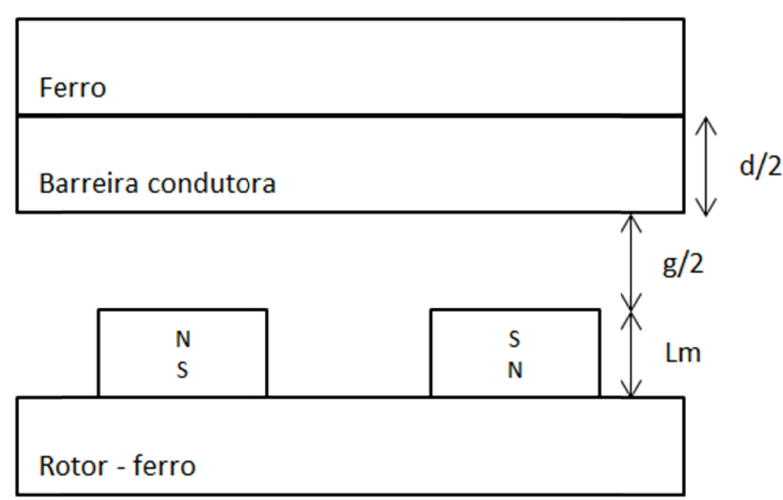

A Figura 3.2 representa uma visão superior planificada do acoplamento magnético, na qual $g / 2$ é a distância entre o ímã e a barreira; $L_{m}$ é a espessura do ímã e $d$ a espessura da barreira condutora. Tal artifício de representar o acoplamento pelo modelo da Figura 3.3 é necessário para poder se basear na formulação de Davies [7], uma vez que essa é a configuração adotada em seu estudo.

Embora a topologia favoreça a adoção de um sistema de coordenadas polar, será adotado o sistema cartesiano planificado ilustrado na Figura 3.4, cuja origem se encontra na barreira ou disco condutor. Os vetores $\overrightarrow{\mathrm{e}_{\mathrm{x}}}, \overrightarrow{\mathrm{e}_{\mathrm{y}}}$ e $\overrightarrow{\mathrm{e}_{\mathrm{z}}}$ se referem aos versores nas direções tangencial, axial e radial, respectivamente. 
Figura 3.4 - Sistema de coordenadas adotado
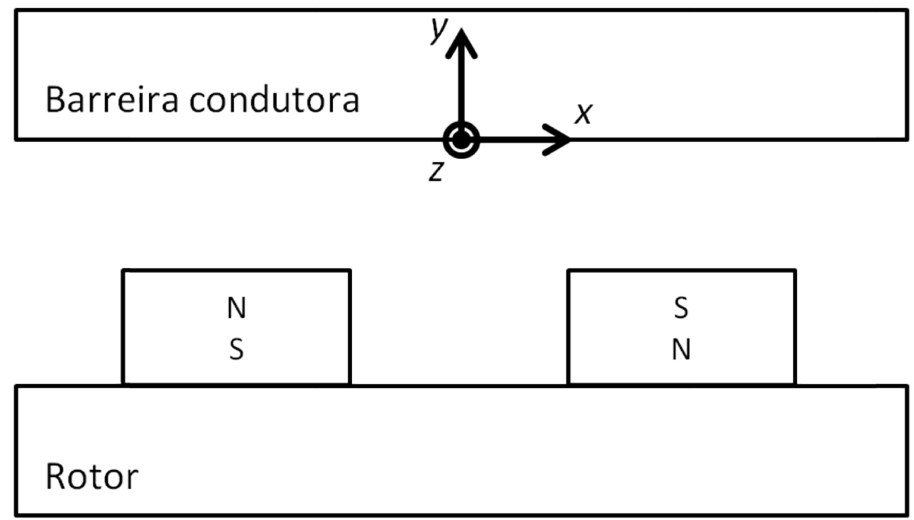

Para descrever o fenômeno das correntes induzidas em meios condutores é necessário solucionar a equação da difusão para geometria descrita. Tal equação é obtida através das equações:

$$
\begin{gathered}
\nabla \times \vec{E}=-\frac{\partial \vec{B}}{\partial t} \\
\vec{E}=\rho \cdot \vec{J}
\end{gathered}
$$

e

$$
\vec{B}=\mu_{r} \cdot \mu_{0} \cdot \vec{H}
$$

sendo $\rho$ a resistividade do material utilizado na barreira ou no disco condutor; $\mu_{r}$, a permeabilidade magnética relativa e $\mu_{0}$, a permeabilidade magnética do vácuo.

Ao substituir (3.2) e (3.3) em (3.1), resulta:

$$
\nabla \times(\rho \cdot \vec{J})=-\frac{\partial\left(\mu_{r} \cdot \mu_{0} \cdot \vec{H}\right)}{\partial t}
$$

Considerando a resistividade do meio $\rho$ constante, vem:

$$
\nabla \times \vec{J}=-\frac{\mu_{r} \cdot \mu_{0}}{\rho} \cdot \frac{\partial \vec{H}}{\partial t}
$$

Após essa etapa, aplica-se o rotacional a ambos os membros da equação (3.5), obtendo: 


$$
\nabla \times(\nabla \times \vec{J})=\nabla \times\left(-\frac{\mu_{r} \cdot \mu_{0}}{\rho} \cdot \frac{\partial \vec{H}}{\partial t}\right)
$$

A identidade $\nabla \times(\nabla \times \vec{X})=\nabla(\nabla \cdot \vec{X})-\nabla^{2} \vec{X}$, sendo $\vec{X}$ um vetor qualquer, pode ser empregada na equação (3.6), o que resulta:

$$
\nabla(\nabla \cdot \vec{J})-\nabla^{2} \vec{J}=\nabla \times\left(-\frac{\mu_{r} \cdot \mu_{0}}{\rho} \cdot \frac{\partial \vec{H}}{\partial t}\right)
$$

Ao aplicar o resultado da equação da continuidade de correntes, $\nabla \cdot \vec{J}=0$, na equação (3.7), vem:

$$
\nabla^{2} \vec{J}=\frac{\mu_{r} \cdot \mu_{0}}{\rho} \cdot \frac{\partial(\nabla \times \vec{H})}{\partial t}
$$

Como $\nabla \times \vec{H}=\vec{J}$, então finalmente resulta na barreira:

$$
\nabla^{2} \vec{J}=\frac{\mu_{r} \cdot \mu_{0}}{\rho} \cdot \frac{\partial \vec{J}}{\partial t}
$$

Esta é a equação de difusão das correntes em meios lineares (3.9), de maneira que sua solução permitirá a determinação das expressões do fluxo por polo $\phi_{a c}$ e para a força magneto-motriz de reação de armadura $F_{r}$.

Antes de aplicar a equação de difusão na geometria do acoplamento magnético, serão adotadas algumas simplificações no modelo. Primeiramente, será aproximado por uma distribuição senoidal o vetor densidade de corrente $\vec{J}$ ao longo da região ativa do acoplamento, isto é, o disco ou a barreira condutora. Além dessa simplificação, será adotada uma direção de circulação das correntes induzidas apenas radial, de maneira que o caminho de seu fechamento na direção tangencial será desprezado no cálculo das perdas.

A partir da segunda hipótese, ou seja, desprezando os caminhos de fechamento das correntes induzidas, é possível escrever $J_{x}=J_{y}=0$, o que resulta:

$$
\vec{J}=J_{z} \cdot \overrightarrow{e_{z}}
$$

Eliminando também os efeitos de borda, é possível assumir que a densidade de corrente é praticamente constante ao longo da direção $\overrightarrow{e_{z}}$, logo: 


$$
\frac{\partial \vec{J}}{\partial z}=0 \Rightarrow \frac{\partial^{2} \vec{J}}{\partial z^{2}}=0
$$

Assim, ao substituir as equações (3.10) e (3.11) na equação da difusão (3.9), implica:

$$
\frac{\partial^{2} \overrightarrow{J_{z}}}{\partial x^{2}}+\frac{\partial^{2} \overrightarrow{J_{z}}}{\partial y^{2}}=\frac{\mu_{r} \cdot \mu_{0}}{\rho} \cdot \frac{\partial \overrightarrow{J_{z}}}{\partial t}
$$

A densidade de corrente da equação anterior, considerando a hipótese de sua distribuição senoidal ao longo da região ativa, pode ser escrita na forma de (3.13), sendo $\omega$ a frequência angular das correntes induzidas:

$$
J_{z}=J(y) \cdot \cos \left(\omega \cdot t-\frac{2 \cdot \pi}{\lambda} \cdot x\right)
$$

Para simplificar o equacionamento a seguir, trabalharemos com a forma complexa de (3.13). Para tanto, será utilizado o operador $R e[]$, que extrai a componente real de um determinado número complexo, de forma que isso resulta:

$$
J_{z}=\operatorname{Re}\left[J(y) \cdot e^{j \cdot\left(\omega \cdot t-\frac{2 \cdot \pi}{\lambda} \cdot x\right)}\right]
$$

Substituindo a equação (3.14) em (3.12) e deixando-se implícito o operador $\operatorname{Re}[$ ] implica:

$$
-\frac{4 \cdot \pi^{2}}{\lambda^{2}} \cdot J(y) \cdot e^{j \cdot\left(\omega \cdot t-\frac{2 \cdot \pi}{\lambda} \cdot x\right)}+\frac{d^{2} J(y)}{d y^{2}} \cdot e^{j \cdot\left(\omega \cdot t-\frac{2 \cdot \pi}{\lambda} \cdot x\right)}=\frac{\mu_{r} \cdot \mu_{0} \cdot j \cdot \omega}{\rho} \cdot J(y) \cdot e^{j \cdot\left(\omega \cdot t-\frac{2 \cdot \pi}{\lambda} \cdot x\right)}
$$

ou ainda:

$$
\frac{d^{2} J(y)}{d y^{2}}-J(y) \cdot\left(\frac{4 \cdot \pi^{2}}{\lambda^{2}}+\frac{\mu_{r} \cdot \mu_{0} \cdot j \cdot \omega}{\rho}\right)=0
$$

Adotando a seguinte notação:

$$
k^{2}=\frac{4 \cdot \pi^{2}}{\lambda^{2}}+j \cdot 2 \cdot \alpha^{2}
$$

na qual: 


$$
\alpha^{2}=\frac{\mu_{r} \cdot \mu_{0} \cdot \omega}{2 \cdot \rho}
$$

resulta:

$$
\frac{d^{2} J(y)}{d y^{2}}-k^{2} \cdot J(y)=0
$$

Cabe ressaltar que $\alpha^{-1}$ é a profundidade de penetração das correntes induzidas, de maneira que essa notação facilitará a interpretação dos resultados.

A solução geral de (3.19) é do tipo:

$$
J(y)=A_{1} \cdot e^{k \cdot y}+A_{2} \cdot e^{-k \cdot y}
$$

Como a amplitude das correntes induzidas $J_{z}$ decresce exponencialmente ao longo da espessura do material, de maneira que a cada distância $\alpha^{-1}$ seu módulo se reduz a 1/e do valor inicial, é possível escrever as seguintes condições de contorno:

1. Para uma profundidade tendendo ao infinito, ou seja, $y \rightarrow \infty$, o módulo da corrente induzida tende à zero, o que implica:

$$
J_{z} \rightarrow 0 \Rightarrow J(y) \rightarrow 0 \Rightarrow A_{1}=0
$$

2. Na superfície, ou seja, $y=0$, o módulo da corrente induzida é máximo, assim:

$$
J_{z}=J_{z_{\max }} \Rightarrow J(0)=J_{z_{\max }} \Rightarrow A_{2}=J_{z_{\max }}
$$

Dessa forma, a solução de (3.20) fica resumida a:

$$
J(y)=J_{z_{\max }} \cdot e^{-k \cdot y}
$$

Ao substituir a expressão (3.21) na equação (3.14), obtém-se:

$$
J_{z}=\operatorname{Re}\left[J_{z_{\max }} \cdot e^{-k \cdot y} \cdot e^{j \cdot\left(\omega \cdot t-\frac{2 \cdot \pi}{\lambda} \cdot x\right)}\right]
$$

Adotando a seguinte representação complexa para $k^{2}$ :

$$
k^{2}=\frac{4 \cdot \pi^{2}}{\lambda^{2}}+j \cdot 2 \cdot \alpha^{2}=R^{2} \cdot e^{2 \cdot j \cdot \phi}
$$

na qual 


$$
R=\sqrt[4]{\left(\frac{4 \cdot \pi^{2}}{\lambda^{2}}\right)^{2}+\left(2 \cdot \alpha^{2}\right)^{2}}
$$

e

$$
2 \cdot \phi=\arctan \left(\frac{2 \cdot \alpha^{2}}{4 \cdot \pi^{2} / \lambda^{2}}\right)
$$

é possível substituir $k=R \cdot e^{j \cdot \phi}=R \cdot \cos \phi+j \cdot R \cdot \operatorname{sen} \phi$ na equação (3.22), o que resulta:

$$
J_{z}=\operatorname{Re}\left[J_{z_{\max }} \cdot e^{-R \cdot \cos \phi \cdot y} \cdot e^{j \cdot\left(\omega \cdot t-\frac{2 \cdot \pi}{\lambda} \cdot x-R \cdot \operatorname{sen} \phi \cdot y\right)}\right]
$$

Ao adotar

$$
\beta=R \cdot \cos \phi
$$

e

$$
\gamma=R \cdot \operatorname{sen} \phi
$$

pode-se escrever ainda:

$$
J_{z}=\operatorname{Re}\left[J_{z_{\max }} \cdot e^{-\beta \cdot y} \cdot e^{j \cdot\left(\omega \cdot t-\frac{2 \cdot \pi}{\lambda} \cdot x-\gamma \cdot y\right)}\right]
$$

Considerando que a profundidade de penetração das correntes induzidas $\alpha^{-1}$ é muito menor que o comprimento de onda das induções na barreira $\lambda$, ou seja,

$$
\sqrt{2} \cdot \alpha>>\frac{2 \cdot \pi}{\lambda}
$$

as seguintes simplificações podem ser feitas:

$$
\begin{gathered}
R \rightarrow \sqrt{2} \cdot \alpha \\
\phi \rightarrow \frac{\pi}{4} \\
\beta \rightarrow \alpha
\end{gathered}
$$

e

$$
\gamma \rightarrow \alpha
$$

Dessa maneira, a equação (3.26) pode ser simplificada a: 


$$
J_{z}=\operatorname{Re}\left[J_{z_{\max }} \cdot e^{-\alpha \cdot y} \cdot e^{j \cdot\left(\omega \cdot t-\frac{2 \cdot \pi}{\lambda} \cdot x-\alpha \cdot y\right)}\right]
$$

ou ainda

$$
J_{z}=J_{z_{\max }} \cdot e^{-\alpha \cdot y} \cdot \cos \left(\omega \cdot t-\frac{2 \cdot \pi}{\lambda} \cdot x-\alpha \cdot y\right)
$$

A equação (3.33) mostra que as correntes induzidas possuem uma distribuição senoidal não somente no tempo, mas também ao longo da direção $\overrightarrow{e_{x}}$ para uma mesma profundidade $y$ constante. Ademais, é possível notar que entre camadas distintas, existe uma diferença de fase entre as correntes induzidas, além da redução exponencial em sua amplitude.

Uma vez calculada a expressão de $J_{z}$, procede-se ao cálculo do campo magnético devido à distribuição das correntes induzidas. Primeiramente, determina-se o campo $\vec{H}$ por meio das equações (3.1) e (3.2), sendo que (3.1) pode ser reescrita na forma:

$$
\nabla \times \vec{E}=-\frac{\partial \vec{B}}{\partial t}=-\mu_{r} \cdot \mu_{0} \cdot \frac{\partial \vec{H}}{\partial t}
$$

A expressão do rotacional de $\vec{E}$ pode ser calculada a partir da equação (3.2) e da hipótese de que as correntes induzidas possuem apenas componentes na direção $\overrightarrow{e_{z}}$, o que resulta:

$$
\vec{E}=\rho \cdot J_{z} \cdot \overrightarrow{e_{z}}
$$

e consequentemente,

$$
\nabla \times \vec{E}=\frac{\partial E_{z}}{\partial y} \cdot \overrightarrow{e_{x}}-\frac{\partial E_{z}}{\partial x} \cdot \overrightarrow{e_{y}}
$$

Substituindo (3.36) em (3.34) implica:

$$
\frac{\partial E_{z}}{\partial y} \cdot \overrightarrow{e_{x}}-\frac{\partial E_{z}}{\partial x} \cdot \overrightarrow{e_{y}}=-\mu_{r} \cdot \mu_{0} \cdot\left(\frac{\partial H_{x}}{\partial t} \cdot \overrightarrow{e_{x}}-\frac{\partial H_{y}}{\partial t} \cdot \overrightarrow{e_{y}}\right)
$$

Considerando ainda regime permanente senoidal, é possível substituir $\frac{\partial}{\partial t}$ por $j \cdot \omega$ na equação anterior, resultando para cada direção $\overrightarrow{e_{x}}$ e $\overrightarrow{e_{y}}$, respectivamente: 


$$
\frac{\partial E_{z}}{\partial y}=-\mu_{r} \cdot \mu_{0} \cdot j \cdot \omega \cdot H_{x}
$$

e

$$
\frac{\partial E_{z}}{\partial x}=-\mu_{r} \cdot \mu_{0} \cdot j \cdot \omega \cdot H_{y}
$$

Substituindo a equação (3.32) na equação (3.35) e deixando-se novamente implícito o operador $\operatorname{Re}[]$, temos:

$$
E_{z}=\rho \cdot J_{z}=\rho \cdot J_{z_{\max }} \cdot e^{-\alpha \cdot y} \cdot e^{j \cdot\left(\omega \cdot t-\frac{2 \cdot \pi}{\lambda} \cdot x-\alpha \cdot y\right)}
$$

de maneira que ao derivar (3.40) em relação à $y$, chega-se a:

$$
\frac{\partial E_{z}}{\partial y}=-\rho \cdot J_{z_{\max }} \cdot(\alpha+j \cdot \alpha) \cdot e^{-\alpha \cdot y} \cdot e^{j \cdot\left(\omega \cdot t-\frac{2 \cdot \pi}{\lambda} \cdot x-\alpha \cdot y\right)}=\rho \cdot(\alpha+j \cdot \alpha) \cdot J_{z}
$$

Substituindo esse resultado na equação (3.38), implica:

$$
\rho \cdot(\alpha+j \cdot \alpha) \cdot J_{z}=-\mu_{r} \cdot \mu_{0} \cdot j \cdot \omega \cdot H_{x}
$$

e

$$
H_{x}=\frac{\rho \cdot(\alpha+j \cdot \alpha)}{\mu_{r} \cdot \mu_{0} \cdot \omega} \cdot J_{z}=\frac{\alpha \cdot(1+j)}{2 \cdot \alpha^{2}} \cdot J_{z}
$$

ou ainda:

$$
H_{x}=\operatorname{Re}\left[J_{z} \cdot \frac{1}{\sqrt{2} \cdot \alpha} \angle 45^{\circ}\right]
$$

Repetindo o mesmo procedimento para determinar $H_{y}$, isto é, derivando (3.40) agora em relação a $x$, tem-se:

$$
\frac{\partial E_{z}}{\partial x}=-\rho \cdot J_{z_{\max }} \cdot j \cdot \frac{2 \cdot \pi}{\lambda} \cdot e^{-\alpha \cdot y} \cdot e^{j \cdot\left(\omega \cdot t-\frac{2 \cdot \pi}{\lambda} \cdot x-\alpha \cdot y\right)}=-j \cdot \frac{2 \cdot \pi}{\lambda} \cdot \rho \cdot J_{z}
$$

Substituindo tal resultado na equação (3.39), resulta:

$$
\begin{gathered}
-j \cdot \frac{2 \cdot \pi}{\lambda} \cdot \rho \cdot J_{z}=-\mu_{r} \cdot \mu_{0} \cdot j \cdot a \\
H_{y}=\frac{2 \cdot \pi}{\lambda} \cdot \frac{\rho}{\mu_{r} \cdot \mu_{0} \cdot \omega} \cdot J_{z}
\end{gathered}
$$




$$
H_{y}=\frac{2 \cdot \pi}{\lambda} \cdot \frac{1}{2 \cdot \alpha^{2}} \cdot J_{z}
$$

e finalmente

$$
H_{y}=\operatorname{Re}\left[\frac{\pi}{\lambda \cdot \alpha^{2}} \cdot J_{z}\right]
$$

É possível estabelecer uma comparação entre $H_{x}$ e $H_{y}$ a partir da condição (3.27):

$$
\sqrt{2} \cdot \alpha>>\frac{2 \cdot \pi}{\lambda}
$$

Multiplicando ambos os membros por $\frac{J_{z}}{2 \cdot \alpha^{2}}$ tem-se:

$$
\frac{J_{z}}{2 \cdot \alpha^{2}} \cdot \sqrt{2} \cdot \alpha>>\frac{J_{z}}{2 \cdot \alpha^{2}} \cdot \frac{2 \cdot \pi}{\lambda}
$$

de forma que ao simplificar, resulta em:

$$
J_{z} \cdot \frac{1}{\sqrt{2} \cdot \alpha}>>\frac{\pi}{\lambda \cdot \alpha^{2}} \cdot J_{z}
$$

ou ainda,

$$
\left|H_{x}\right|>>\left|H_{y}\right|
$$

Portanto, a componente axial do campo $\vec{H}$, ou seja, $H_{y}$, pode ser desprezada, de maneira que o campo $\vec{H}$ gerado por $\overrightarrow{J_{z}}$ pode ser descrito por:

$$
\vec{H}=\operatorname{Re}\left[\frac{J_{z} \angle 45^{\circ}}{\sqrt{2} \cdot \alpha}\right] \cdot \overrightarrow{e_{x}}
$$

Para o cálculo da indução no entreferro $B_{y}$, utiliza-se o resultado de $H_{y}$ na equação:

$$
B_{y}=\mu_{r} \cdot \mu_{0} \cdot H_{y}
$$

o que resulta em:

$$
B_{y}=\mu_{r} \cdot \mu_{0} \cdot \frac{\pi}{\lambda \cdot \alpha^{2}} \cdot J_{z}=-\frac{\pi}{\lambda} \cdot \frac{2 \cdot \rho}{\omega} \cdot J_{z}
$$

Na superfície da barreira condutora, ou seja, em $y=0$, tem-se da equação (3.33): 


$$
J_{z_{(y=0)}}=J_{z_{\max }} \cdot \cos \left(\omega \cdot t-\frac{2 \cdot \pi}{\lambda} \cdot x\right)
$$

implicando:

$$
B_{y_{(y=0)}}=-\frac{2 \cdot \pi \cdot \rho}{\lambda \cdot \omega} \cdot J_{z_{\max }} \cdot \cos \left(\omega \cdot t-\frac{2 \cdot \pi}{\lambda} \cdot x\right)
$$

Assim, o valor médio de meio ciclo da densidade de fluxo no entreferro fica:

$$
B_{y}=\frac{2}{\pi} \cdot\left(\frac{2 \cdot \pi \cdot \rho}{\lambda \cdot \omega} \cdot J_{z_{\max }}\right)=\frac{4 \cdot \rho}{\lambda \cdot \omega} \cdot J_{z_{\max }}
$$

O valor do fluxo por polo é então obtido através da multiplicação deste resultado pela área do polo $S_{\text {polo }}$ :

$$
\phi_{a c}=B_{y} \cdot S_{p o l o}=\frac{4 \cdot \rho}{\lambda \cdot \omega} \cdot J_{z_{\max }} \cdot \frac{\pi \cdot L^{2}}{2 \cdot p}
$$

Como $\lambda=2 \cdot \pi \cdot r_{1} / p$, podemos escrever:

$$
\phi_{a c}=\frac{4 \cdot \rho}{\lambda \cdot \omega} \cdot J_{z_{\max }} \cdot \frac{\pi \cdot L^{2}}{2 \cdot\left(\frac{2 \cdot \pi \cdot r_{1}}{\lambda}\right)}=\frac{\rho \cdot L^{2}}{r_{1} \cdot \omega} \cdot J_{z_{\max }}
$$

Para relacionar o fluxo por polo $\phi_{a c}$ com a potência dissipada por unidade de área do disco condutor, denominada $W$, é necessário integrar $\rho \cdot J^{2}$ sobre o volume do disco e sobre um período de tempo:

$$
W=\iiint \rho \cdot J_{z}^{2} d x d y d t=\iiint \rho \cdot J_{z_{\max }}^{2} \cdot e^{-2 \cdot \alpha \cdot y} \cdot \cos ^{2}\left(\omega \cdot t-\frac{2 \cdot \pi}{\lambda}-\alpha \cdot y\right) d y d[f(t, x)]
$$

Como o valor médio de $\cos ^{2}$ é $\frac{1}{2}$, é possível escrever a integração da seguinte forma:

$$
W=\frac{\rho \cdot J_{z_{\max }}^{2}}{2} \cdot \int_{0}^{d} e^{-2 \cdot \alpha \cdot y} d y
$$

sendo $d$ a espessura da barreira condutora. Assim, a integração resulta em:

$$
W=\frac{\rho \cdot J_{z_{\max }}^{2}}{4 \cdot \alpha} \cdot\left(1-e^{-2 \cdot \alpha \cdot d}\right)
$$

Isolando $J_{z_{\max }}$ na equação (3.55) e substituindo em (3.52), vem: 


$$
\phi_{a c}=\frac{\rho \cdot L^{2}}{r_{1} \cdot \omega} \cdot\left(\frac{4 \cdot \alpha \cdot W}{\rho \cdot\left(1-e^{-2 \cdot \alpha \cdot d}\right)}\right)^{0,5}=\frac{2 \cdot \rho^{0,5} \cdot L^{2} \cdot W^{0,5}}{r_{1} \cdot \omega \cdot\left(1-e^{-2 \cdot \alpha \cdot d}\right)^{0,5}} \cdot \alpha^{0,5}
$$

Substituindo ainda $\alpha$ da equação (3.18) na equação (3.56), implica:

$$
\phi_{a c}=\frac{2 \cdot \rho^{0,5} \cdot L^{2} \cdot W^{0,5}}{r_{1} \cdot \omega \cdot\left(1-e^{-2 \cdot \alpha \cdot d}\right)^{0,5}} \cdot\left(\frac{\mu_{r} \cdot \mu_{0} \cdot \omega}{2 \cdot \rho}\right)^{0,25}=\frac{2^{0,75} \cdot\left(\mu_{r} \cdot \mu_{0} \cdot \rho\right)^{0,25} \cdot L^{2} \cdot W^{0,5}}{\left(1-e^{-2 \cdot \alpha \cdot d}\right)^{0,5} \cdot r_{1} \cdot \omega^{0,75}}
$$

O torque resistivo desenvolvido a uma dada rotação remete a uma potência mecânica que é igual à potência elétrica dissipada no disco pelas correntes induzidas, se desprezados os atritos. Com isso, é possível escrever:

$$
W=\frac{P_{m e c}}{S_{\text {ativa }}}=\frac{2 \cdot \pi \cdot n \cdot T}{\pi \cdot L^{2}}=\frac{2 \cdot n \cdot T}{L^{2}}
$$

na qual $n$ é a rotação em rotações por segundo, $T$ é o torque resistivo e $S_{\text {ativa }}$ é a área da barreira condutora. Como a velocidade angular $\omega$ é dada por:

$$
\omega=2 \cdot \pi \cdot n \cdot p
$$

é possível substituir as equações (3.58) e (3.59) em (3.57):

$$
\phi_{a c}=\frac{2^{0,75} \cdot\left(\mu_{r} \cdot \mu_{0} \cdot \rho\right)^{0,25} \cdot L^{2}}{\left(1-e^{-2 \cdot \alpha \cdot d}\right)^{0,5} \cdot r_{1}} \cdot\left(\frac{2 \cdot n \cdot T}{L^{2}}\right)^{0,5} \cdot \frac{1}{(2 \cdot \pi \cdot n \cdot p)^{0,75}}
$$

o que resulta finalmente em:

$$
\phi_{a c}=\frac{2^{0,5} \cdot\left(\mu_{r} \cdot \mu_{0} \cdot \rho\right)^{0,25} \cdot L \cdot T^{0,5}}{\pi^{0,75} \cdot\left(1-e^{-2 \cdot \alpha \cdot d}\right)^{0,5} \cdot r_{1} \cdot p^{0,75} \cdot n^{0,25}}
$$

Um efeito que distorce a distribuição de induções no entreferro é a reação de armadura. Essa reação é efeito do campo magnético gerado pela circulação das correntes induzidas e interfere na distribuição de induções quando se compara com a do acoplamento com velocidade nula. Assim, o padrão de induções no entreferro durante a rotação é dado pela composição da distribuição quando os rotores estão parados e a reação de armadura. O cálculo da força magneto-motriz da reação de armadura é feito através da integração da expressão de $J_{z}$ em relação à $y$ :

$$
\left.\int_{0}^{d} J_{z} d y=\int_{0}^{d} \operatorname{Re}\left[J_{z_{\max }} \cdot e^{-\beta \cdot y} \cdot e^{j \cdot\left(\omega \cdot t-\frac{2 \cdot \pi}{\lambda} \cdot x-\gamma \cdot y\right.}\right)\right] d y=
$$




$$
=\operatorname{Re}\left[\frac{J_{z_{\max }} \cdot\left(1-e^{-(\beta+j \cdot \gamma) d}\right)}{(\beta+j \cdot \gamma)} \cdot e^{j \cdot\left(\omega t-\frac{2 \cdot \pi}{\lambda} \cdot x\right)}\right]
$$

Em seguida, é feito o cálculo da integral em relação à $x$ sobre esse resultado:

$$
\begin{aligned}
& F_{r}=\int \operatorname{Re}\left[\frac{J_{z_{\max }} \cdot\left(1-e^{-(\beta+j \cdot \gamma) \cdot d}\right)}{(\beta+j \cdot \gamma)} \cdot e^{j \cdot\left(\omega \cdot \frac{2 \cdot \pi}{\lambda} \cdot x\right)}\right] d x=
\end{aligned}
$$

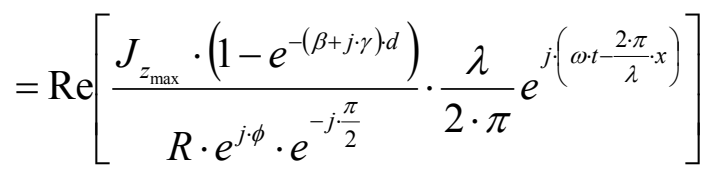

Aplicando a condição da expressão (3.27) $\sqrt{2} \cdot \alpha \gg \frac{2 \cdot \pi}{\lambda}$ nas equações (3.24) e (3.25), resulta:

$$
R \rightarrow \sqrt{2} \cdot \alpha
$$

e

$$
\phi \rightarrow \frac{\pi}{4}
$$

Tais resultados em (3.63) e (3.64) podem ser utilizados na equação (3.62), implicando:

$$
\begin{gathered}
F_{r}=\operatorname{Re}\left[\frac{J_{z_{\max }} \cdot\left(1-e^{-(\alpha+j \cdot \alpha) \cdot d}\right)}{\left.\sqrt{2} \cdot \alpha \cdot e^{-j \cdot \frac{\pi}{4}} \cdot \frac{\lambda}{2 \cdot \pi} e^{j \cdot\left(\omega \cdot t-\frac{2 \cdot \pi}{\lambda} \cdot x\right)}\right]=}\right. \\
=\operatorname{Re}\left[\frac{J_{z_{\max }} \cdot \lambda \cdot e^{j \cdot\left(\omega \cdot t-\frac{2 \cdot \pi}{\lambda} \cdot x+\frac{\pi}{4}\right)}}{2 \sqrt{2} \cdot \pi \cdot \alpha}-\frac{J_{z_{\max }} \cdot \lambda}{2 \sqrt{2} \cdot \pi \cdot \alpha} \cdot e^{j \cdot\left(\omega \cdot \frac{2 \cdot \pi}{\lambda} \cdot x+\frac{\pi}{4}-\alpha \cdot d\right)}\right]
\end{gathered}
$$

Para simplificar a notação, pode-se adotar:

$$
A=\frac{J_{z_{\max }} \cdot \lambda}{2 \sqrt{2} \cdot \pi \cdot \alpha}
$$

e

$$
\theta=-\frac{2 \cdot \pi}{\lambda} \cdot x+\frac{\pi}{4}
$$

de maneira que (3.65) pode ser reescrita na forma fasorial: 


$$
\begin{aligned}
& F_{r}=\operatorname{Re}\left[A \angle \theta-A \cdot e^{-\alpha \cdot d} \angle(\theta-\alpha \cdot d)\right]= \\
& =\operatorname{Re}\left[A \angle \theta+A \cdot e^{-\alpha \cdot d} \angle(\theta-\alpha \cdot d+\pi)\right]
\end{aligned}
$$

Aplicando a soma fasorial $A_{3} \angle \theta_{3}=A_{1} \angle \theta_{1}+A_{2} \angle \theta_{2}$, na qual:

$$
A_{3}^{2}=A_{1}^{2}+A_{2}^{2}-2 \cdot A_{1} \cdot A_{2} \cdot \cos \left(\pi-\left(\theta_{1}-\theta_{2}\right)\right)
$$

resulta:

$$
F_{r}=J_{z_{\max }} \cdot \frac{\lambda \cdot \sqrt{1+e^{-2 \cdot \alpha \cdot d}-2 \cdot e^{-\alpha \cdot d} \cdot \cos (\alpha \cdot d)}}{2 \sqrt{2} \cdot \pi \cdot \alpha} \cdot \cos \left(\omega \cdot t+\theta_{3}\right)
$$

Tomando o módulo de (3.70) e substituindo nela a expressão de $J_{z_{\max }}$ da equação (3.55), implica:

$$
\begin{gathered}
F_{r}=\left(\frac{4 \cdot \alpha \cdot W}{\rho \cdot\left(1-e^{-2 \cdot \alpha \cdot d}\right)}\right)^{0,5} \cdot \frac{\lambda \cdot \sqrt{1+e^{-2 \cdot \alpha \cdot d}-2 \cdot e^{-\alpha \cdot d} \cdot \cos (\alpha \cdot d)}}{2 \sqrt{2} \cdot \pi \cdot \alpha}= \\
F_{r}=\frac{\sqrt{1+e^{-2 \cdot \alpha \cdot d}-2 \cdot e^{-\alpha \cdot d} \cdot \cos (\alpha \cdot d)}}{\sqrt{2} \cdot \pi \cdot \rho^{0,5} \cdot\left(1-e^{-2 \cdot \alpha \cdot d}\right)^{0,5}} \cdot \lambda \cdot W^{0,5} \cdot \frac{1}{\alpha^{0,5}}
\end{gathered}
$$

Substituindo as expressões de $\lambda, W, \alpha$ e $\omega$ na equação (3.71) resulta finalmente em:

$$
\begin{gathered}
F_{r}=\frac{\sqrt{1+e^{-2 \cdot \alpha \cdot d}-2 \cdot e^{-\alpha \cdot d} \cdot \cos (\alpha \cdot d)}}{\sqrt{2} \cdot \pi \cdot \rho^{0,5} \cdot\left(1-e^{-2 \cdot \alpha \cdot d}\right)^{0,5}} \cdot\left(\frac{2 \cdot \pi \cdot r_{1}}{p}\right) \cdot\left(\frac{2 \cdot n \cdot T}{L^{2}}\right)^{0,5} \cdot\left(\frac{2 \cdot \rho}{\mu_{r} \cdot \mu_{0} \cdot(2 \cdot \pi \cdot n \cdot p)}\right)^{0,25} \\
F_{r}=\frac{2}{\pi^{0,25}} \frac{\sqrt{1+e^{-2 \cdot \alpha \cdot d}-2 \cdot e^{-\alpha \cdot d} \cdot \cos (\alpha \cdot d)}}{\left(1-e^{-2 \cdot \alpha \cdot d}\right)^{0,5}} \cdot \frac{r_{1} \cdot T^{0,5} \cdot n^{0,25}}{\left(\mu_{r} \cdot \mu_{0} \cdot \rho\right)^{0,25} \cdot L \cdot p^{1,25}}
\end{gathered}
$$

Os equacionamentos anteriores permitiram a obtenção de uma expressão para o fluxo por polo e outra para a força magneto-motriz da reação de armadura, em função da rotação $n$ e do torque resistivo $T$. À medida que a velocidade de rotação aumenta, maior se torna a reação de armadura, que atua diminuindo o fluxo por polo e tende a enfraquecer os ímãs. Com isso, a interação magnética entre os ímãs também enfraquece, implicando maior deslocamento angular entre os rotores para um determinado torque.

A distribuição de induções no entreferro com o acoplamento a uma determinada velocidade não nula será denominada $B_{a c}$, que é a composição entre a indução a uma velocidade nula, $B_{\text {estat }}$, e a reação de armadura, chamada $B_{r}$. 
Comparando as equações (3.50) e (3.65), é possível notar que a reação de armadura está atrasada em relação ao fluxo que a produz de um ângulo que tende a $135^{\circ}$, o que equivale a escrever:

$$
B_{a c} \angle 0=B_{\text {estat }} \angle \theta_{\text {estat }}+B_{r} \angle-135^{\circ}
$$

ou ainda

$$
B_{\text {estat }} \angle \theta_{\text {estat }}=B_{a c}-B_{r} \angle-135^{\circ}
$$

O ângulo de $B_{\text {estat }}, \theta_{\text {estat }}$, possui valor muito próximo de zero, sendo de pouco interesse prático. Assim, o módulo de $B_{\text {estat }}$ resulta:

$$
B_{\text {estat }}=B_{a c}+B_{r} \angle 45^{\circ}
$$

ou ainda,

$$
\begin{gathered}
B_{\text {estat }}^{2}=B_{a c}^{2}+B_{r}^{2}-2 \cdot B_{a c} \cdot B_{r} \cdot \cos \left(135^{\circ}\right)= \\
=B_{a c}^{2}+B_{r}^{2}+\sqrt{2} \cdot B_{a c} \cdot B_{r}
\end{gathered}
$$

na qual

$$
B_{a c}=\frac{\phi_{a c}}{S_{p o l o}}
$$

e

$$
B_{r}=\frac{F_{r}}{\mathfrak{R} \cdot S_{\text {polo }}}
$$

onde $\mathfrak{R}$ é a relutância do circuito magnético em $\mathrm{H}^{-1}$. Analisando a Figura 3.3 , a expressão dessa relutância $\mathfrak{R}$ pode ser escrita da seguinte forma:

$$
\mathfrak{R}=\frac{2}{\mu_{0}} \cdot\left[\frac{\left(\frac{d}{2}+\frac{g}{2}\right)}{S_{\text {polo }}}+\frac{L_{m}}{S_{m}}\right]
$$

enquanto a expressão de $B_{\text {estat }}$, que é o campo no entreferro com o acoplamento estático, é descrita por

$$
B_{\text {estat }}=\frac{B_{r e m} \cdot L_{m}}{\frac{S_{p o l o}}{S_{m}} \cdot L_{m} \cdot\left(1+p \cdot \frac{(d+g)}{\pi \cdot r_{1}}\right)+1,05 \cdot\left(\frac{d}{2}+\frac{g}{2}\right)}
$$


onde $S_{m}$ é a área do ímã e $B_{\text {rem }}$ é a sua remanência, como mostrado no Anexo C.

Com todo o equacionamento descrito, é possível obter para cada rotação $n$ o respectivo torque resistivo $T$ que satisfaz a equação (3.74), solucionando-se assim, o problema. No presente trabalho, foi utilizada a ferramenta Matlab ${ }^{\circledR}$ para sua resolução, de maneira que a programação através de scripts está detalhada no Anexo D.

Para se melhor visualizar o desenvolvimento analítico descrito anteriormente, na Figura 3.5 está ilustrado um fluxograma resumindo toda essa tratativa.

Figura 3.5 - Fluxograma da metodologia analítca adotada

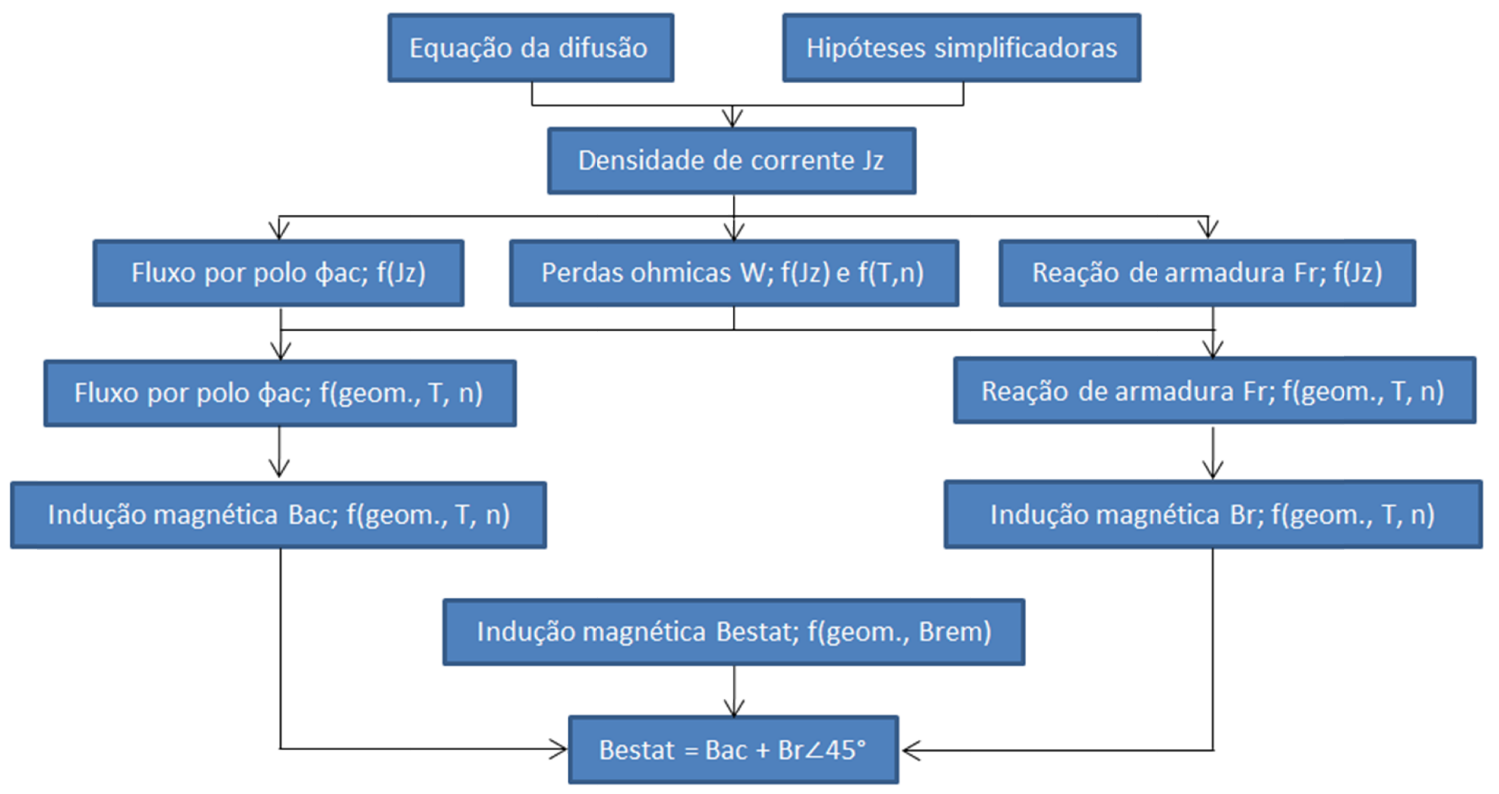

Uma vez obtido o valor do torque resistivo, é preciso calcular a influência do enfraquecimento dos ímãs devido à reação de armadura na curva característica do acoplamento magnético, isto é, na curva torque transmitido pelo deslocamento angular.

A metodologia de cálculo da força entre os ímãs está baseada na teoria dos polos magnéticos, como mostrado em [37], de maneira que não é calculado o campo magnético no entreferro devido à interação dos ímãs. Assim, não é possível relacionar diretamente o campo resultante descrito em (3.75) com a força de atração e de repulsão entre os ímãs para a obtenção da curva característica. Entretanto, ao calcular o torque resistivo para uma determinada condição, é possível calcular 
também a relação entre a indução de operação do ímã nessa condição e a indução correspondente estática. Com essa relação, é realizada a correção da indução remanente dos ímãs para o cálculo das forças e, assim, é computado o enfraquecimento dos ímãs na curva característica. Para o cálculo do novo ponto de operação do ímã $B_{m}^{\prime}$, deve-se considerar a reação de armadura $F_{r}$ e a espessura do ímã $L_{m}$, como mostrado na Figura 3.6.

Figura 3.6 - Novo ponto de operação do ímã considerando a reação de armadura

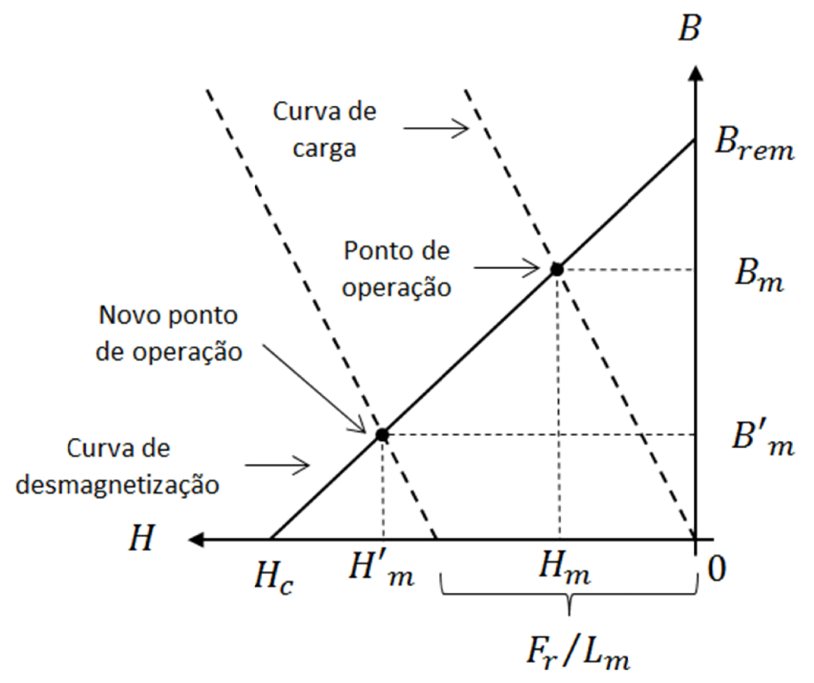

Analisando-se a Figura 3.6 conclui-se que

$$
\frac{B_{m}^{\prime}}{B_{m}}=\frac{H_{c}-F_{r} / L_{m}}{H_{c}}
$$

ou ainda,

$$
\frac{B_{m}^{\prime}}{B_{m}}=1-\frac{F_{r}}{L_{m}} \cdot \frac{1,05 \cdot \mu_{0}}{B_{r e m}}
$$

Dessa forma, para se computar o efeito final da barreira na curva característica do acoplamento deve-se calcular o torque resistivo para uma determinada configuração e velocidade angular; calcular a relação entre a indução de operação do ímã nessa condição e o correspondente estático conforme (3.79); corrigir a indução remanente dos ímãs por este fator e então obter a nova de curva de torque transmitido em função do deslocamento angular com essa indução corrigida. Essa nova curva característica do acoplamento é a curva degradada pelo enfraquecimento causado pelas correntes parasitas induzidas na barreira condutora. 


\section{VERIFICAÇÃO EXPERIMENTAL}

A validação da formulação analítica descrita no capítulo anterior foi realizada através de ensaios no protótipo do acoplamento magnético em diversas configurações de materiais e de espessuras de barreiras, além de entreferros distintos. Foram levantados os torques resistivos em função da rotação para barreiras de cobre, alumínio e aço inox, todas com espessuras de 1,5 $\mathrm{mm}$ e de $3 \mathrm{~mm}$. Além disso, os testes foram feitos com entreferros de $6 \mathrm{~mm}$ e de $8 \mathrm{~mm}$, totalizando 12 configurações de ensaio.

O arranjo experimental, ilustrado esquematicamente na Figura 4.1, consiste de um motor de corrente contínua dinamométrico, cujo eixo será monitorado por um tacômetro óptico para aferição da velocidade angular. A esse eixo do motor será interligado um dos rotores do acoplamento magnético, enquanto o outro rotor estará desconectado de qualquer carga. Entre tais rotores será colocada a barreira condutora, de maneira a estar equidistante deles. O torque será medido através de um braço fixado na armadura da máquina de corrente contínua, que estará apoiado sobre uma balança.

Dessa maneira, conforme o torque resistivo se desenvolve na barreira condutora, sua reação ocorre no eixo do rotor do acoplamento que está interligado ao motor de acionamento. Tal reação se manifesta na armadura do motor de corrente contínua, podendo então ser aferida conhecendo-se o braço e a medição da balança.

Figura 4.1 - Arranjo experimental esquemático para medição do torque resistivo

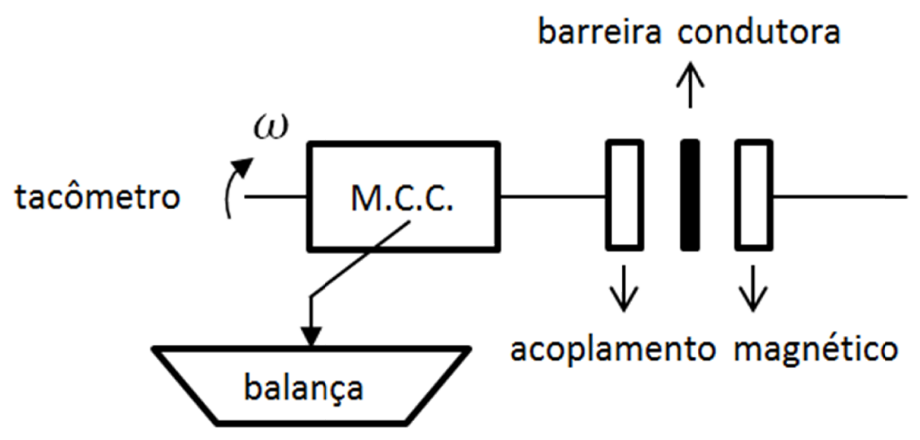


Além dos componentes ilustrados na Figura 4.1, foi necessário introduzir um ventilador para resfriar a barreira entre os rotores por conta do calor dissipado durante os ensaios. Tal equipamento foi necessário para tentar manter a barreira a uma temperatura mais constante possível. A Figura 4.2 mostra o arranjo na sala de ensaios.

Figura 4.2 - Arranjo experimental na sala de ensaios

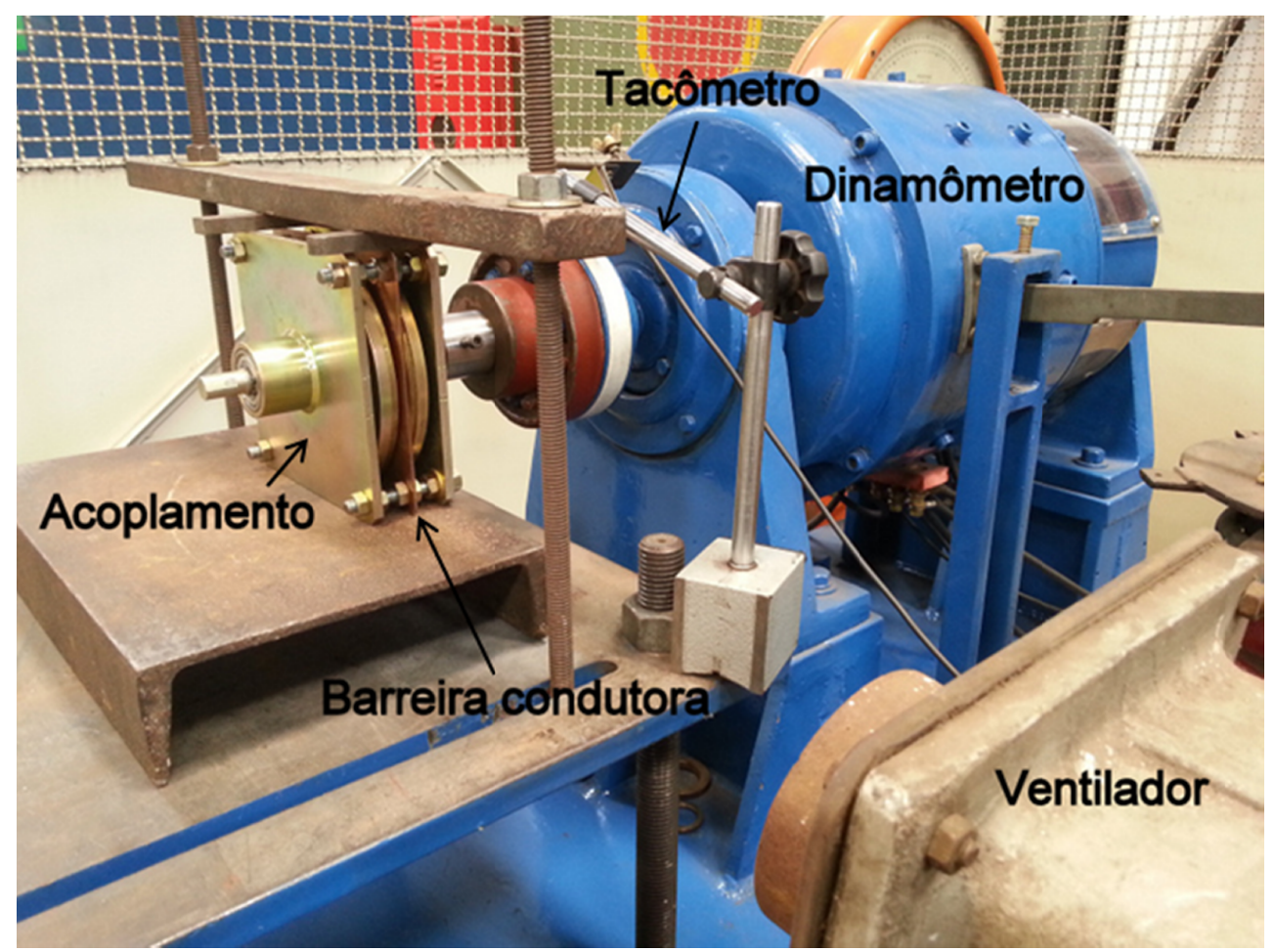

Outra característica medida foi o deslocamento angular entre os rotores em uma determinada condição de carregamento com e sem a presença da barreira. Tal aferição, não encontrada até o momento na literatura, é de suma importância, pois mostra claramente a influência da barreira na capacidade de transmitir torque do acoplamento magnético. Para a realização desta medição, foram fixadas fitas milimetradas em ambos os rotores de forma que ficassem alinhadas e foi fixada uma linha entre os suportes dos rotores, servindo de referência para o deslocamento das fitas, como mostrado na Figura 4.3. 
Figura 4.3 - Arranjo para medição do deslocamento angular em movimento

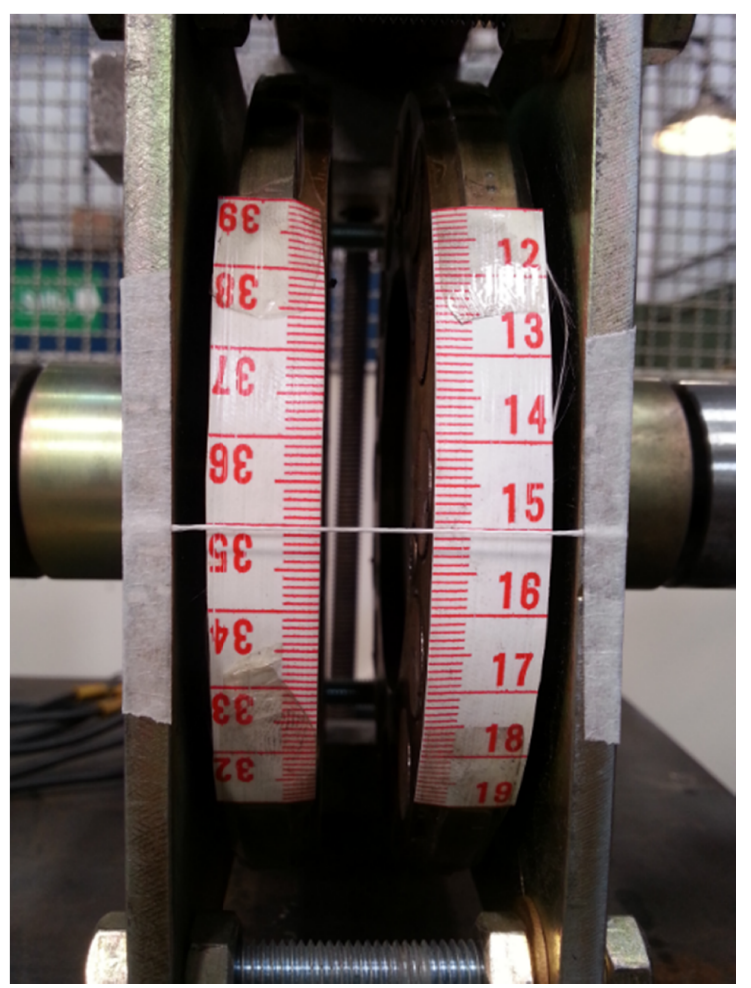

Dessa maneira, com o auxílio de um estroboscópio foi possível medir o deslocamento angular entre os rotores para a configuração com e sem a barreira de alumínio de $3 \mathrm{~mm}$ de espessura e um entreferro de 12,2 $\mathrm{mm}$.

A carga mecânica no eixo do rotor de saída foi aplicada por uma segunda máquina de corrente contínua dinamométrica, operando como gerador CC com a armadura ligada a um banco de resistências, conforme esquematizado na Figura 4.4.

Figura 4.4 - Arranjo experimental esquemático para medição do torque transmitido pelo acoplamento

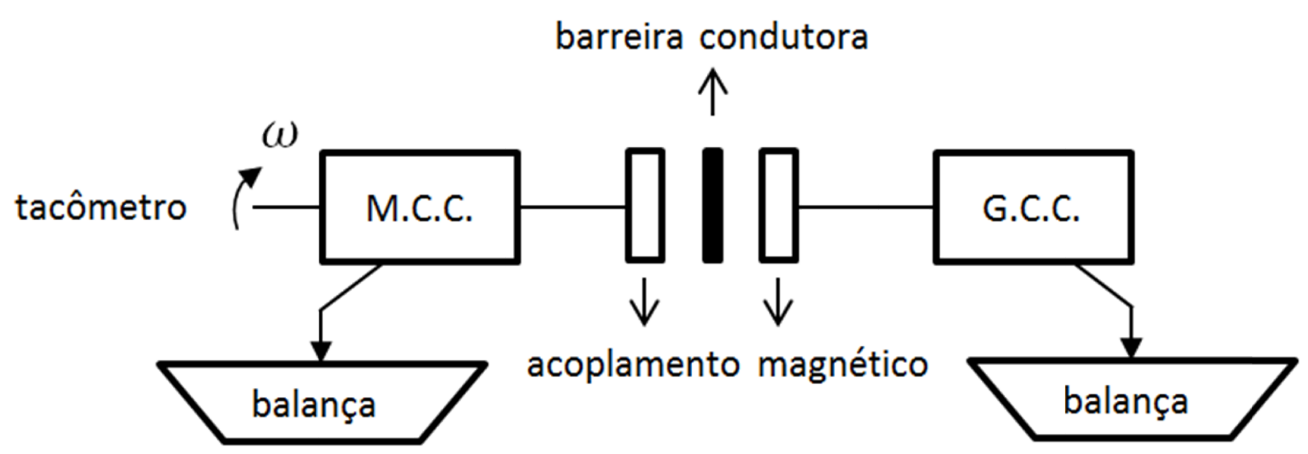


Com a metodologia de ensaio descrita no capítulo anterior, obtiveram-se as curvas de torque resistivo para diversas configurações de barreiras. Dessa maneira, foi possível comparar tais resultados experimentais com os calculados através da metodologia analítica descrita na seção 3.2. Os resultados com as barreiras de alumínio, de cobre e de aço inox estão mostradas nas Figuras 5.1, 5.2 e 5.3, respectivamente.

Figura 5.1 - Resultados analíticos e experimentais para a barreira de alumínio
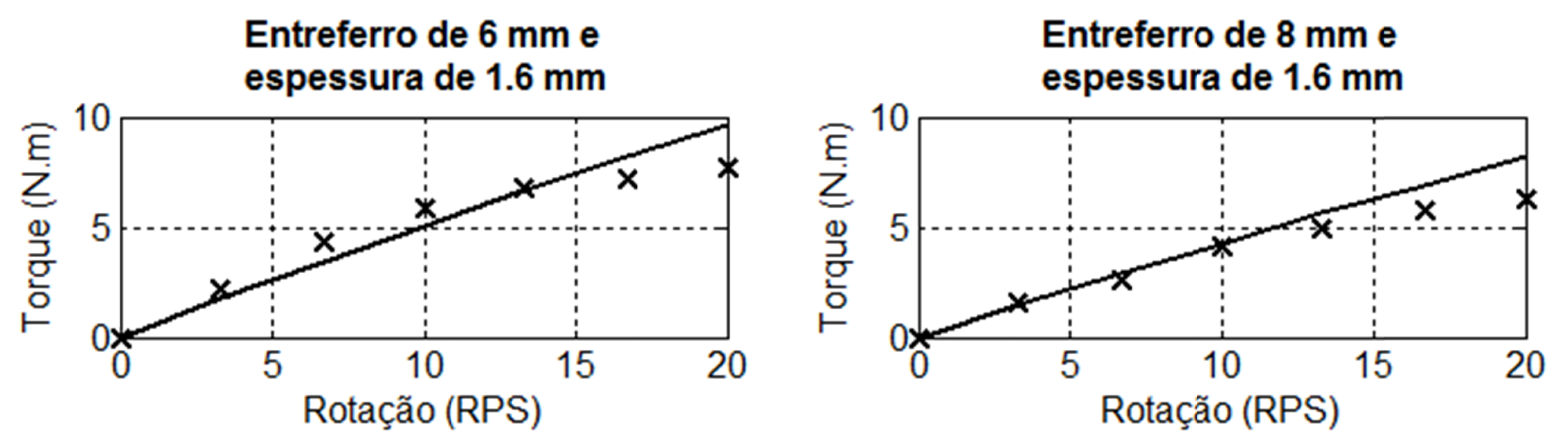

Entreferro de $6 \mathrm{~mm}$ e

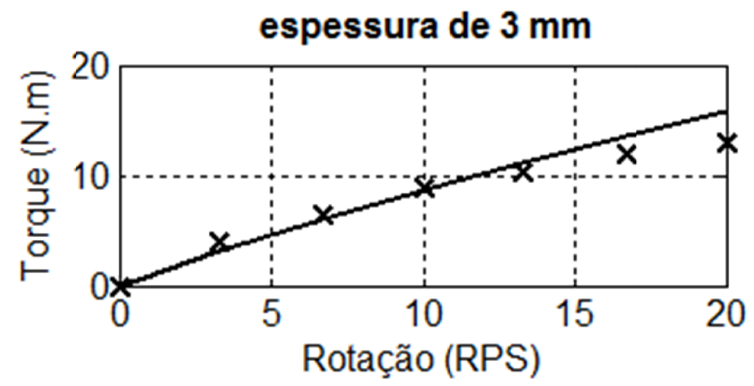

Entreferro de $8 \mathrm{~mm}$ e

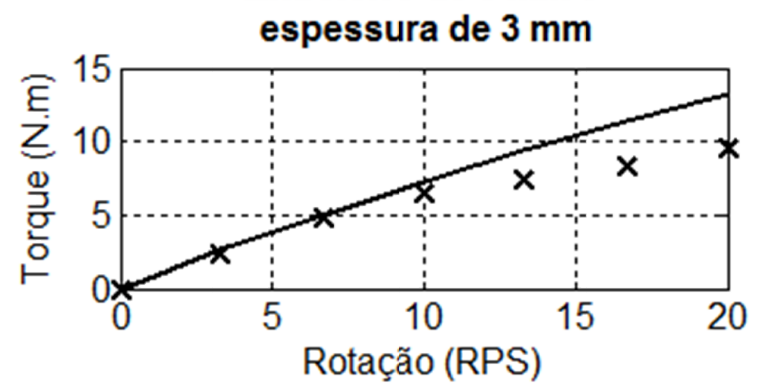

$\times$ Valores experimentais Valores calculados 
Figura 5.2 - Resultados analíticos e experimentais para a barreira de cobre

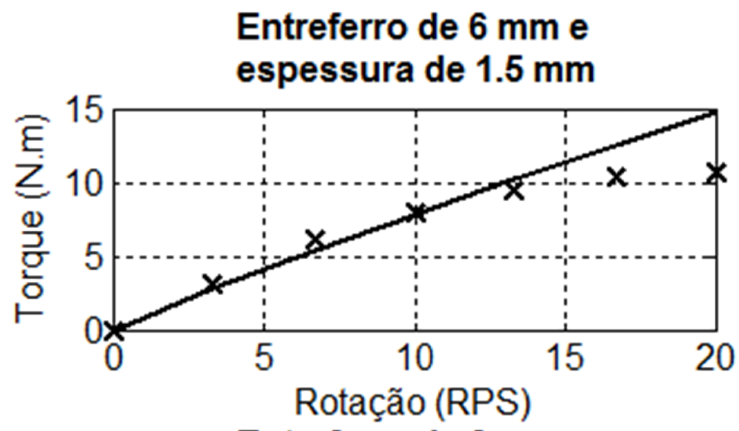

Entreferro de $6 \mathrm{~mm}$ e espessura de $3.1 \mathrm{~mm}$

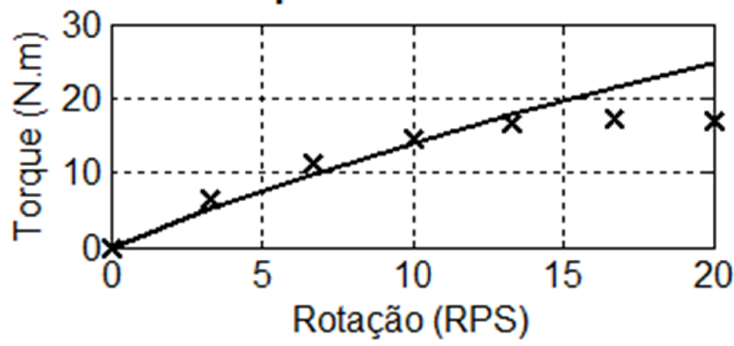

Entreferro de $8 \mathrm{~mm} \mathrm{e}$ espessura de $1.5 \mathrm{~mm}$

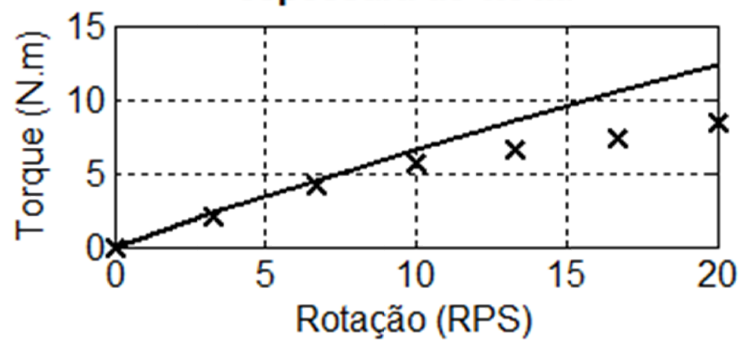

Entreferro de $8 \mathrm{~mm}$ e espessura de $3.1 \mathrm{~mm}$

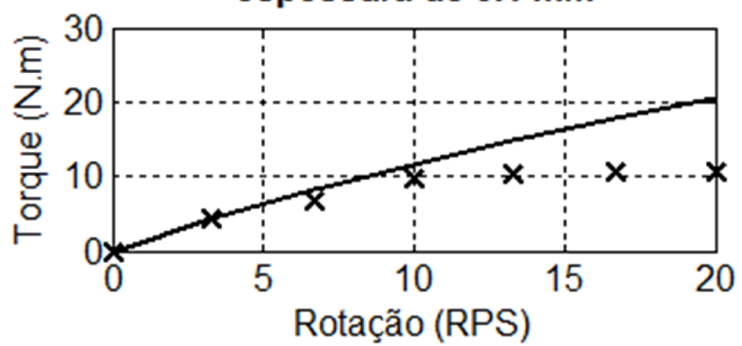

$\times$ Valores experimentais Valores calculados

Figura 5.3 - Resultados analíticos e experimentais para a barreira de aço inox

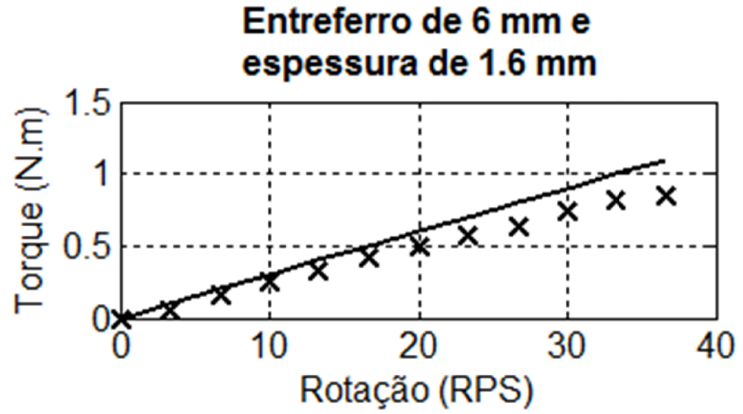

Entreferro de $6 \mathrm{~mm} e$

espessura de $3 \mathrm{~mm}$

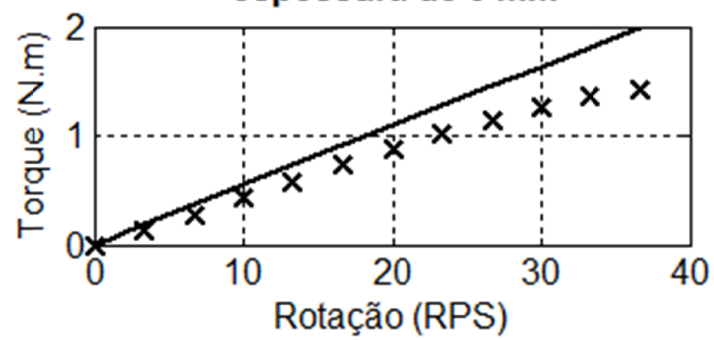

Entreferro de $8 \mathrm{~mm}$ e espessura de $1.6 \mathrm{~mm}$

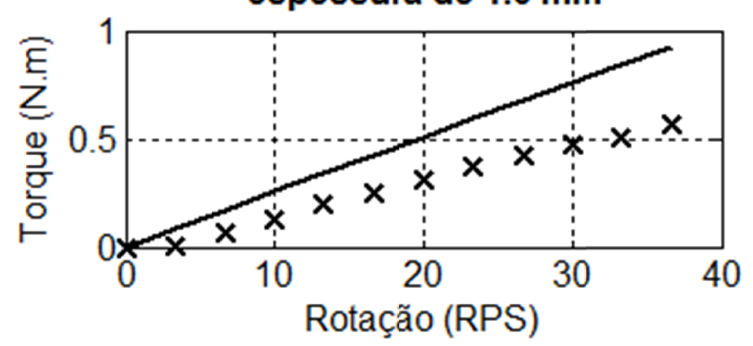

Entreferro de $8 \mathrm{~mm}$ e espessura de $3 \mathrm{~mm}$

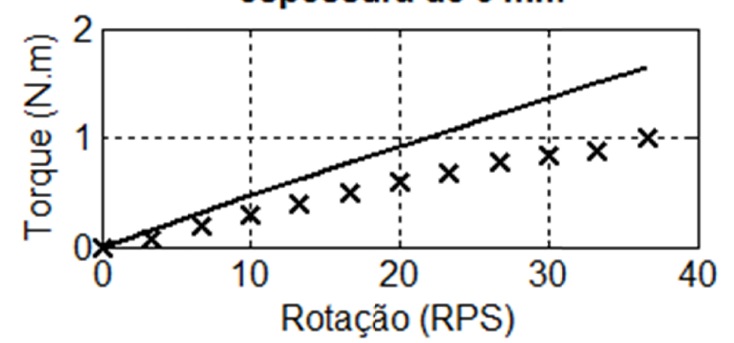


Analisando-se os gráficos mostrados nas Figuras 5.1, 5.2 e 5.3, é possível destacar que os resultados teóricos são razoavelmente próximos dos experimentais, com uma média aritmética dos valores absolutos dos desvios de $20 \%$. O principal fator que influencia nesses desvios é a variação de temperatura que ocorre por conta das perdas geradas na barreira. Mesmo com o ventilador direcionado sobre a mesma, foi possível notar que para os materiais mais condutivos, no caso, o cobre e o alumínio, a barreira alcançava temperaturas muito elevadas. Embora a metodologia analítica considere a resistividade do material a certa temperatura, ela não prevê a variação da mesma ao longo da barreira, tampouco considerando as perdas geradas e a transmissão de calor para o ambiente. A tendência das curvas medidas, de sistematicamente se curvarem no sentido do aumento da rotação parece estar justificada por esse aspecto. Outros fatores que influenciam no erro em relação ao valor calculado são os desvios no ajuste do entreferro, além de desvios na centralização da barreira entre os rotores.

Ainda um aspecto adicional observado foi a deformação da barreira condutora por dilatação térmica durante os ensaios, fazendo-a aproximar-se mais de um rotor do que do outro (em alguns pontos de rotação maior chegou a ocorrer a raspagem do rotor contra a barreira). Esse efeito provoca a aproximação irregular da barreira do conjunto de imãs de um rotor, situando-a numa região de campo magnético mais intenso, numa condição diferente, portanto, daquela em que foram feitas as previsões teóricas. Esse fato parece ser mais significativo para entreferros menores, e talvez justifique em parte porque sistematicamente para menores entreferros os valores medidos de torque resultaram maiores que os calculados, enquanto para os entreferros maiores ocorreu o contrário.

Para efeitos de comparação entre o torque resistivo nas barreiras dos diferentes materiais, os resultados teóricos estão mostrados na Figura 5.4, considerando entreferro de $6 \mathrm{~mm}$ e barreiras de 1,6 $\mathrm{mm}$ de espessura.

Além da medição do torque resistivo, também foi possível aferir a influência da barreira condutora em diversas condições de transferência de torque. Na Figura 5.5 estão mostrados os valores medidos e calculados para o deslocamento angular com e sem a barreira de alumínio de $3 \mathrm{~mm}$ de espessura e com um entreferro total de $12,2 \mathrm{~mm}$. 
Figura 5.4 - Comparativo entre o torque resistivo para as barreiras de diferentes materiais

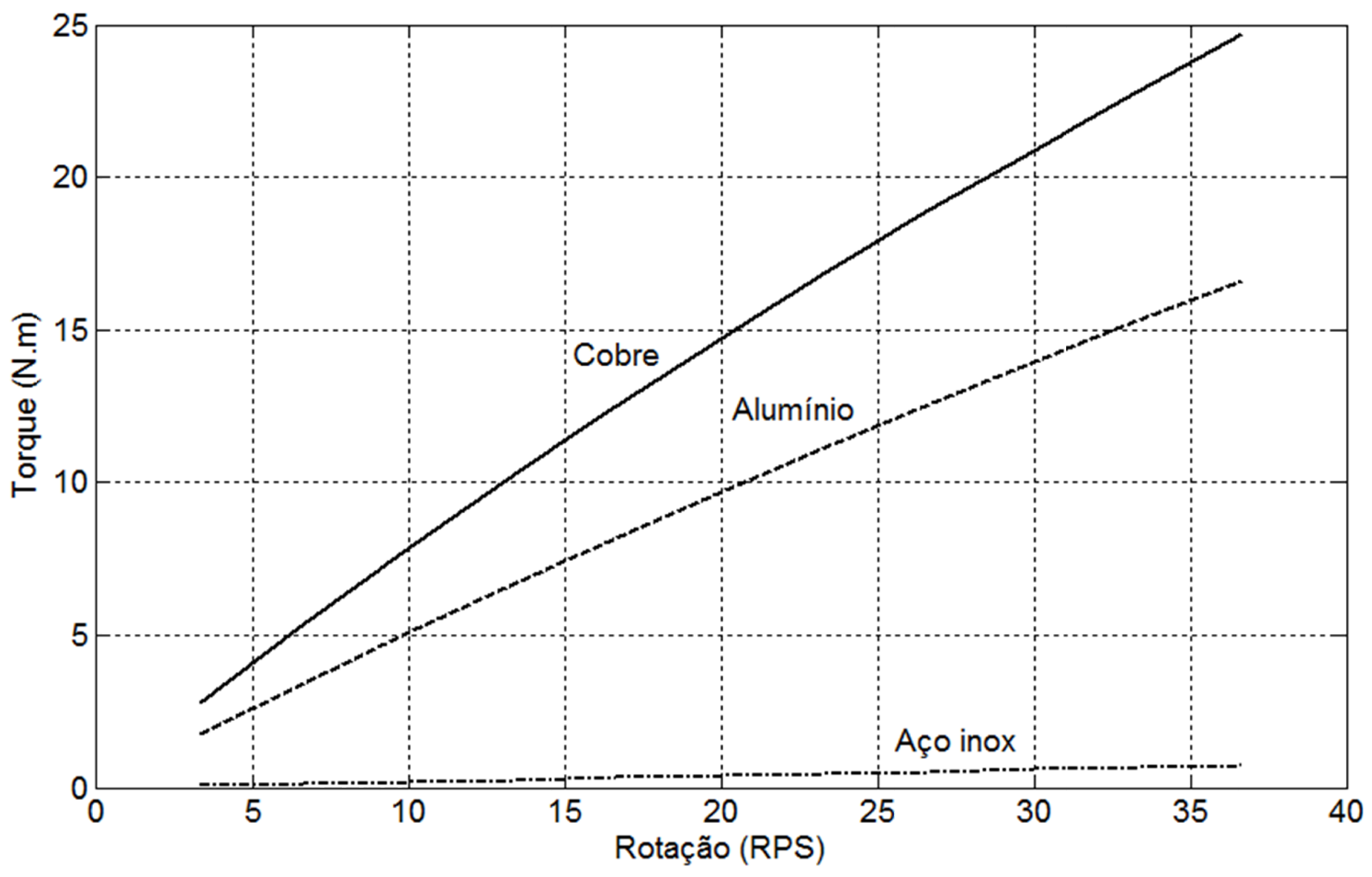

Figura 5.5 - Deslocamento angular com e sem a barreira para diversos carregamentos

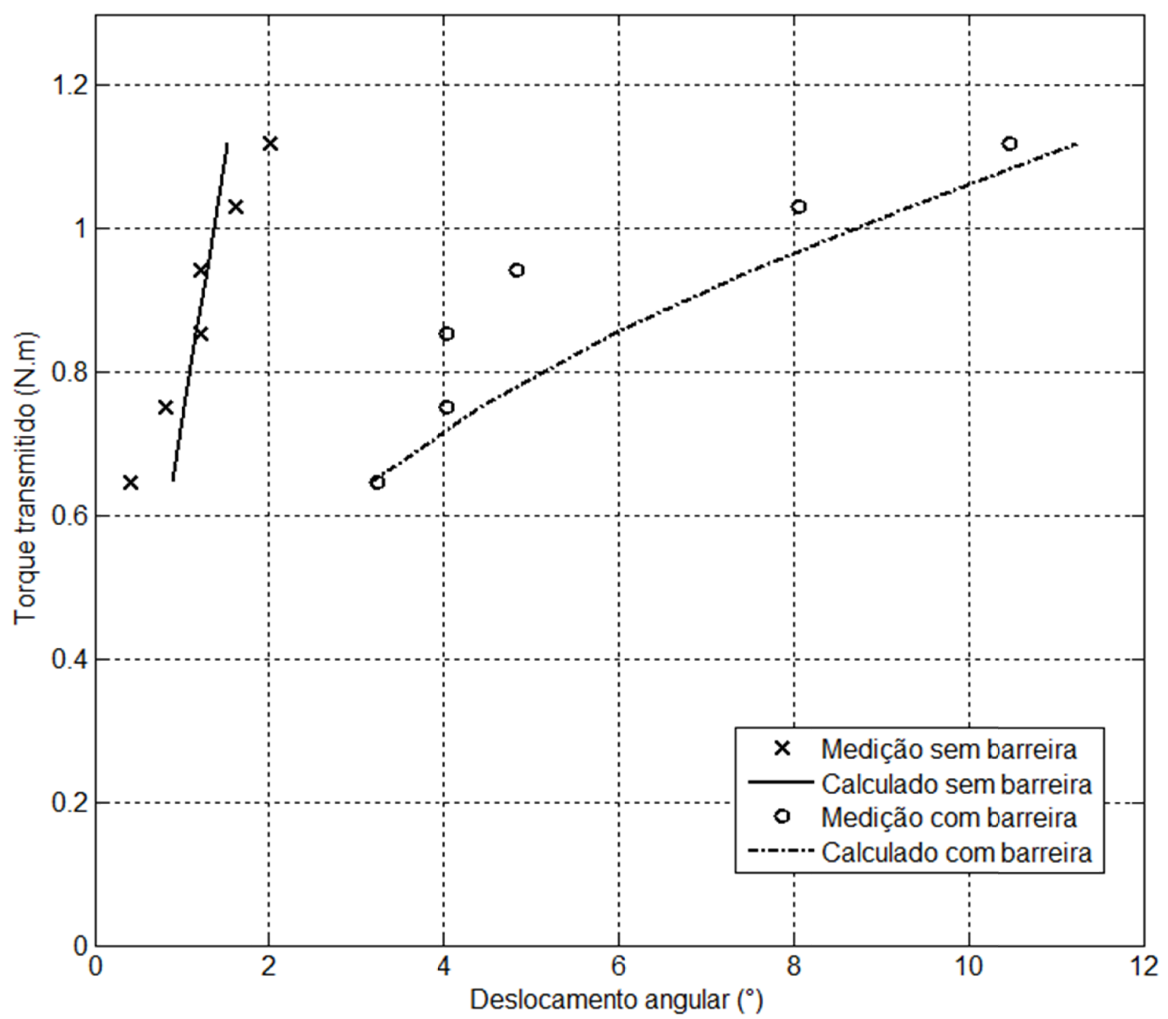


Na Figura 5.5 é possível notar a grande influência da barreira sobre o deslocamento angular para um determinado torque transmitido, devido ao enfraquecimento do campo principal causado pela reação de armadura. Cabe ressaltar que o máximo torque que pode ser transmitido para um determinado entreferro neste protótipo ocorre com um deslocamento angular de $11,25^{\circ}$. A dispersão dos valores medidos deve-se principalmente a dificuldades experimentais, notadamente na medição do ângulo entre rotores.

Outro ponto relevante é que os diversos carregamentos foram medidos em rotações diferentes, como mostra a Tabela 5.1, de forma que a influência do enfraquecimento se torna mais pronunciada conforme aumenta a rotação. Para uma comparação mais apropriada do efeito da reação de armadura sobre o torque transmitido pelo acoplamento o ideal teria sido um ensaio, com a barreira condutora inserida, sempre na mesma velocidade de rotação, apenas incrementando-se o torque no eixo de saída e medindo-se o deslocamento angular entre rotores. $O$ experimento não foi feito dessa forma por limitação dos equipamentos, principalmente do gerador dinamométrico disponível, de pequena capacidade de torque em baixas velocidades.

Tabela 5.1 - Velocidades angulares e fatores de correção da indução remanente

\begin{tabular}{|c|c|c|}
\hline $\begin{array}{c}\text { Torque } \\
\text { transmitido } \\
\text { (N.m) }\end{array}$ & $\begin{array}{c}\text { Velocidade } \\
\text { angular } \\
\text { (RPM) }\end{array}$ & $\begin{array}{c}\text { Relação } \\
\mathrm{B}_{\mathrm{m}}^{\prime} / \mathrm{B}_{\mathrm{m}}\end{array}$ \\
\hline 0.65 & 1030 & 0.829 \\
\hline 0.75 & 1200 & 0.798 \\
\hline 0.85 & 1400 & 0.768 \\
\hline 0.94 & 1600 & 0.738 \\
\hline 1.03 & 1800 & 0.710 \\
\hline 1.12 & 2000 & 0.682 \\
\hline
\end{tabular}

Dessa forma, como os valores foram obtidos em diferentes velocidades angulares, é necessário corrigir a curva característica para cada ponto por conta do enfraquecimento do campo principal causado pela reação de armadura. Tal influência pode ser calculada através da relação (3.79), conforme descrito na seção 3.2. Assim, com a indução remanente corrigida através dessa relação, é determinada a nova curva característica para cada velocidade angular e, então, obtêm-se o deslocamento angular calculado. 
Na primeira parte do trabalho foi mostrada a importância dos ímãs permanentes na atualidade, com diversos exemplos nas mais variadas áreas de aplicações. Em seguida, discorreu-se sobre a evolução da característica dos ímãs ao longo da história da humanidade. Após essa etapa, apresentaram-se os acoplamentos magnéticos a ímãs permanentes e suas características, assim como suas aplicações na área industrial. Para concluir a primeira parte, foi destacada a importância da caracterização das perdas em acoplamentos magnéticos com barreiras entre os rotores para o correto dimensionamento desses dispositivos.

$\mathrm{Na}$ segunda parte, as topologias mais comuns dos acoplamentos magnéticos foram mostradas, assim como suas respectivas peculiaridades. Em seguida, apresentou-se o protótipo do acoplamento magnético estudado e comparativos entre sua curva característica calculada e experimental sem a barreira entre os rotores. Ainda na segunda parte do trabalho, uma revisão bibliográfica abrangente foi realizada dos estudos até o momento sobre a presença de barreiras condutoras entre os rotores, cujo efeito é o mesmo que ocorre em freios e acoplamentos por correntes parasitas.

$\mathrm{Na}$ terceira parte do trabalho, foram adotadas as simplificações de que as correntes induzidas possuem uma distribuição senoidal e sentido de circulação apenas na radial, por conta da dificuldade de se resolver a equação da difusão. A partir dessas premissas, desenvolveu-se a abordagem analítica para o problema, com base na revisão bibliográfica então realizada. Além disso, foi proposta uma nova abordagem para o cálculo da curva característica do acoplamento, levando-se em consideração o enfraquecimento dos ímãs por conta da reação de armadura.

$\mathrm{Na}$ quarta parte, a metodologia de ensaio foi apresentada, assim como os equipamentos e arranjos utilizados. Cabe ressaltar que além da medição do torque resistivo, também foi aferida e calculada a influência do enfraquecimento dos ímãs no deslocamento angular para diversas condições de torque transferido, o que até o momento não foi possível encontrar na literatura. Uma das dificuldades encontradas ao se medir o deslocamento angular com auxílio do estroboscópio foi a 
sincronização da frequência dos disparos de luz com a velocidade do eixo. Isso ocorreu por conta de pequenas variações de velocidade no eixo da máquina, fazendo com que a imagem oscilasse. Para se contornar este problema, foi empregada uma câmera fotográfica no modo de múltiplos disparos, o que permitiu uma leitura precisa do deslocamento entre os rotores.

Na quinta e última parte do trabalho, os resultados obtidos experimentalmente foram confrontados com os resultados analíticos do torque resistivo. Embora o desvio médio tenha sido de $20 \%$, os resultados são satisfatórios considerando os diversos fatores que influenciaram nesse resultado. Um desses fatores foi a variação da resistividade do material por conta da temperatura. Embora tenha sido empregado um ventilador para dissipar as perdas geradas, a temperatura variou muito durante os ensaios. Outro fator relacionado a esse foi a deformação da barreira por dilatação térmica, deixando partes da barreira em posição assimétrica no entreferro e influenciando no comportamento do torque resistivo.

Além disso, também cabe ressaltar que a metodologia analítica considera uma barreira sem bordas, diferentemente das condições de ensaio, nas quais a barreira se limita às dimensões do acoplamento. Dessa maneira, as correntes induzidas provavelmente se adensam mais nas bordas da barreira, aumentando a resistividade e diminuindo o torque resistivo, principalmente em altas rotações.

Em suma, com base no exposto neste trabalho, é possível concluir que a metodologia desenvolvida para o cálculo das perdas e do torque resistivo é muito útil para o dimensionamento de acoplamentos magnéticos em aplicações reais na indústria. Com essa metodologia, é possível prever o torque disponível que pode ser transmitido para determinada configuração na presença da barreira e, assim, dimensionar corretamente o acoplamento para a aplicação em questão. 
Com base nos resultados obtidos, uma das propostas sugeridas para a continuação dos estudos é a de elaborar uma metodologia que englobe o comportamento térmico do acoplamento. Assim, seria possível prever com mais precisão a temperatura da barreira e sua resistividade para uma determinada condição de operação.

Outra sugestão é a de simular através de programas de elementos finitos o comportamento do torque resistivo e comparar com os resultados analíticos. Dessa maneira, seria possível analisar com mais detalhes o comportamento das correntes induzidas na barreira e, possivelmente, melhorar a metodologia analítica.

A investigação de uma metodologia para determinação do torque transmitido que esteja baseada no campo resultante no entreferro, ao invés do campo remanente dos imãs, provavelmente permitirá um cálculo mais direto e preciso da capacidade de transmissão do acoplamento, inclusive com a barreira condutora.

Medições mais precisas do efeito da barreira sobre o torque transmitido, com o uso de recursos experimentais mais elaborados, por exemplo, com o uso de um encoder em cada eixo, permitiriam um levantamento de características mais amplo e completo para o conhecimento desse tipo de acoplamento. Esse aspecto, até onde foi pesquisado, não é abordado na literatura. 


\section{REFERÊNCIAS}

[1] PARKER, R. J. Advances in Permanent Magnetism. $1^{\text {st }}$ ed. New York: John Wiley \& Sons, Inc., 1990. 337 p.

[2] FURLANI, E. P. Permanent Magnet and Electromechanical Devices: Materials, Analysis and Applications. $1^{\text {st }}$ ed. San Diego: Academic Press, 2001. 518 p.

[3] MATSUMOTO, T. R.; CHABU, I. E. Estudo e Desenvolvimento de um Acoplamento Magnético. 2010. 62 p. Projeto de Formatura (Graduação) - Escola Politécnica da Universidade de São Paulo, Departamento de Engenharia de Energia e Automação Elétricas, São Paulo.

[4] MATSUMOTO, T. R.; CHABU, I. E. Estudo e Desenvolvimento de um Acoplamento Magnético a Imãs Permanentes. In: MOMAG. João Pessoa: 2012.

[5] ELIĖS, P.; LEMARQUAND, G. Comparison of the Torque of Flat Air Gap Synchronous Couplings versus the Magnetization Direction of the Magnets. In: IEEE Transactions on Magnetics, v. 35, n. 1, p. 548-556, 1999.

[6] AKOUN, G.; YONNET, J. P. 3D Analytical Calculation of the Forces Exerted Between Two Cuboidal Magnets. In: IEEE Transactions on Magnetics, v. 20, n. 5, p. 1962-1964, 1984.

[7] DAVIES, E. J. An Experimental and Theoretical Study of Eddy-Current Couplings and Brakes. In: IEEE Trans. P. A. S., v. 82, n. 67, pp. 401-419, 1963.

[8] HANSEN, A.; TIMMLER JR., W. R. Theory for Eddy-Current Couplings: Unidirectional Flux Type. In: IEEE Trans. P. A. S., v. 82, n. 67, pp. 436-442, 1963.

[9] MALTI, M. G.; RAMAKUMAR., R. Three-Dimensional Theory of the EddyCurrent Coupling. In: IEEE Trans. P. A. S., v. 82, n. 68, pp. 793-800, 1963.

[10] SMYTHE, W. R. On Eddy Currents in a Rotating Disk. In: Trans. AIEE, v. 61, n. 9, pp. 681-684, 1942.

[11] GONEN, D.; STRICKER, S. Analysis of an Eddy-Current Brake. In: IEEE Trans. P. A. S., v. 84, n. 5, pp. 357-361, 1965. 
[12] DAVIES, E. J. General Theory of Eddy-Current Couplings and Brakes. In: Proceedings of IEE, v. 113, n. 5, pp. 825-837, 1966.

[13] SCHIEBER, D. Unipolar Induction Braking of Thin Metal Sheets. In: Proceedings of IEE, v. 119, n. 10, pp. 1499-1503, 1972.

[14] SCHIEBER, D. Breaking Torque on Rotating Sheet in Stationary Magnetic Field. In: Proceedings of IEE, v. 121, n. 2, pp. 117-122, 1974.

[15] DAVIES, E. J. Experimental Verification of the Generalized Theory of EddyCurrent Couplings. In: Proceedings of IEE, v. 122, n. 1, pp. 67-73, 1975.

[16] DAVIES, E. J.; WRIGHT, M. T.; MCKIBBIN, H. Three-Dimensional Theory of Eddy-Current Couplings with Copper-Faced Loss Drums. In: Proceedings of IEE, v. 124, n. 12, pp. 1187-1196, 1977.

[17] NAGAYA, K. et al. Braking Forces and Damping Coefficients of Eddy Current Brakes Consisting of Cylindrical Magnets and Plate Conductors of Arbitrary Shape. In: IEEE Transactions on Magnetics, v. 20, n. 6, pp. 2136-2145, 1984.

[18] NAGAYA, K.; KARUBE, Y. A Rotary Eddy-Current Brake or Damper Consisting of Several Sector Magnets and a Plate Conductor of Arbitrary Shape. In: IEEE Transactions on Magnetics, v. 23, n. 2, pp. 1819-1826, 1987.

[19] WOUTERSE, J. H. Critical Torque and Speed of Eddy Current Brake with Widely Separated Soft Iron Poles. In: IEE Proceedings-B, v. 138, n. 4, pp. 153-158, 1991.

[20] LIU, Z. J.; VOURDAS, A.; BINNS, K. J. Magnetic Field and Eddy Current Losses in Linear and Rotating Permanent Magnet Machines with a Large Number of Poles. In: IEE Proceedings-A, v. 138, n. 6, pp. 289-294, 1991.

[21] NEHL, T. W. et al. Nonlinear Two-Dimensional Finite Element Modeling of Permanent Magnet Eddy Current Couplings and Brakes. In: IEEE Transactions on Magnetics, v. 30, n. 5, pp. 3000-3003, 1994.

[22] LEQUESNE, B.; LIU, B.; NEHL, T. W. Eddy Current Machines with Permanent Magnets and Solid Rotors. In: IEEE Transactions on Industry Applications, v. 33, n. 5, pp. 1289-1294, 1997. 
[23] EDWARDS, J. D. et al. Permanent-Magnet Linear Eddy-Current Brake with a Non-Magnetic Reaction Plate. In: IEE Proceedings Electric Power Applications, v. 146, n. 6, pp. 627-631, 1999.

[24] DIETRICH, A. B. Um Estudo de Correntes Induzidas em Meios Maciços Ferromagnéticos - Aplicação no Projeto de Freios de Correntes Parasitas. 2000. 74 p. Dissertação (Mestrado) - Escola Politécnica da Universidade de São Paulo, Departamento de Engenharia de Energia e Automação Elétricas, São Paulo.

[25] LESOBRE, A.; BEN AHMED, A. H.; DRECQ, D. An Analytical Dynamic Model of Eddy-Current Brakes. In: IEEE International Electric Machines and Drives Conference, pp. 122-125, 2001.

[26] LEE, K.; PARK, K. Analysis of an Eddy-Current Brake Considering Finite Radius and Induced Magnetic Flux. In: Journal of Applied Physics, v. 92, n. 9, pp. 5532-5538, 2002.

[27] CANOVA, A.; VUSINI, B. Design of Axial Eddy Current Couplers. In: IEEE Transactions on Industry Applications, v. 39, n. 3, pp. 725-733, 2003.

[28] CANOVA, A.; VUSINI, B. Analytical Modeling of Rotating Eddy-Current Couplers. In: IEEE Transactions on Magnetics, v. 41, n. 1, pp. 24-35, 2005.

[29] AMATI, N. et al. Dynamic Behavior of Torsional Eddy-Current Dampers: Sensitivity of the Design Parameters. In: IEEE Transactions on Magnetics, v. 43, n. 7, pp. 3266-3277, 2007.

[30] BAUM, E.; EBERHARDT, S. Eddy Current Brake with Two Pole Pairs. In: COMPEL, v. 28, n. 1, pp. 67-76, 2009.

[31] SRIVASTAVA, R. K.; KUMAR, S. An Alternative Approach for Calculation of Braking Force of an Eddy-Current Brake. In: IEEE Transactions on Magnetics, v. 45, n. 1, pp. 150-154, 2009.

[32] MAGNADRIVE CORPORATION. Washington. Fabricante de acoplamentos magnéticos. Disponível em: <http://www.magnadrive.com/allphotos.html>. Acesso em: 20 nov. 2013.

[33] AMAR EQUIPMENTS PVT. LTD. Mumbai. Fabricante de equipamentos para a indústria química. Disponível em: <http://www.amarequip.com/magnetic-drive- 
couplings-stirrers.asp?gclid=CMvosJ2v9LoCFQpnOgodICsAaQ>. Acesso em: 20 nov. 2013.

[34] M.A.L. PUMPS LTD. Saint Helens. Representante de fabricantes de bombas. Disponível em: <http://www.malpumps.co.uk/products/cdr/>. Acesso em: 20 nov. 2013.

[35] DEXTER MAGNETIC TECHNOLOGIES. Illinois. Fabricante de produtos magnéticos. Disponível em: <http://www.dextermag.com/products/magneticassemblies/couplings\#Synchronous Coupling>. Acesso em: 20 nov. 2013.

[36] CHARPENTIER, J. F.; LEMARQUAND, G. Calculation of ironless permanent magnet couplings using semi-numerical magnetic pole theory method. In: COMPEL, v.20, n. 1, pp. 72-89, 2001.

[37] MATSUMOTO, T. R.; CHABU, I. E. Study of losses in permanent magnet couplings due to highly conductive walls. In: $X X I^{\text {th }}$ International Conference on Electrical Machines (ICEM'2014). Berlin: 2014. 


\section{ANEXO A - FORMULAÇÃO DA FORÇA TANGENCIAL NA CONFIGURAÇÃO AXIAL}

Conforme mostrado por Eliès e Lemarquand [5], a expressão da força tangencial (Fy) entre os ímãs é decorrente das Equações (A.1) e (A.2), sendo a primeira fórmula do campo magnético gerado por um ímã no espaço em um ponto $\mathrm{M}$ e a segunda, da força resultante devido à interação entre uma distribuição de cargas plana num campo externo.

$$
\begin{gathered}
\vec{B}=\int_{S_{0}} \frac{J}{4 \cdot \pi} \cdot \frac{\overrightarrow{M_{S}^{+} M}}{M_{S}^{+} M^{3}} d S_{0}-\int_{S_{-0}} \frac{J}{4 \cdot \pi} \cdot \frac{\overrightarrow{M_{S}^{-} M}}{M_{S}^{-} M^{3}} d S_{-0} \\
\vec{F}=\int_{S_{1}} \frac{J}{\mu_{0}} \cdot \vec{B} \cdot d S_{1}-\int_{S_{-1}} \frac{J}{\mu_{0}} \cdot \vec{B} \cdot d S_{-1}
\end{gathered}
$$

$\mathrm{Na}$ equação (A.1), $\mathrm{MS}_{\mathrm{S}}^{+}$corresponde a um ponto na superfície de $\mathrm{S}_{0}$, enquanto $\mathrm{M}_{\mathrm{S}}^{-}$, a um ponto na superfície de $\mathrm{S}_{-0}$ e $\mathrm{M}$, ao ponto no qual se deseja obter o campo magnético.

De posse da Equação (A.2), a componente tangencial da força pode ser obtida, como mostra a Equação (A.3).

$$
F_{y}=\frac{J}{\mu_{0}} \cdot \int_{x^{\prime}=0}^{x^{\prime}=a^{\prime}} \int_{y^{\prime}=0}^{y^{\prime}=b^{\prime}}\left[B_{y}\left(x, y, z_{01}+c^{\prime}, a, b, c, J\right)-B_{y}\left(x, y, z_{01}, a, b, c, J\right)\right] \cdot d y^{\prime} d x^{\prime}
$$

As funções intermediárias utilizadas na Equação (A.3) estão mostradas nas Equações (A.4) e (A.5), na qual (A.4) é a componente y do campo magnético em um ponto de coordenadas $(x, y, z)$ devido a um ímã de dimensões $a, b$ e c e magnetização J. Já a equação (A.5) é uma equação intermediária, utilizada apenas para facilitar a visualização.

$$
\begin{gathered}
B_{y}(x, y, z, a, b, c, J)=\frac{J}{4 \cdot \pi} \cdot \ln \left[\frac{N(x, y, z, a, b, c) \cdot N(x, y, z, 0,0, c) \cdot N(x, y, z, a, 0,0) \cdot N(x, y, z, 0, b, 0)}{N(x, y, z, a, 0, c) \cdot N(x, y, z, 0, b, c) \cdot N(x, y, z, a, b, 0) \cdot N(x, y, z, 0,0,0)}\right] \\
N(x, y, z, a, b, c)=a-x+\sqrt{(x-a)^{2}+(y-b)^{2}+(z-c)^{2}}
\end{gathered}
$$


Além dessas Equações, também é possível parametrizar as coordenadas do sistema com o centro em $\mathrm{O}$ em função das coordenadas do outro sistema, como mostram as Equações (A.6) a (A.8).

$$
\begin{aligned}
& x=x_{01}+x^{\prime} \cdot \cos (\alpha)+y^{\prime} \cdot \sin (\alpha) \\
& y=y_{01}-x^{\prime} \cdot \sin (\alpha)+y^{\prime} \cdot \cos (\alpha) \\
& z=z_{01}+z^{\prime}
\end{aligned}
$$

Dessa forma, é possível substituir as Equações (A.6) a (A.8) na Equação (A.3) para então efetuar uma integração numérica, já que até o presente momento não foi desenvolvida uma solução analítica para essa integração dupla. 


\section{ANEXO B - PROGRAMAÇÃO EM MATLAB ${ }^{\circledR}$ DA FORMULAÇÃO DA FORÇA TANGENCIAL NA CONFIGURAÇÃO AXIAL}

As funções e os scripts utilizados no Matlab $^{\circledR}$ para o cálculo numérico das expressões apresentadas no Anexo A são:

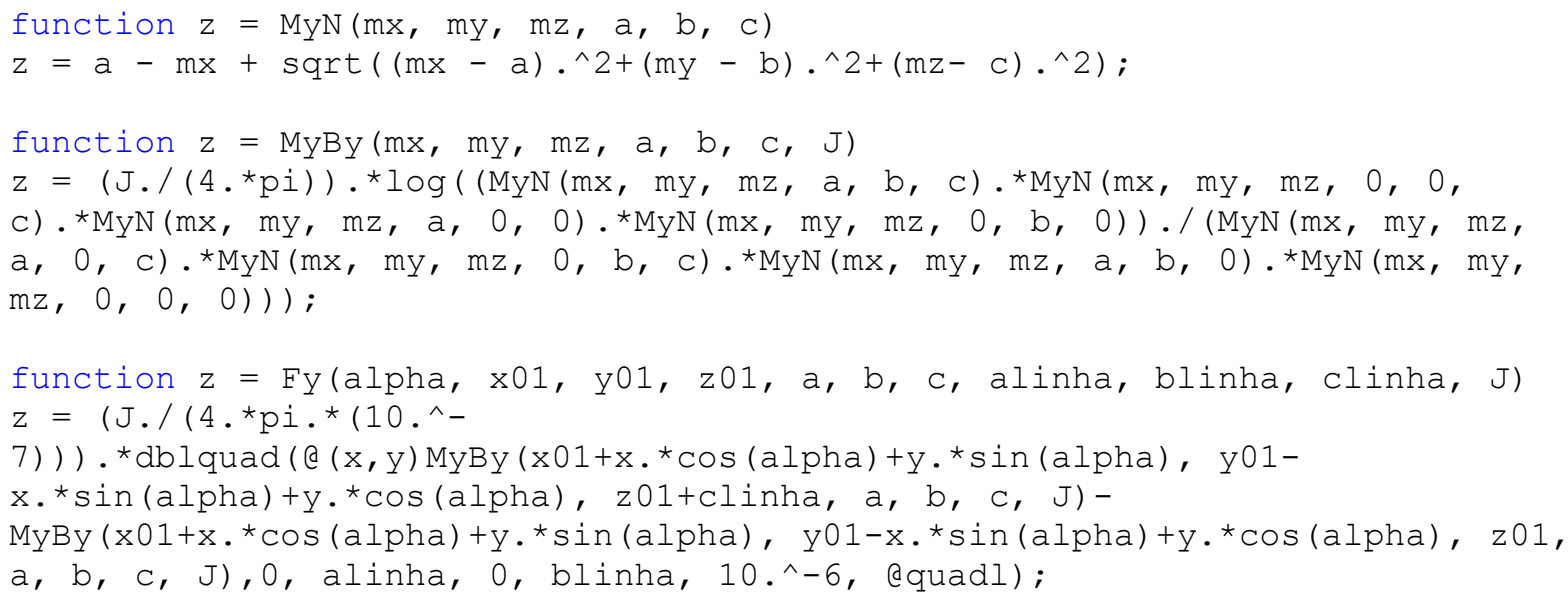

- Script para o cálculo da força tangencial em função do ângulo de rotação:

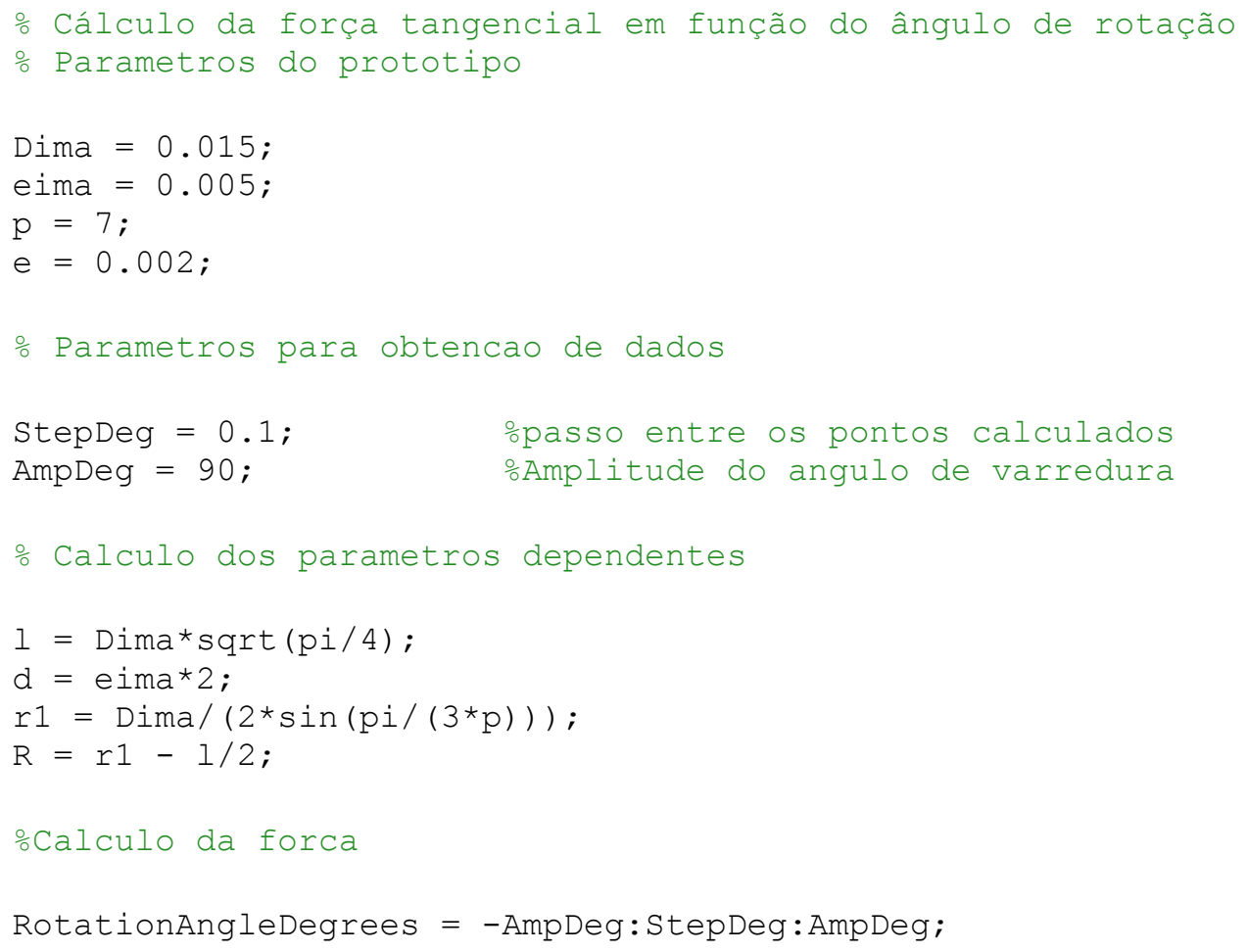




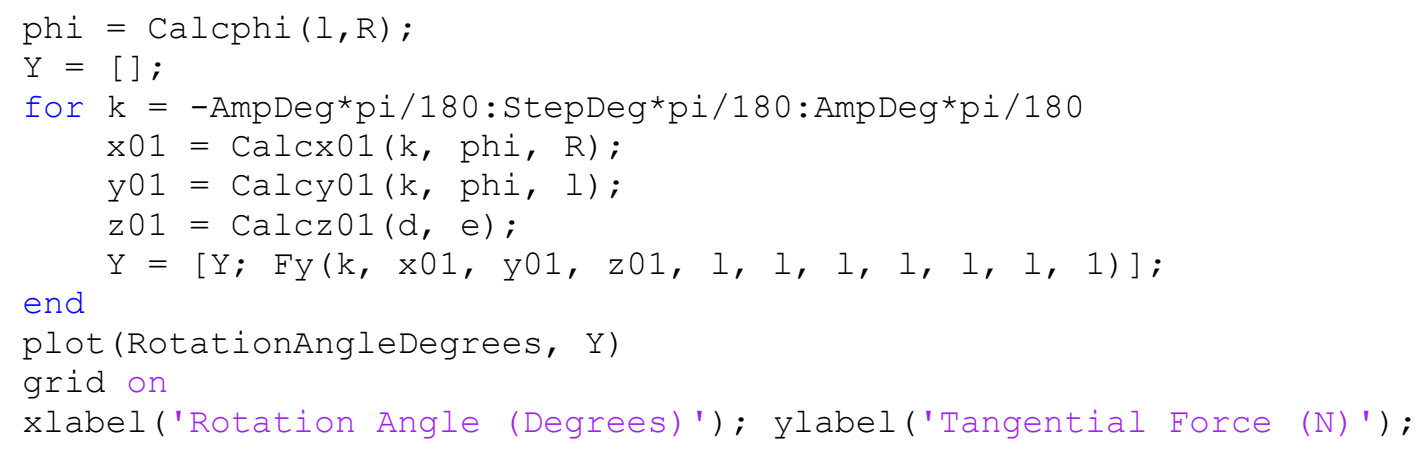

\section{- Script para o cálculo do torque em função do ângulo de rotação:}

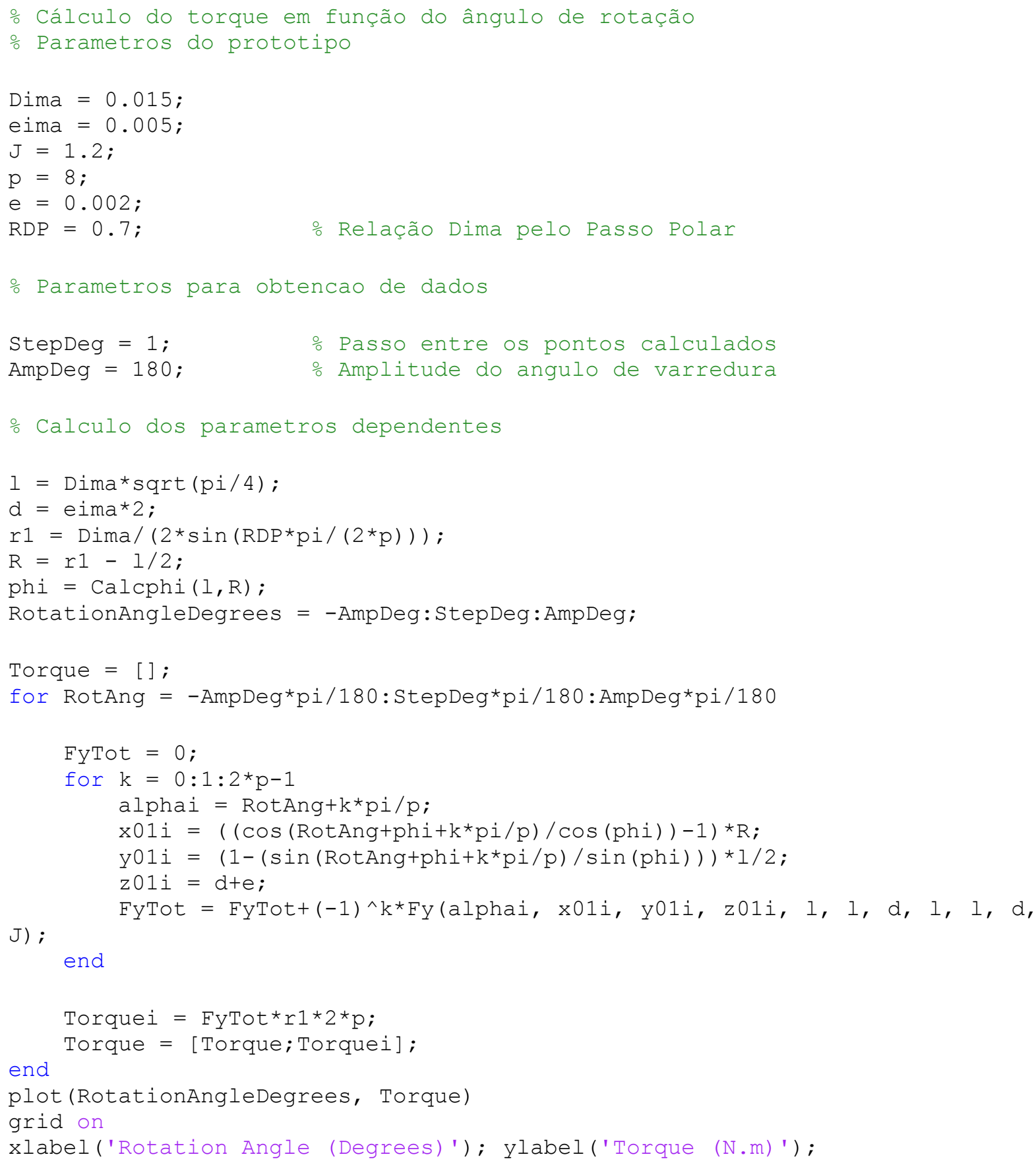




\section{ANEXO C - OBTENÇÃO DA INDUÇÃO NO ENTREFERRO NA CONDIÇÃO ESTÁTICA}

A indução no entreferro é obtida através do cálculo do ponto de operação do ímã, que é a intersecção entre a curva de desmagnetização do ímã com a linha de carga do circuito magnético. Na figura C.1 estão representadas tais curvas, sendo $B_{\text {rem }}$ a remanência do ímã em $\mathrm{T}$ e $H_{c}$, sua força coercitiva em $\mathrm{A} / \mathrm{m}$.

Figura C.0.1 - Ponto de operação do ímã

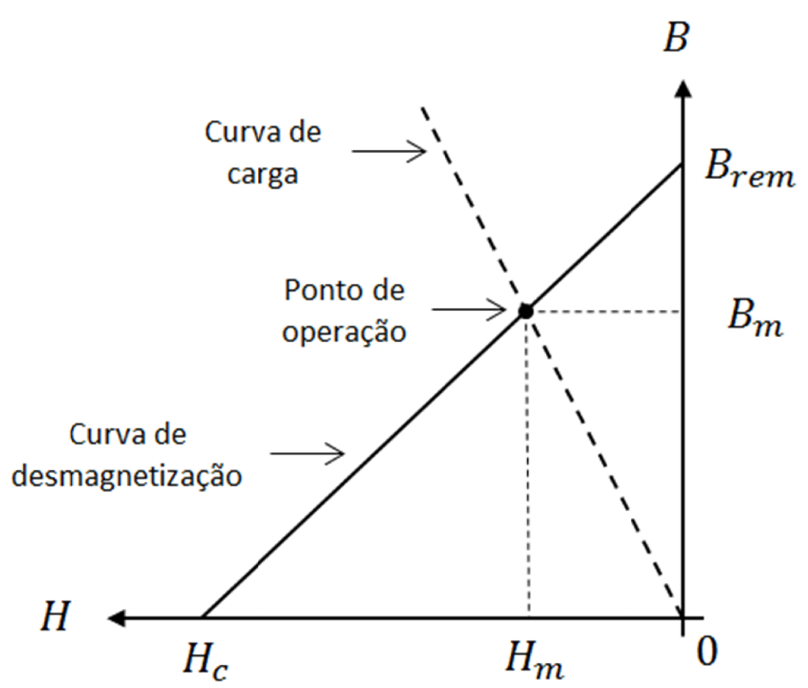

Embora as curvas descritas na Figura C.1 estejam no segundo quadrante, é possível escrever as equações como se elas estivessem no primeiro, sem perda de generalidade. Desse modo, tanto $B_{m}$ e $H_{m}$, que são as coordenadas do ponto de operação, podem ser representados por números positivos. Assim, a curva de desmagnetização típica pode ser descrita por:

$$
B=-1,05 \cdot \mu_{0} \cdot H+B_{\text {rem }}
$$

de forma que o ponto de operação faz parte dessa curva, o que resulta:

$$
B_{m}=-1,05 \cdot \mu_{0} \cdot H_{m}+B_{r e m}
$$

A curva de carga pode ser obtida aplicando a lei de Ampère na Figura 3.3, o que implica para o campo principal e para o fluxo de dispersão: 


$$
H_{m} \cdot L_{m}-H_{g} \cdot\left(\frac{d}{2}+\frac{g}{2}\right)=0
$$

e

$$
2 \cdot H_{m} \cdot L_{m}-H_{l} \cdot \frac{\lambda}{2}=0
$$

na qual $L_{m}$ é a altura do ímã; $H_{m}$ é a intensidade de campo magnético no seu interior; $H_{g}$ é a intensidade de campo magnético no entreferro; $H_{l}$ é a intensidade de campo magnético de dispersão; $\lambda$ é um passo polar; $d$ é a espessura da barreira e $g$ é o entreferro. Computando-se o fluxo total do ímã, tem-se:

$$
B_{m} \cdot S_{m}=B_{g} \cdot S_{p o l o}+B_{l} \cdot S_{l}
$$

na qual $B_{g}$ é a indução no entreferro, $S_{\text {polo }}$, sua área, $B_{l}$ é a indução de dispersão e $S_{l}$, sua respectiva área. Além disso, no entreferro é possível escrever:

$$
\begin{aligned}
& B_{g}=\mu_{0} \cdot H_{g} \\
& B_{l}=\mu_{0} \cdot H_{l}
\end{aligned}
$$

Com alguma manipulação algébrica é possível isolar $H_{m}$ em (C.2) e substituir em (C.3), resultando:

$$
\frac{\left(B_{r e m}-B_{m}\right)}{1,05 \cdot \mu_{0}} \cdot L_{m}-H_{g} \cdot\left(\frac{d}{2}+\frac{g}{2}\right)=0
$$

Isolando $H_{g}$ em (C.6), $H_{l}$ em (C.4), $B_{m}$ em (C.5), $B_{l}$ em (C.7) e substituindo em (C.8), tem-se ainda:

$$
\frac{\left(B_{\text {rem }}-\frac{B_{g} \cdot S_{\text {polo }}}{S_{m}}-\frac{2 \cdot B_{g} \cdot(d+g)}{\lambda} \cdot \frac{S_{l}}{S_{m}}\right)}{1,05 \cdot \mu_{0}} \cdot L_{m}-\frac{B_{g}}{\mu_{0}} \cdot\left(\frac{d}{2}+\frac{g}{2}\right)=0
$$

de forma que simplificando resulta:

$$
B_{g}=\frac{B_{r e m} \cdot L_{m}}{\left(\frac{S_{p o l o}}{S_{m}} \cdot L_{m} \cdot\left(1+\frac{(d+g)}{\pi \cdot r_{1}} \cdot p\right)+1,05 \cdot\left(\frac{d}{2}+\frac{g}{2}\right)\right)}
$$

Tal fórmula em (C.9) é a expressão da indução no entreferro quando não há movimentação entre os rotores, que também é denominada $B_{\text {estat }}$. 


\section{ANEXO D - PROGRAMAÇÃO EM MATLAB ${ }^{\circledR}$ DO CÁLCULO DO TORQUE RESISTIVO}

As funções e os scripts utilizados no Matlab $^{\circledR}$ para o cálculo do torque resistivo desenvolvido no acoplamento em movimento na presença de uma barreira condutora são:

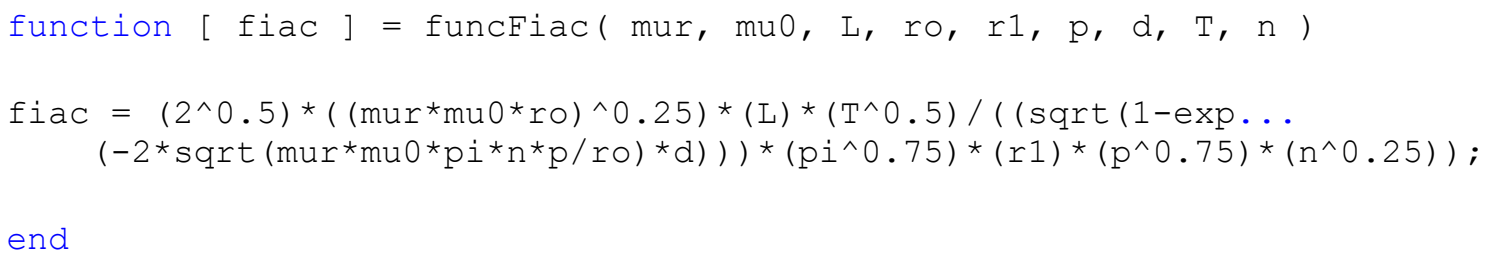

end

- Script para o cálculo do torque resistivo:

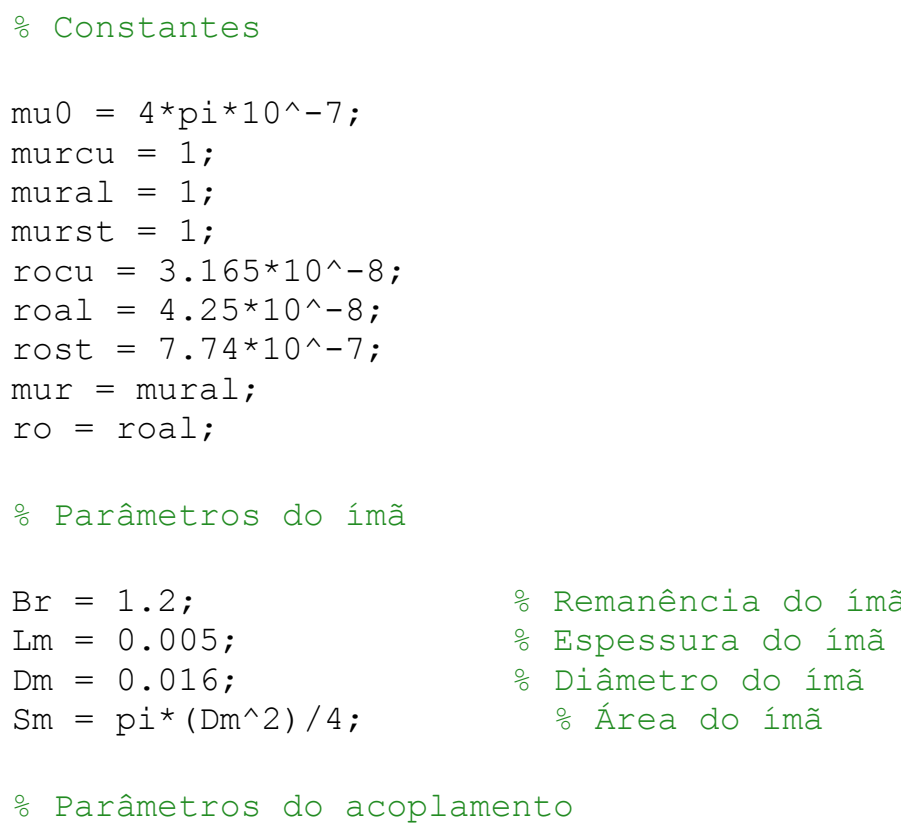




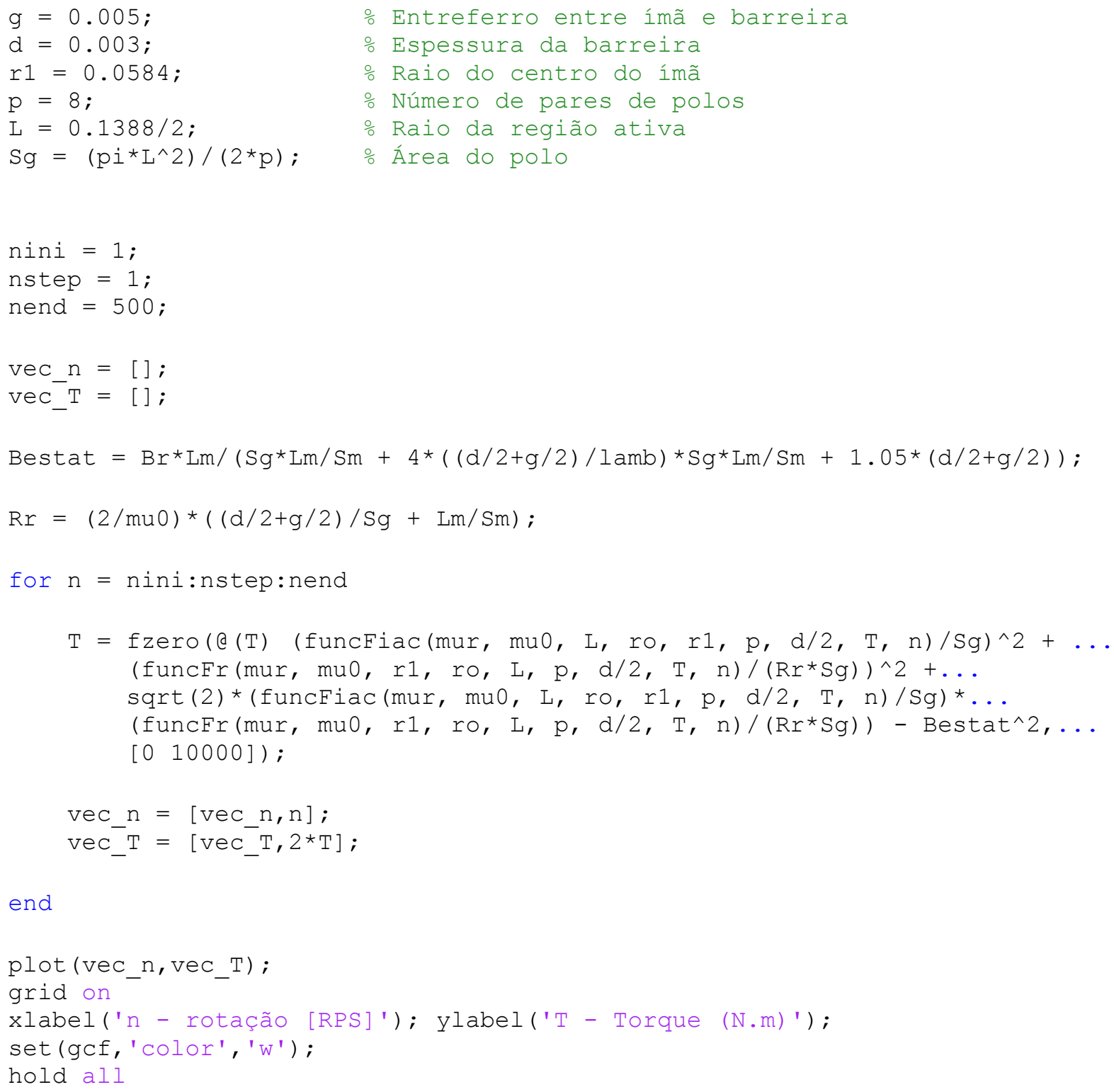

end

plot (vec n, vec T);

grid on

xlabel('n - rotação [RPS]'); ylabel('T - Torque (N.m)');

set (gcf,' 'color', 'w') ;

hold all 